\title{
Avaliação de desempenho de modelos de Credit Score ajustados por Análise de Sobrevivência \\ Susana Miyuki Okaze Tomazela
}

\author{
Dissertação apresentada ao Instituto de \\ Matemática e Estatística da \\ Universidade de São Paulo para a \\ obtenção do Grau de Mestre em Ciências
}

\author{
Área de Concentração: Estatística \\ Orientador: Antonio Carlos Pedroso de Lima
}




\section{Avaliação de desempenho de modelos de Credit Score ajustados por Análise de Sobrevivência}

Este exemplar corresponde à redação final da dissertação devidamente corrigida e defendida por Susana Miyuki Okaze Tomazela e aprovada pela comissão julgadora.

São Paulo, 9 de abril de 2007.

Banca Examinadora:

- Prof. Dr. Antonio Carlos Pedroso de Lima (orientador)- IME/USP

- Profa. Dra. Lúcia Pereira Barroso - IME/USP

- Prof. Dr. Abraham Laredo Sicsu - FGV-SP 
"Even a stopped clock is right twice a day".

-Anonymous 
Ao Rogério e minha familia pelo amor e incentivo. 


\section{Agradecimentos}

Ao Antonio Carlos pela paciência, orientação, motivação e apoio em todos os momentos.

Ao Abrahan Laredo pela inspiração e exemplo.

Ao Nelson Tanaka pela sugestão do indicador: Área entre as curvas de distribuição acumulada dos escores utilizadas para o cálculo do KS.

À Serasa pela disponibilização de dados para a pesquisa.

À Simone Andrade pela amizade e ombro amigo nos momentos difíceis.

$\mathrm{E}$ a todos que torceram e incentivaram mais uma etapa de meu aprendizado. 


\section{Resumo}

Esta pesquisa tratou de modelos de Credit Score desenvolvidos pela metodologia de Regressão Logística e de Análise de Sobrevivência, com destaque para a determinação do modelo mais adequado, baseando-se em medidas de avaliação de desempenho conhecidas, como a estatística de Kolmogorov-Smirnov, a área sob a curva de Lorentz (ROC), o coeficiente de Gini, uma medida pouco utilizada como a distância de Mahalanobis e ainda, duas novas propostas: uma envolvendo a área entre as curvas de distribuição acumulada dos escores e outra considerando a diferença entre as taxas de inadimplência nos intervalos do escore definidos pelos decis, com destaque para os intervalos extremos.

Palavras-chave: Credit Score, Regressão Logística, Analise de Sobrevivência, medidas de avaliação de desempenho de modelos. 


\begin{abstract}
This research considered the modeling of Credit Score data, developed by two methodologies: Logistic Regression and Survival Analysis. The main issue assessed was the comparison of the models, based on well known performance measures, namely, the Kolmogorov-Sminov statistics, the Area under the Lorentz Curve (ROC), the Gini coefficient, and the rarely used Mahalanobis distance. Two new approaches were also considered: one is the area between cumulative distribution curves of the scores and other is the difference among the delinquency rate in the score buckets based on deciles, specialy the extremes buckets.
\end{abstract}

Keywords: Credit Score, Logistic Regression, Survival Analysis, and performance measures. 


\section{Sumário}

1 Introdução 1

1.1 Centrais de Informação de Crédito . . . . . . . . . . . . . . . . 2

1.2 Estrutura da dissertação . . . . . . . . . . . . . . . . 3

2 Uma Aplicação Prática 5

2.1 Descrição da Amostra . . . . . . . . . . . . . . . . . 5

2.2 Análise Descritiva . . . . . . . . . . . . . . 7

3 Metodologias 10

3.1 Modelo de Regressão Logística . . . . . . . . . . . . . . . . . . 10

3.2 Modelo de Análise de Sobrevivência . . . . . . . . . . . . 12

3.2 .1 Família Weibull . . . . . . . . . . . . . . 14

3.2.2 Modelo de Riscos Proporcionais de Cox . . . . . . . . 17

4 Medidas de Avaliação de Desempenho 21

4.1 Estatística de Kolmogorov-Smirnov . . . . . . . . . . . . . . 21

4.2 Área Entre as Curvas . . . . . . . . . . . . . . . . . . 23

4.3 Curva de Lorentz e Coeficiente de Gini . . . . . . . . . . . . . . 24

4.4 Distância de Mahalanobis . . . . . . . . . . . . . . . . 27

4.5 Diferença Entre as Taxas de Inadimplência . . . . . . . . . . . 28

5 Modelos Ajustados e Resultados 31

5.1 Seleção das Variáveis e Ajuste dos Modelos . . . . . . . . . . . 31

5.2 Reamostragem por Bootstrap . . . . . . . . . . . . . 35

5.3 Resultados. . . . . . . . . . . . . . . . . . 38 
5.3.1 Coeficientes Estimados . . . . . . . . . . . . . . . . . 38

5.3.2 Resultados das Medidas de Avaliação de Desempenho . 44

6 Considerações Finais

A Tabelas Descritivas

B Gráficos

C Coeficientes estimados - validação

65

D Macros SAS 


\section{Lista de Tabelas}

2.1 Distribuição da inadimplência e adimplência nas amostras. . . . 7

2.2 Distribuição das empresas segundo a idade. . . . . . . . . . . 8

2.3 Variáveis dummies associadas a covariável idade da empresa . 9

4.1 Exemplo de matriz de confusão . . . . . . . . . . . . . . . . 26

4.2 Cálculo da taxa de inadimplência em cada intervalo . . . . . . 29

5.1 Ajuste do Modelo Logístico. . . . . . . . . . . . . . . . . 33

5.2 Ajuste do Modelo Exponencial. . . . . . . . . . . . . . . . 33

5.3 Ajuste do Modelo Weibull. . . . . . . . . . . . . . . . . . . . 34

5.4 Ajuste do Modelo de Cox. . . . . . . . . . . . . . . . . . . . 34

5.5 Função de sobrevivência basal para o Modelo de Cox. . . . . . 35

5.6 Distribuição dos adimplentes e inadimplentes nas amostras com menos casos censurados . . . . . . . . . . . . . . . . . . 37

5.7 Distribuição dos adimplentes e inadimplentes nas amostras com mais casos censurados . . . . . . . . . . . . . 38

5.8 Coeficientes estimados pela Regressão Logística - amostra de desenvolvimento. . . . . . . . . . . . . . . . . . . 39

5.9 Coeficientes estimados pelo Modelo Weibull - amostra de desenvolvimento. . . . . . . . . . . . . . . . 40

5.10 Coeficientes estimados pelo Modelo Exponencial - amostra de desenvolvimento. . . . . . . . . . . . . . . . . 44 4

5.11 Coeficientes estimados pelo Modelo de Cox - amostra de desenvolvimento. . . . . . . . . . . . . . . . . . . . 42

5.12 Estimativas da função de sobrevivência basal $\left(S_{0}\right)$ - amostra de desenvolvimento. . . . . . . . . . . . . . 43 
5.13 Média e desvio-padrão para medida KS - amostra desenvolvimento. . . . . . . . . . . . . . . . . . . . . . . 44

5.14 Média e desvio-padrão para medida: KS - amostra de validação. 46

5.15 Média e desvio-padrão para a medida: área entre as curvas amostra de desenvolvimento. . . . . . . . . . . . . . 46

5.16 Média e desvio-padrão para a medida: área entre as curvas amostra de validação. . . . . . . . . . . . . . . 47

5.17 Média e desvio-padrão para a medida: área sob a curva ROC amostra de desenvolvimento. . . . . . . . . . . . . . 47

5.18 Média e desvio-padrão para a medida: área sob a curva ROC amostra de validação. . . . . . . . . . . . . . . . . . . 48

5.19 Média e desvio-padrão para a medida: coeficiente de GINI amostra de desenvolvimento. . . . . . . . . . . . . . . . 49

5.20 Média e desvio-padrão para a medida: coeficiente de GINI amostra de validação. . . . . . . . . . . . . . . . . 49

5.21 Média e desvio-padrão para a medida: distância de Mahalanobis - amostra de desenvolvimento. . . . . . . . . . . . . . 49

5.22 Média e desvio-padrão para a medida: distância de Mahalanobis - amostra de validação. . . . . . . . . . . . . . 50

5.23 Média e desvio-padrão para a medida: diferença entre as taxas de inadimplência - amostra de desenvolvimento. . . . . . . . . 50

5.24 Média e desvio-padrão para a medida: diferença entre as taxas de inadimplência - amostra de validação. . . . . . . . . . . . 51

A.1 Quantidade de dívidas com empresa no momento da consulta. . 54

A.2 Quantidade cheques devolvidos no momento da consulta. . . . 54

A.3 Quantidade de ações judiciais ou executivas de busca e apreensão no momento da consulta. . . . . . . . . . . . . . . . . . 54

A.4 Quantidade de protestos no momento da consulta. . . . . . 55

A.5 Soma das quantidades de restrições no momento da consulta. . 55

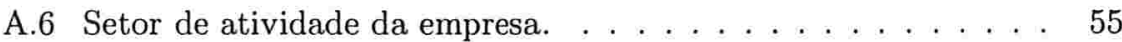

A.7 Quantidade de sócios pessoa-física da empresa. . . . . . . . 55

A.8 Região ou estado da sede da empresa . . . . . . . . . . . . . . . 56 
A.9 Número de funcionários da empresa. . . . . . . . . . . . . . 56

A.10 Percentual de participação do sócio majoritário da empresa. . . 56

A.11 Capital social da empresa. . . . . . . . . . . . . . . . . . 57

A.12 Tipo de controle acionário. . . . . . . . . . . . . . . 57

C.1 Coeficientes estimados pela Regressão Logística - amostra de validação. . . . . . . . . . . . . . . . . 65

C.2 Coeficientes estimados pela Modelo de Cox - amostra de validação. 66

C.3 Estimativas da função basal $S_{0}$ - amostra de validação. . . . . . 66

C.4 Coeficientes estimados pela Modelo Weibull - amostra de validação. . . . . . . . . . . . . . . . . . . 67

C.5 Coeficientes estimados pela Modelo Exponencial - amostra de validação. . . . . . . . . . . . . . . . . 68 


\section{Lista de Figuras}

2.1 Curvas de sobrevivência para as categorias da covariável idade da empresa. . . . . . . . . . . . . . . . 9

4.1 Gráfico da medida KS. . . . . . . . . . . . . . . . . . 23

4.2 Gráfico da área entre as curvas. . . . . . . . . . . . . . . 25

4.3 Exemplo de curva ROC. . . . . . . . . . . . . . . . . . . . 27

4.4 Taxa de inadimplentes por intervalo do escore. . . . . . . . . 30

5.1 Esquema da reamostragem por Bootstrap. . . . . . . . . . . 36

5.2 Curvas de sobrevivência basal. . . . . . . . . . . . . . 43

5.3 Gráficos da medida: KS - amostra de desenvolvimento . . . . 45

5.4 Gráficos da área sob a curva ROC - amostra de desenvolvimento original. . . . . . . . . . . . . . . . . . 48

5.5 Gráficos da taxa de inadimplência nos intervalos definidos pelos decis - amostra de desenvolvimento original . . . . . . . . 51

B.1 Quantidade de dívidas com empresa no momento da consulta. . 58

B.2 Quantidade cheques devolvidos no momento da consulta. . . . 59

B.3 Quantidade de ações judiciais ou executivas de busca e apreenção no momento da consulta. . . . . . . . . . . . . . . . 59

B.4 Quantidade de protestos no momento da consulta. . . . . . . 60

B.5 Soma das quantidades de restrições no momento da consulta. . 60

B.6 Setor de atividade da empresa. . . . . . . . . . . . . . . 61

B.7 Quantidade de sócios pessoa-física na empresa. . . . . . . . 61

B.8 Região ou estado de sede da empresa. . . . . . . . . . . . . 62 
B.9 Número de funcionários da empresa. . . . . . . . . . . . . 62

B.10 Percentual de participação do sócio majoritário da empresa. . . 63

B.11 Capital social da empresa. . . . . . . . . . . . . . . . . . 63

B.12 Tipo de controle acionário. . . . . . . . . . . . . . . 64 


\section{Capítulo 1}

\section{Introdução}

O processo de concessão de crédito exige que o fornecedor faça uma análise criteriosa do solicitante visando minimizar suas perdas com o não pagamento da dívida contratada. Este evento é conhecido como inadimplência. Há alguns anos atrás, as instituições financeiras contavam com um grande número de especialistas em crédito para a realização dessas análises. Estas pessoas avaliavam inúmeras informações e forneciam um relatório dando um parecer sobre o solicitante do crédito. O resultado era subjetivo e dependia do especialista que realizava a análise, determinando sob que condições o negócio poderia ou não ser realizado [Thomas et al, 2002].

Com o crescimento e a popularização da concessão de crédito nas últimas décadas, tornou-se inevitável o desenvolvimento e aperfeiçoamento de ferramentas que garantissem maior objetividade à análise e aumentassem a rapidez no momento da concessão do crédito. Tudo isso, não deixando de lado o aspecto de rentabilidade do negócio e mantendo sob controle a inadimplência.

Para ajudar a identificar e diferenciar os bons dos maus clientes e ordená-los em relação ao risco do não pagamento da dívida, desenvolveram-se ferramentas conhecidas como Sistemas de Credit Scoring [Sicsu, 1998].

O primeiro a utilizar a estatística para identificar grupos com perfis diferentes numa população foi Fisher [Fisher, 1936] em um trabalho com plantas. Em 1941, Durand [Durand, 1941] utilizou a mesma técnica para diferenciar bons e maus empréstimos, dando assim, início ao processo de separação dos bons e maus clientes. Altman [Altman, 1968] foi um dos primeiros a utilizar metodologias de Credit Score para prever falências de empresas.

A idéia básica do Credit Score consiste em selecionar uma amostra de clientes onde o histórico de pagamentos já é conhecido, podendo assim separar 
os bons dos maus pagadores. Cada instituição adota um conceito de inadimplência de acordo com suas políticas internas. Baseado nos dados históricos dos clientes amostrados, pode-se determinar quais características servem para discriminá-los em relação a esse conceito previamente definido. Desta forma é possível inferir quais as chances de um cliente pagar ou não uma dívida em um determinado período de tempo, dada suas características no momento da consulta de crédito. Para um modelo de Credit Score adota-se, normalmente, a convenção de que quanto maior o escore, maiores são as chances deste cliente ser um bom pagador.

Existem diversas metodologias estatísticas utilizadas para obter essa discriminação. Entre as mais conhecidas estão a Regressão Logística, a Análise Discriminante, a Árvore de Decisão e a Análise de Sobrevivência. Além disso, existem também alguns métodos numéricos como a Programação Linear, as Redes Neurais e os Algoritmos Genéticos [Thomas et al, 2002].

\subsection{Centrais de Informação de Crédito}

Considerando que os modelos são desenvolvidos baseando-se somente no histórico dos clientes já existentes na própria base da instituição que concedeu o crédito, temos um problema em prever qual o comportamento de um novo cliente. Com o objetivo de resolver este e outros problemas comuns ao mercado de crédito brasileiro, algumas instituições se uniram e criaram empresas que centralizam os dados necessários ao sistema de análise de crédito. Internacionalmente estas empresas são conhecidas como "Credit Bureaus" e no Brasil como "Centrais de Informações de Crédito".

Estas empresas coletam, armazenam e transformam os dados em informações importantes para a tomada de decisão de crédito. Esses registros compreendem o cadastro de pessoas físicas e jurídicas com sua devida autorização. Também possuem informações públicas, denominadas restritivas ou negativas, disponíveis nos cartórios brasileiros e juntas comerciais, tais como: protestos, falências, concordatas e ações judiciais ou executivas de busca e apreensão, além da base de CCF (Cadastro de Cheque sem Fundo) disponibilizado pelo Banco Central e mais algumas informações de dívidas com o comércio em geral e com instituições financeiras.

A Serasa, uma das empresas que centralizam informações de crédito no mercado brasileiro, gentilmente disponibilizou um conjunto de dados para a realização desta pesquisa. São dados de pequenas empresas brasileiras, que 
foram codificadas para preservar o seu sigilo. Este trabalho tratou de avaliar o desempenho de modelos de Credit Score utilizando medidas de desempenho comuns ao mercado de crédito, considerando para isso os ajustes por Regressão Logística e Análise de Sobrevivência, avaliados em três diferentes cenários com relação a quantidade de adimplentes (censurados).

\subsection{Estrutura da dissertação}

No Capítulo 2, apresenta-se o problema prático, a descrição da amostra e a metodologia utilizada na análise descritiva, bem como os métodos de seleção das covariáveis utilizadas.

As metodologias utilizadas para a avaliação do Credit Score deste trabalho foram a Regressão Logística [Hosmer \& Lemeshow, 1989] e a Análise de Sobrevivência [Klein \& Moeschberger, 1997], descritas no Capítulo 3.

Uma questão tão importante quanto discriminar o bom e o mau cliente é a decisão de qual modelo produz melhor resultado [Oliveira \& Andrade, 2002]. Como a quantidade de metodologias para desenvolvimento de modelos de Credit Score disponíveis no mercado é muito grande, a análise das medidas de avaliação de desempenho dos modelos tornou-se fundamental em um Sistema de Credit Score. O Capítulo 4 descreve as medidas de desempenho consideradas nesta pesquisa: a estatística de Kolmogorov-Smirnov (KS), a área sob a curva de Lorentz ou ROC (Receiving Operational Characteristic), o coeficiente de Gini e a distância de Mahalanobis (MAH) [Thomas et al, 2002]. O KS é a medida mais utilizada, enquanto a distância de Mahalanobis é a menos empregada no mercado brasileiro [Pereira, 2004]. Duas novas medidas são também estudadas: uma abordando a área entre as curvas de distribuição acumulada utilizadas para o cálculo do KS, que recebeu o nome de Área entre as curvas (AEC), e outra baseada na diferença entre as taxas de inadimplência nas diferentes faixas de escore separadas em decis, com destaque para os intervalos extremos. Essa medida recebeu o nome de diferença entre taxa de inadimplência (DTI).

Com o intuito de comparar as medidas de avaliação de desempenho entre as diferentes metodologias, foi aplicada a técnica de reamostragem por Bootstrap [Efron \& Tibshirani, 1993] de modo que, para cada nova amostra, fosse ajustado o modelo e calculadas todas as estatísticas. Assim, foi possível determinar numericamente a variância das medidas de avaliação possibilitando 
a comparação de desempenho entre os modelos ajustados por Regressão Logística e Análise de Sobrevivência.

Ainda por simulação, variou-se a quantidade de casos de inadimplência (falha) e adimplência (censura) para verificar se as medidas em estudo sofriam influência da censura. A descrição do método, sua aplicação e os resultados são apresentados no Capítulo 5.

Por fim, as conclusões e sugestões para pesquisas futuras são apresentadas no Capítulo 6. 


\section{Capítulo 2}

\section{Uma Aplicação Prática}

Em uma central de crédito, encontram-se os dados de empresas atuantes no mercado como um todo. Com isso é possível avaliar o comportamento daquelas que começam a apresentar problemas de crédito. De posse das informações registradas, pode-se criar políticas mais ou menos agressivas considerando o risco de inadimplência de cada empresa.

Dentro deste contexto, quanto maior a informação disponível para a tomada de decisão, maior vantagem competitiva uma instituição credora terá para oferecer, pois conseguirá oferecer melhores produtos com prazos e preços melhores definidos de acordo com o perfil de cada cliente. Sendo assim, considerando os mesmos aspectos dos modelos tradicionais, os modelos ajustados por Análise de Sobrevivência fornecem como diferencial a probabilidade de uma unidade experimental superar um determinado instante sem apresentar o evento (nesta pesquisa as unidades experimentais são as empresas e o evento foi definido como a inadimplência).

\subsection{Descrição da Amostra}

Foi utilizada uma amostra de 15.973 empresas brasileiras de pequeno porte que possuíam Credit Rating@Serasa, calculado no período entre janeiro de 1998 a junho de 2003, e que foram acompanhadas por até 18 meses subsequentes à data da primeira consulta. A definição de pequeno porte fornecida pela Serasa refere-se a empresas com faturamento e ativo anual de até $\mathrm{R} \$ 1.200 .000,00$. Essas empresas foram divididas em uma amostra para estimação dos modelos (amostra de desenvolvimento), com 10.000 empresas, e uma amostra para validação (verificação da consistência das estimativas), com 5.973 empresas. 
As covariáveis utilizadas nesta pesquisa foram: idade da empresa, quantidade de dívidas com empresas, quantidade de cheques devolvidos, quantidade de ações judiciais, quantidade de protestos, setor de atividade da empresa, número de sócios, estado onde está estabelecida a sede da empresa, número de funcionários, percentuais de participação dos sócios, capital social e tipo de controle acionário. As análises descritivas para essas quantidades encontramse nos Apêndices A e B.

O primeiro modelo foi baseado na metodologia tradicionalmente utilizada, a Regressão Logística e os demais modelos na metodologia de Análise de Sobrevivência, considerando um enfoque paramétrico (baseado na família Weibull) e um enfoque semi-paramétrico, baseado no modelo de Cox.

Utilizando a definição fornecida pela Serasa, chamou-se inadimplência à ocorrência de pelo menos um dos seguintes eventos, considerados negativos: falência, concordata, dívidas com instituições financeiras ou com o comércio em geral, cheques devolvidos com registro no Banco Central e ações judiciais ou executivas de busca e apreensão, que ocorreram no mercado brasileiro até 18 meses subseqüentes à nota atribuída na primeira consulta de cada empresa analisada. O Credit Rating®Serasa é um modelo de escoragem das empresas que fornece como resposta uma nota variando de 1 a 17 , sendo que quanto maior a nota, maior o risco da empresa se tornar inadimplente. As notas 15, 16 e 17 indicam a ocorrência de algumas das restrições acima mencionadas no momento do cálculo do Rating.

Para a construção dos modelos avaliados neste trabalho, foram consideradas duas notas para cada empresa, a primeira marcava o estado inicial da empresa no instante $\left(T_{0}\right)$. Todas as empresas selecionadas nesta amostra não apresentavam inadimplência no início da análise, isto é, não tinham notas superiores a 14 como primeira nota. A segunda nota foi relacionada ao instante que a empresa apresentou alguma restrição (notas 15, 16 ou 17) e foi denominada como inadimplência (falha ou mau). Para o caso em que a empresa não apresentou a inadimplência ao final do acompanhamento, definiu-se como adimplente uma observação censurada (censura ou bom). Assim, o indicador de falha $\delta_{i}$ recebeu 1 (um) quando houve alguma informação negativa e 0 (zero) quando houve censura. A diferença em meses entre o instante da primeira nota (fixado como o mês zero) e o instante da segunda nota considerada, determinou o tempo de acompanhamento.

$\mathrm{O}$ escore adotado neste projeto foi o normalmente utilizado no mercado, uma pontuação variando de 0 a 1000, sendo que quanto maior o escore, menor 
o risco da empresa avaliada. Para esta pesquisa, o reescalonamento adotado para o cálculo do escore para o modelo ajustado por Regressão Logística foi dado por:

$$
S_{L}=[1-\operatorname{Prob}(\text { Maus })] \times 1000,
$$

e para os modelos ajustados por Análise de Sobevivência:

$$
S_{S}=[\operatorname{Prob}(T>t)] \times 1000,
$$

em que $T$ é uma variável aleatória representando o tempo entre a primeira consulta e o instante da inadimplência ou final do período e $t$ é o instante fixado que deseja-se avaliar o escore.

A Tabela 2.1 mostra que as amostras de validação e de desenvolvimento são homogêneas com relação à adimplência.

Tabela 2.1: Distribuição da inadimplência e adimplência nas amostras.

\begin{tabular}{lcccc} 
& \multicolumn{2}{c}{ Desenvolvimento } & \multicolumn{2}{c}{ Validação } \\
\cline { 2 - 5 } Empresas & $\mathrm{N}$ & $\%$ & $\mathrm{~N}$ & $\%$ \\
\hline Inadimplentes (maus) & 4.286 & $43 \%$ & 2.547 & $43 \%$ \\
Adimplentes (bons) & 5.714 & $57 \%$ & 3.426 & $57 \%$ \\
\hline Total & 10.000 & $100 \%$ & 5.973 & $100 \%$
\end{tabular}

\subsection{Análise Descritiva}

As covariáveis categorizadas e numéricas foram analisadas individualmente, observando-se a distribuição da freqüência e percentis. Para as covariáveis do tipo categorizada, foram considerados critérios de agrupamento baseados na natureza da variável e aplicação prática do negócio. Por exemplo, neste trabalho a localização das empresas foi categorizada segundo a proximidade geográfica, entretanto isso não constitui uma regra. As variáveis numéricas foram ordenadas sequencialmente e agrupadas em percentis com o mínimo de $5 \%$ de freqüência total.

Depois, cada covariável foi avaliada em relação à variável resposta, em que foram comparados os percentuais de adimplentes e inadimplentes de cada categoria em relação ao total observado na amostra. 
Calculou-se a razão entre os percentuais de inadimplência $(M)$ e adimplência $(B)$ da seguinte forma:

$$
R\left(\frac{M}{B}\right)=\frac{\frac{M_{r}}{M t_{M}}}{\frac{B_{r}}{B_{t_{M}}}}=\frac{M_{r} \times B_{t_{M}}}{B_{r} \times M_{t_{M}}}
$$

sendo que:

$r$ é a categoria em questão da covariável,

$M_{r}$ é a quantidade de maus clientes na categoria $r$,

$B_{r}$ é a quantidade de bons clientes na categoria $r$,

$M_{t_{M}}$ é a quantidade de Maus clientes no total da amostra e

$B_{t_{B}}$ é a quantidade de Bons clientes no total da amostra.

Este critério não considera o tempo em relação a ocorrência do evento, o que pode trazer desvantagem aos modelos utilizando a análise de sobrevivência. A Tabela 2.2 apresenta a distribuição das empresas segundo a idade e observase que razão vai diminuindo com aumento da idade da empresa. As tabelas das demais covariáveis encontram-se no Apêndice A.

Para criar as variáveis dummies [Neter et al, 1996], utilizou-se a codificação de casela de referência.

Tabela 2.2: Distribuição das empresas segundo a idade.

\begin{tabular}{lrrrc} 
Variável & BONS (\%) & MAUS (\%) & Total & Razão M/B \\
\hline 0 a 2 anos & $371(27)$ & $984(73)$ & 1355 & 3,54 \\
3 anos & $562(56)$ & $436(44)$ & 998 & 1,03 \\
4 a 5 anos & $991(58)$ & $708(42)$ & 1699 & 0,95 \\
6 a 10 anos & $1724(62)$ & $1039(38)$ & 2763 & 0,80 \\
11 ou + anos & $2066(65)$ & $1119(35)$ & 3185 & 0,72 \\
\hline Total & $5714(57)$ & $4286(43)$ & 10000 &
\end{tabular}

Dada a categorização de cada covariável, adotou-se uma regra para a determinação da casela de referência na contrução das variáveis dummies. Nessa regra, a casela de referência foi adotada para a categoria em que a razão $R\left(\frac{M}{B}\right)$ era mais próxima de 1 , o que indica que esta categoria tem a sua proporção mais parecida com a proporção de bons e maus da amostra total. A Tabela 2.3 mostra o exemplo das variáveis dummies criadas para a covariável idade da empresa. 
Tabela 2.3: Variáveis dummies associadas a covariável idade da empresa

\begin{tabular}{lcccc} 
Variável & Idade1 & Idade2 & Idade3 & Idade4 \\
\hline 0 a 2 anos & 1 & 0 & 0 & 0 \\
3 anos & 0 & 0 & 0 & 0 \\
4 a 5 anos & 0 & 1 & 0 & 0 \\
6 a 10 anos & 0 & 0 & 1 & 0 \\
11 ou + anos & 0 & 0 & 0 & 1 \\
\hline
\end{tabular}

Para avaliar o efeito das covariáveis no tempo até a inadimplência utilizou-se gráficos com as curvas de sobrevivência estimadas por Kaplan-Meier [Hosmer \& Lemeshow, 1999] considerando-se cada categoria separadamente. Na Figura 2.1 segue um exemplo do gráfico com a idade da empresa. Os demais gráficos encontram-se no Apêndice B.

Pode-se notar, no exemplo, que a idade da empresa demonstra um comportamento diferente em relação à sobrevivência para as empresas com até dois anos. Para as empresas com três ou mais anos as curvas de sobrevivência apresentam tendência parecida.

Figura 2.1: Curvas de sobrevivência para as categorias da covariável idade da empresa.

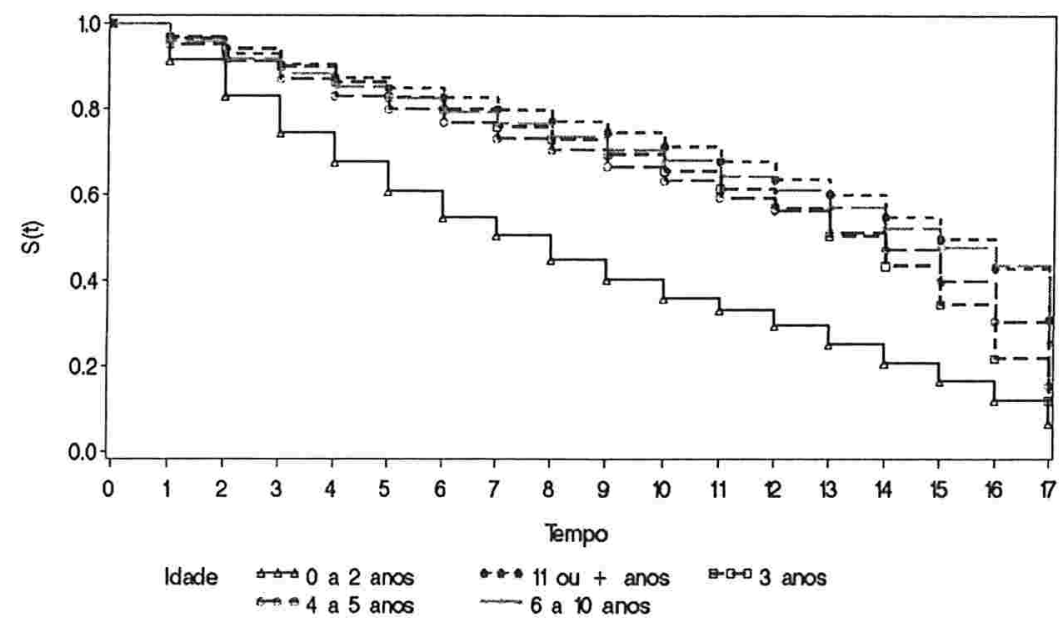




\section{Capítulo 3}

\section{Metodologias}

Para a estimação dos coeficientes de cada modelo, utilizou-se a Regressão Logística e a Análise de Sobrevivência. As covariáveis foram as mesmas para as duas técnicas, sendo que para a regressão logística a resposta considerada foi 0 (zero) para adimplente e 1 (um) para inadimplente. Para os Modelos de Análise de Sobrevivência, a resposta considerada foi o tempo entre a data da primeira consulta e o instante até a inadimplência (evento) ou final do acompanhamento (censura), o que ocorresse primeiro.

\subsection{Modelo de Regressão Logística}

A Regressão Logística descreve a relação entre uma variável resposta e uma ou mais covariáveis [Hosmer \& Lemeshow, 1989], quando essa variável resposta é binária.

Considere a quantidade $E(Y \mid Z)$ que descreve a relação entre a variável resposta $Y$ (binária) e o vetor de covariáveis $Z$, em que $0 \leq E(Y \mid Z) \leq 1$.

Para um conjunto de valores $z_{i}$ de $\boldsymbol{Z}$, seja:

$$
E\left(Y \mid z_{i}\right)=\pi\left(z_{i}\right)=\frac{e^{\boldsymbol{\beta}^{\prime} z_{\mathbf{i}}}}{1+e^{\boldsymbol{\beta}^{\prime} z_{i}}} .
$$

Usando a transformação logit, tem-se que para $i=1, \ldots, n$,

$$
g\left(z_{i}\right)=\ln \left(\frac{\pi\left(z_{i}\right)}{1-\pi\left(z_{i}\right)}\right)=\boldsymbol{\beta}^{\prime} z_{i}
$$

sendo $z_{i}=\left(1, z_{i 1}, \ldots, z_{i p}\right)$ o vetor de covariáveis da empresa $i, p$ o número de covariáveis e $\boldsymbol{\beta}^{\prime}=\left(\beta_{0}, \beta_{1}, \ldots, \beta_{p}\right)^{\prime}$ o vetor $p+1$ de parâmetros do modelo. 
A importância da transformação logit é que $g\left(z_{i}\right)$ possui muitas das propriedades desejáveis do modelo de Regressão Linear. O logit, $g\left(z_{i}\right)$ é linear em seus parâmetros, podendo ser contínuo e ainda variar de $-\infty$ a $+\infty$, dependendo da amplitude de $Z$.

Para o caso de resposta binária, pode-se expressar a variável como: $y=$ $\pi\left(z_{i}\right)+\varepsilon$, em que a quantidade $\varepsilon$ pode assumir um de dois possíveis valores: se $y=1$, então $\varepsilon=1-\pi\left(z_{i}\right)$ com probabilidade $\pi\left(z_{i}\right)$ e se $y=0$, então $\varepsilon=-\pi\left(z_{i}\right)$ com probabilidade $1-\pi\left(z_{i}\right)$. Portanto, a distribuição condicional de $y \mid z_{i}$ segue uma distribuição Bernoulli com parâmetro $\pi\left(z_{i}\right)$.

O método normalmente utilizado para a estimação dos parâmetros do modelo de Regressão Logística é o da máxima verossimilhança, baseado na verossimilhança:

$$
L(Y \mid \boldsymbol{\beta})=\prod_{i=1}^{n} \pi\left(z_{i}\right)^{y_{i}}\left[1-\pi\left(z_{i}\right)\right]^{1-y_{i}}
$$

com

$$
\pi\left(z_{i}\right)=\frac{e^{\boldsymbol{\beta}^{\prime} z_{i}}}{1+e^{\boldsymbol{\beta}^{\prime} z_{i}}} .
$$

Derivando-se o logaritmo de (3.3) em relação ao vetor de parâmetro $\boldsymbol{\beta}$ e igualando-o a 0 , não é possível obter uma expressão fechada. Os programas estatísticos adotam então, métodos numéricos como o processo iterativo de Fisher-Scoring ou Newton-Raphson [Lawless, 2003]. A variância assintótica do estimador de máxima verossimilhança é obtido pelo inverso da matriz de informação de Fisher. Uma formulação usual é dada por: $\widehat{I}(\boldsymbol{\beta})=Z^{\prime} V Z$, em que $Z$ é uma matriz $n \times(p+1)$ e $V$ é uma matriz diagonal $(n \times n)$, com os elementos diagonais dados por: $\left\{\pi\left(z_{i}\right)\left(1-\pi\left(z_{i}\right)\right)\right\}$.

A interpretação dos parâmetros estimados se dá a partir da razão de chances [Agresti, 1990], que pode ser definida como:

$$
\ln \left(\psi_{i}\right)=\ln \frac{P\left(y_{i}=1 \mid z_{i}\right)}{P\left(y_{i}=0 \mid z_{i}\right)}=\beta_{i}, i=1, \ldots, p .
$$

Neste estudo, $e^{\beta_{i}}$ expressa a razão entre a chance de uma empresa ser inadimplente em relação a ser adimplente, considerando a presença da covariável $z_{i}=1$ e mantendo as demais covariáveis preditoras constantes. 


\subsection{Modelo de Análise de Sobrevivência}

Assim como no modelo de Regressão Logística o interesse é estimar a probabilidade do evento ocorrer. Em um modelo de Análise de Sobrevivência estudam-se as relações entre as covariáveis e o tempo que leva até a ocorrência do evento de interesse. Considerado este aspecto do tempo, este modelo pode ter bastante utilidade na área de crédito, já que dado um conjunto de covariáveis associado a um cliente, a alta probabilidade deste superar o final do prazo para o financiamento sem apresentar inadimplência, fornece maior segurança durante a negociação. Por exemplo, um financiamento solicitado com um prazo de 24 meses, em que a probabilidade deste cliente superar esses meses sem apresentar inadimplência é alta, a instituição financeira poderá oferecer uma taxa de juros mais competitiva ou ainda aumentar o prazo do financiamento sem comprometer a rentabilidade.

Definindo $T$ como o tempo de sobrevivência, que neste estudo foi definido como o tempo até o instante da inadimplência, seja $S(t)$ a função de sobrevivência associada à inadimplência, dada por:

$$
S(t)=P(T>t)=\int_{t}^{+\infty} f(x) d x, t \geqslant 0,
$$

com $f(x)$ a função densidade de probabilidade associada a $T$.

$S(t)$ representa a probabilidade de um cliente superar um dado instante $t$ [Klein \& Moeschberger, 1997] sem se tornar inadimplente dado um conjunto de covariáveis associadas.

A função de sobrevivência $S(t)$ e a função densidade de probabilidade $f(t)$, podem ser escritas através da função de taxa de inadimplência $h(t)$, dada por:

$$
h(t)=\frac{f(t)}{S(t)}
$$

de onde podem ser tiradas as relações:

$$
S(t)=e^{-\int_{0}^{t} h(u) d u}=e^{-H(t)}
$$

e

$$
f(t)=h(t) e^{-\int_{0}^{t} h(u) d u}=h(t) e^{-H(t)}
$$

sendo que 


$$
H(t)=\int_{0}^{t} h(u) d u
$$

é a função de risco de inadimplência acumulada.

Neste trabalho considerou-se um modelo em uma abordagem semi-paramétrica utilizando-se o modelo de Cox [Cox, 1972] e modelos paramétricos considerando a família Weibull (incluindo o caso particular da distribuição exponencial) [Hosmer \& Lemeshow, 1999].

Adotou-se como horizonte de previsão o período de até 18 meses subseqüentes à primeira avaliação e, embora essa premissa não seja necessária na abordagem por análise de sobrevivência, foi mantida para que o modelo pudesse ter seu desempenho comparado ao modelo estimado por Regressão Logística sob as mesmas condições.

Para o cálculo dos tempos associados aos instantes de inadimplência ou adimplência foram consideradas duas notas do Credit Rating(R)Serasa para cada empresa, que foram calculados no período de janeiro de 1998 a julho 2003. Escolhida a primeira nota, foi fixado como limite para acompanhamento o $18^{\circ}$ mês e selecionada a segunda nota. Sendo assim, para cada empresa o tempo $t_{i}$ associado foi o número de meses entre as duas notas, sendo que a segunda correspondeu a inadimplência quando a empresa apresentou uma nota maior que 14 ou permaneceu adimplente quando a segunda nota foi menor ou igual a 14. Nesse caso, o tempo até a nota inferior a 15 caracterizou a censura $C_{i}$.

Sendo assim, para cada empresa no estudo tem-se um tempo associado à inadimplência ou à censura (adimplência).

$$
t_{i}=\min \left(T_{i}, C_{i}\right)
$$

Considere o vetor $\left(T_{i}, \delta_{i}, z_{i}\right), i=1, \ldots, n$, em que $T_{i}$ é o tempo observado para a $i$-ésima empresa, $\delta_{i}$ é o indicador de que houve inadimplência para a $i$-ésima empresa (ou seja 1 , se houve inadimplência e 0 se a empresa continuou adimplente) e $z_{i}$ é o vetor de covariáveis associado a $i$-ésima empresa no instante em que foi atribuída a primeira nota. Baseando em (3.6), segue que a função densidade de probabilidade é dada por:

$$
f(t, Z, \boldsymbol{\beta})=h(t, Z, \boldsymbol{\beta}) \times S(t, Z, \boldsymbol{\beta}), t \geqslant 0, \boldsymbol{\beta} \in \mathbb{R}^{\mathrm{p}}
$$

A estimativa do vetor de parâmetros $\beta$ é o valor que maximiza o logarítmo da função de verossimilhança, dado por 


$$
\log L(\boldsymbol{\beta})=\sum_{i=1}^{n} \delta_{i} \log \left[h\left(t_{i}, z_{i}, \boldsymbol{\beta}\right)\right]+\left(1-\delta_{i}\right) \log \left[S\left(t_{i}, z_{i}, \boldsymbol{\beta}\right)\right]
$$

Dependendo do quanto é especificado de $h$ e $S$ temos as abordagens paramétrica e semi-paramétrica, conforme discutido a seguir.

\subsubsection{Família Weibull}

Quando podemos associar uma distribuição aos dados e eles produzem um bom ajuste, eles tendem a dar estimativas mais precisas dos parâmetros [Hosmer \& Lemeshow, 1999]. Para os modelos da Família Weibull, foi considerada uma representação por modelo de tempo de vida acelerada, baseada no logarítmo do tempo $(T)$.

Considere $T>0$ um tempo de falha e o vetor $Z=\left(z_{1}, \ldots, z_{p}\right)$ de covariáveis associadas a $T$. O modelo de tempo de vida acelerado é dado por:

$$
S(t \mid Z)=S_{0}\left[t e^{\beta^{\prime} Z}\right]
$$

para todo $t$, sendo que $S_{0}$ é a função sobrevivência basal e $e^{\boldsymbol{\beta}^{\prime} \boldsymbol{Z}}$ é um fator de aceleração, que fornece a mudança na escala do tempo à medida que a covariável $Z$ muda. O vetor de covariáveis $Z$ é um conjunto das variáveis dummies correspondentes às covariáveis categorizadas (sendo que, $z_{i j}=1$ se a empresa $i$ apresenta a característica $j$ e $z_{i j}=0$ se a empresa $i$ não apresenta a característica $j$, com $i=i, \ldots, n$ e $j=1, \ldots, p$ ). De (3.12) temos que o efeito da presença da característica $j$ na sobrevivência é dada por:

$$
S\left(t \mid z_{i j}=1\right)=S\left[t e^{\beta^{\prime} z_{i j}} \mid z_{i j}=0\right], i=i, \ldots, n .
$$

para todo $t$ e mantidas as demais covariáveis constantes. Pode-se portanto, interpretar que para $\beta \neq 0$ ocorre uma aceleração no tempo de sobrevivência da empresa. Isto é, se $\beta>0$, a presença da característica $j$ leva a uma diminuição no tempo de sobrevivência, ao passo que $\beta<0$ leva a um aumento no tempo de sobrevivência da empresa, mantidas as demais covariáveis constantes.

No modelo de vida acelerada, a função de risco de inadimplência para uma empresa com covariáveis $Z$ está também relacionada à função de risco de inadimplência basal $h_{0}$ dada por:

$$
h(t \mid Z)=e^{\beta^{\prime} Z} h_{0}\left[e^{\beta^{\prime} Z} t\right]
$$


para todo $t$.

Uma forma alternativa de representar o modelo de vida acelerada é através de um modelo log-linear.

$$
Y=\ln T=\boldsymbol{\beta}^{\prime} Z+\sigma W
$$

com $\boldsymbol{\beta}^{\prime}=\left(\beta_{1}, \ldots, \beta_{p}\right)$ o vetor de coeficientes na regressão e $\boldsymbol{W}$ o erro aleatório com distribuição conhecida. Os coeficientes da regressão têm uma interpretação similar àquela do modelo de regressão usual [Klein \& Moeschberger, 1997].

Para a família Weibull, a função de sobrevivência é dada por:

$$
S_{T}(t)=e^{-\lambda t^{\alpha}}, t \geq 0, \alpha>0, \lambda>0
$$

e a função de risco de inadimplência é expressa por:

$$
h_{t}(t)=\lambda \alpha t^{\alpha-1}
$$

Através da transformação logarítmica $Y=\log T$, a função de sobrevivência resulta em:

$$
S_{Y}(y)=e^{-\lambda e^{y \alpha}}
$$

Redefinindo os parâmetros $\lambda=e^{\frac{-\boldsymbol{\beta}_{z}^{\prime} z}{\sigma}}$ e $\sigma=\frac{1}{\alpha}$, considerando o modelo loglinear e assumindo que $W$ segue uma distribuição Valor Extremo [Klein \& Moeschberger, 1997] com parâmetros $\boldsymbol{\beta}^{\prime} \boldsymbol{Z}$ e $\sigma$, a função densidade de probabilidade é dada por:

$$
f_{W}(w)=e^{w-e^{w}}
$$

e a função de sobrevivência por:

$$
S_{W}(w)=e^{-e^{w}}
$$

Com isso, tem-se que para $Y$ a respectiva função densidade de probabilidade é dada por:

$$
f_{Y}(y)=\frac{1}{\sigma} e^{\left[\frac{y-\boldsymbol{\beta}^{\prime} \boldsymbol{Z}}{\sigma}-e^{\frac{y-\boldsymbol{\beta}^{\prime} \boldsymbol{Z}}{\sigma}}\right]}
$$


e a função de sobrevivência por:

$$
S_{Y}(y)=e^{-e^{\frac{y-\beta^{\prime} Z}{\sigma}}} .
$$

Quando $\alpha=1$, ou equivalentemente $\sigma=1$, tem-se o caso especial da distribuição Exponencial.

As estimativas de máxima verossimilhança dos parâmetros $\beta$ e $\sigma$, são obtidas maximizando a função de verossimilhança dada por:

$$
L(\boldsymbol{\beta}, \sigma)=\prod_{j=1}^{n}\left[f_{Y}\left(y_{j}\right)\right]^{\delta_{j}}\left[S_{Y}\left(y_{j}\right)\right]^{1-\delta_{j}},
$$

em que $f_{Y}(y)$ e $S_{Y}(y)$ foram dados em (3.21) e (3.22).

Então:

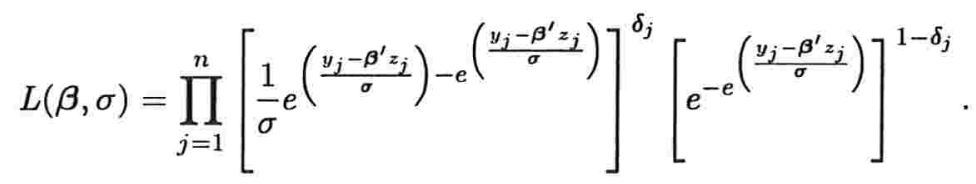

Normalmente trabalha-se $\operatorname{com} l(\boldsymbol{\theta})=\log L(\boldsymbol{\theta})$, sendo $(\boldsymbol{\theta})=(\boldsymbol{\beta}, \sigma)$ e os estimadores de máxima verossimilhança são obtidos resolvendo a equação $U_{j}(\boldsymbol{\theta})=0(j=1, \ldots, p)$, sendo que

$$
U_{j}(\boldsymbol{\theta})=\frac{\partial l(\boldsymbol{\theta})}{\partial \theta_{j}}, j=1, \ldots, p .
$$

Os $U_{j}(\theta)$ 's são chamados função escore e esssas estimativas são encontradas iterativamente utilizando métodos numéricos como Newton-Raphson [Lawless, 2003].

A matriz de variância e covariância dos parâmetros $\log$-lineares $\beta$ e $\sigma$ são obtidos a partir das matrizes de informação observada (disponíveis nos pacotes estatísticos), dada por:

$$
I_{\boldsymbol{\theta}}(\boldsymbol{\beta}, \sigma)=-E\left(\frac{\partial^{2} \log L(\boldsymbol{\theta})}{\partial \theta_{i} \theta_{j}}\right) .
$$

Em grandes amostras a distribuição conjunta de $\hat{\boldsymbol{\beta}}$ e $\hat{\sigma}$ se aproxima de uma normal $(p+1)$ variada, com vetor de média $\left(\boldsymbol{\beta}^{\prime}, \sigma\right)$ e matriz de covariância dada pela informação observada [Lawless, 2003]: 


$$
\mathbf{I}_{0}(\boldsymbol{\beta}, \sigma)=\left(\begin{array}{ll}
\mathbf{I}_{11}(\boldsymbol{\beta}, \sigma)_{p \times p} & \mathbf{I}_{12}(\boldsymbol{\beta}, \sigma)_{p \times 1} \\
\mathbf{I}_{12}^{\prime}(\boldsymbol{\beta}, \sigma)_{1 \times p} & \mathbf{I}_{22}(\boldsymbol{\beta}, \sigma)_{1 \times 1}
\end{array}\right)
$$

sendo que:

$$
\begin{aligned}
& \mathbf{I}_{11}(\boldsymbol{\beta}, \sigma)=\left(-\frac{\partial^{2} l(\boldsymbol{\beta}, \sigma)}{\partial \beta_{l} \partial \beta_{k}}\right)_{p \times p} \\
& \mathbf{I}_{12}(\boldsymbol{\beta}, \sigma)=\left(-\frac{\partial^{2} l(\boldsymbol{\beta}, \sigma)}{\partial \beta_{l} \partial \sigma}\right)_{p \times 1} \\
& \mathbf{I}_{22}(\boldsymbol{\beta}, \sigma)=\left(-\frac{\partial^{2} l(\boldsymbol{\beta}, \sigma)}{\partial \beta_{l} \partial \sigma^{2}}\right)_{1 \times 1}
\end{aligned}
$$

Sob certas condições de regularidade [Sen \& Singer, 1993], tem-se que:

$$
I_{0}(\boldsymbol{\beta}, \sigma) \stackrel{P}{\longrightarrow} I_{F}(\boldsymbol{\beta}, \sigma)
$$

quando $n \longrightarrow+\infty$, o que é verificado pela Lei Fraca dos Grandes Números.

\subsubsection{Modelo de Riscos Proporcionais de Cox}

Seja $h(t \mid Z)$ a taxa de risco de inadimplência de uma empresa no instante $t$ com vetor de covariáveis $Z$. O modelo de riscos proporcionais é dado por:

$$
h(t \mid Z)=h_{0}(t) c\left(\boldsymbol{\beta}^{\prime} Z\right)
$$

em que:

$h_{0}(t)$ é a função de risco de inadimplência basal (baseline);

$\boldsymbol{\beta}=\left(\beta_{1}, \ldots, \beta_{p}\right)^{\prime}$ é o vetor de parâmetros;

$Z$ é o vetor de covariáveis e

$c\left(\boldsymbol{\beta}^{\prime} Z\right)$ é uma função conhecida [Klein \& Moeschberger, 1997] .

O modelo de riscos proporcionais é um modelo semi-paramétrico porque a forma paramétrica é assumida somente para a função $c(\cdot)$, cuja função mais comumente utilizada é a Exponencial. A função basal é estimada de forma não paramétrica. 
Cox [Cox, 1972] foi o primeiro a sugerir usar uma parametrização em função do risco:

$$
h(t \mid Z)=h_{0}(t) e^{\boldsymbol{\beta}^{\prime} Z}
$$

e assim, a razão de riscos é dada por:

$$
H R\left(t, Z_{1}, Z_{0}\right)=\frac{\boldsymbol{c}\left(\boldsymbol{\beta}^{\prime} Z_{1}\right)}{c\left(\boldsymbol{\beta}^{\prime} Z_{0}\right)}=e^{\boldsymbol{\beta}^{\prime}\left(z_{1}-z_{0}\right)}
$$

A interpretação do coeficiente $\beta_{j}$ representa o acréscimo no logarítmo da função da taxa de inadimplência, quando $z_{j}$ é acrescida de uma unidade $\left(z_{i j}=1\right)$ e mantidas todas as outras covariáveis constantes.

Usando as relações entre a função de risco de inadimplência e a função de sobrevivência, sob o modelo de Cox, a função de sobrevivência é dada por:

$$
S(t \mid Z)=\left[S_{0}(t)\right]^{\exp \left(\boldsymbol{\beta}^{\prime} Z\right)},
$$

sendo $S_{0}(t)$ a função de sobrevivência basal. O programa SAS possui o procedimento PHREG que ajusta o modelo de Cox; pode-se solicitar a estimativa da função basal em suas opções (comando "baseline"), que fornece um arquivo com a estimativa de $S_{0}(t)$, estimada pelo Produto - Limite [Kaplan \& Meier, 1958].

Como a amostra para este estudo apresenta dados com empate, utilizouse a função de verossimilhança parcial sugerida por Efron [Efron, 1977] que tende a apresentar estimativas menos viciadas [Klein \& Moeschberger, 1997] e é dada por:

$$
L(\boldsymbol{\beta})=\prod_{i=1}^{D} \frac{e^{\boldsymbol{\beta}^{\prime} s_{i}}}{\prod_{j=1}^{d_{i}}\left[\sum_{k \in R_{i}} e^{\boldsymbol{\beta}^{\prime} z_{k}}-\frac{j-1}{d_{i}} \sum_{k \in D^{*}} e^{\boldsymbol{\beta}^{\prime} z_{k}}\right]}
$$

Em (3.33), assume-se $t_{1}<t_{2}<\ldots<t_{D}$, em que $D$ é o número de eventos de tempos distintos e ordenados; $d_{i}$ é o número de inadimplentes em $t_{i}$ e $D_{i}^{*}$ o conjunto de todos os casos de inadimplência até $t_{i}$. Também $s_{i}$ é a soma do vetor $z_{j}$, para todos os clientes que se tornam inadimplentes até $t_{i}$ e $R_{i}$ é o conjunto de todos os clientes em risco (sem apresentar inadimplência ou ter deixado o estudo) até o instante $t_{i}$ [Klein \& Moeschberger, 1997].

Quando não ocorrem empates, esta função de verossimilhança parcial se reduz à verossimilhança parcial de Cox [Cox, 1975], dada por: 


$$
L(\boldsymbol{\beta})=\prod_{i=1}^{D} \frac{\exp \left[\boldsymbol{\beta}^{\prime} z_{(i)}\right]}{\sum_{j \in R\left(t_{(i)}\right)} \exp \left[\boldsymbol{\beta}^{\prime} z_{(j)}\right]} .
$$

Maximizando-se $L(\boldsymbol{\beta})$ e utilizando-se o método numérico de Newton-Raphson, obtém-se $\hat{\beta}$, o estimador de máxima verossimilhança parcial [Cox, 1975].

As propriedades assintóticas destes estimadores são bem determinadas, sendo as principais a consistência e a normalidade assintótica sob certas condições de regularidade. Estes resultados são obtidos utilizando-se a teoria de processos de contagem [Andersen et al, 1993]. Para se ter uma idéia do que é feito, considere a função de log-verossimilhança baseada em (3.34),

$$
l(\boldsymbol{\beta})=\sum_{i=1}^{D} \boldsymbol{\beta}^{\prime} z_{(i)}-\sum_{i=1}^{D} \log \left[\sum_{j \in R\left(t_{(i)}\right)} e^{\boldsymbol{\beta}^{\prime} z_{i j}}\right] .
$$

Os estimadores de máxima verossimilhança de $\boldsymbol{\beta}$, denotados por $\hat{\boldsymbol{\beta}}$, são obtidos através da solução das equações normais

$$
U_{k}(\boldsymbol{\beta})=\frac{\partial l(\boldsymbol{\beta})}{\partial \beta_{k}}, k=1, \ldots, p .
$$

As quantidades em (3.36) são os escores que podem ser organizados no vetor escores

$$
U^{\prime}(\boldsymbol{\beta})=\left(U_{1}(\boldsymbol{\beta}), U_{2}(\boldsymbol{\beta}), \ldots, U_{p}(\boldsymbol{\beta})\right) .
$$

Usando a teoria de martingais, pode ser mostrado que

$$
n^{-\frac{1}{2}} U\left(\boldsymbol{\beta}_{0}\right)
$$

é assintoticamente normal com média 0 e de variância consistentemente estimada por

$$
\frac{I(\hat{\boldsymbol{\beta}})}{n}=\left.\frac{1}{n}\left[-\frac{\partial^{2} l(\boldsymbol{\beta})}{\partial \boldsymbol{\beta} \partial \boldsymbol{\beta}^{\prime}}\right]\right|_{\boldsymbol{\beta}=\hat{\boldsymbol{\beta}}} .
$$

Logo, usando a expansão de Taylor de $1^{\text {a }}$ ordem, temos que

$$
0=U(\hat{\boldsymbol{\beta}})=U\left(\boldsymbol{\beta}_{0}\right)-I\left(\boldsymbol{\beta}_{0}\right)\left(\hat{\boldsymbol{\beta}}-\boldsymbol{\beta}_{0}\right)
$$

ou seja 


$$
\frac{\sqrt{n}\left(\hat{\boldsymbol{\beta}}-\boldsymbol{\beta}_{0}\right)}{\sqrt{n I^{-1}\left(\boldsymbol{\beta}_{0}\right)}}=\frac{n^{\frac{1}{2}} U\left(\boldsymbol{\beta}_{0}\right)}{\sqrt{\frac{I(\hat{\boldsymbol{\beta}})}{n}}} \times\left[\frac{I(\hat{\boldsymbol{\beta}})}{I\left(\boldsymbol{\beta}_{0}\right)}\right]^{\frac{1}{2}}
$$

[Andersen et al, 1993] mostram que $I(\hat{\boldsymbol{\beta}}) / I\left(\boldsymbol{\beta}_{0}\right)$ converge para 1 em probabilidade, e assim,

$$
\sqrt{n}\left(\hat{\boldsymbol{\beta}}-\boldsymbol{\beta}_{0}\right)
$$

converge para uma distribuição normal com média zero e matriz de variância que pode ser consistentemente estimada por $n I^{-1}(\hat{\boldsymbol{\beta}})$. 


\section{Capítulo 4}

\section{Medidas de Avaliação de Desempenho em Modelos de Credit Score}

Conforme mencionado no Capítulo 1, várias metodologias podem ser empregadas na discriminação de clientes inadimplentes e adimplentes.

Foram abordadas as medidas de avaliação conhecidas e largamente utilizadas no mercado de crédito, como a estatística de Kolmogorv-Smirnov (KS), a Curva de Lorentz e o Coeficiente de Gini, além da distância de Mahalanobis (pouco utilizada na prática). Também foram propostas e avaliadas duas novas medidas: a área entre as curvas de distribuição acumulada utilizadas para o cálculo do $K S$ (AEC) e a diferença entre as taxas de inadimplência nas faixas extremas do escore definidas pelos decis (DTI).

Os programas utilizados para o cálculo de todas as medidas sugeridas foram desenvolvidos em SAS e encontram-se no Apêndice D.

\subsection{Estatística de Kolmogorov-Smirnov}

O teste para duas amostras de Kolmogorov-Smirnov [Conover, 1999] é utilizado para avaliar se essas amostras vêm de uma mesma distribuição. Esse teste é freqüentemente utilizado em inferência não paramétrica [Siegel, 1956].

Sejam as funções de distribuição acumulada para clientes adimplentes e inadimplentes, que são estimadas pelas funções de distribuição empírica dadas por: 


$$
F_{B}(s)=\frac{n^{o} \text { clientes adimplentes com escore } \leq s}{\text { total de clientes adimplentes }}
$$

e

$$
F_{M}(s)=\frac{n^{o} \text { clientes inadimplentes com escore } \leq s}{\text { total de clientes inadimplentes }} .
$$

sendo $s$ o escore.

A estatística de Kolmogorov-Smirnov é dada por:

$$
K S=\max \left(\left|F_{M}(s)-F_{B}(s)\right|\right) .
$$

Este valor de $K S$ é usado no teste de significância, que é baseado na estatística

$$
C h=4 \times(K S)^{2} \times\left(\frac{n_{b} \times n_{m}}{n_{b}+n_{m}}\right),
$$

que segue uma distribuição qui-quadrado com 2 graus de liberdade.

Em (4.4), $n_{b}$ e $n_{m}$ são respectivamente o tamanho da amostra de adimplentes (Bons) e inadimplentes (Maus).

O programa estatístico SAS (PROC NPAR1WAY) calcula, entre outras estatísticas não paramétricas, a estatística de Kolmogorov-Smirnov, representada pela letra $D$ nos resultados apresentados na saída do programa.

Na abordagem mercadológica, utiliza-se somente o valor máximo da distância entre as distribuições como a grandeza que expressa a qualidade do modelo e tornou-se popularmente conhecido como $K S$ do modelo. Em geral não se dá muita importância para a significância da estatística, pois as amostras normalmente utilizadas são muito grandes, o que torna até pequenas distâncias significantes, não implicando, porém numa boa separação entre bons e maus clientes do ponto de vista do crédito.

Quanto maior o $K S$, melhor é a discriminação do modelo, pois significa que concentra maior quantidade de clientes bons com escores altos, enquanto os clientes maus possuem escores mais baixos. Tão importante quanto o valor desta medida é também o seu posicionamento na distribuição. O melhores modelos apresentam alto $K S$ nos primeiros decis da distribuição do escore.

A Figura 4.1 apresenta as curvas da função de distribuição acumulada empírica para os clientes inadimplentes (maus) e adimplentes (bons) por faixa 
de escore e a máxima distância entre as duas curvas é denominada o $K S$ do modelo.

Figura 4.1: Gráfico da medida KS.

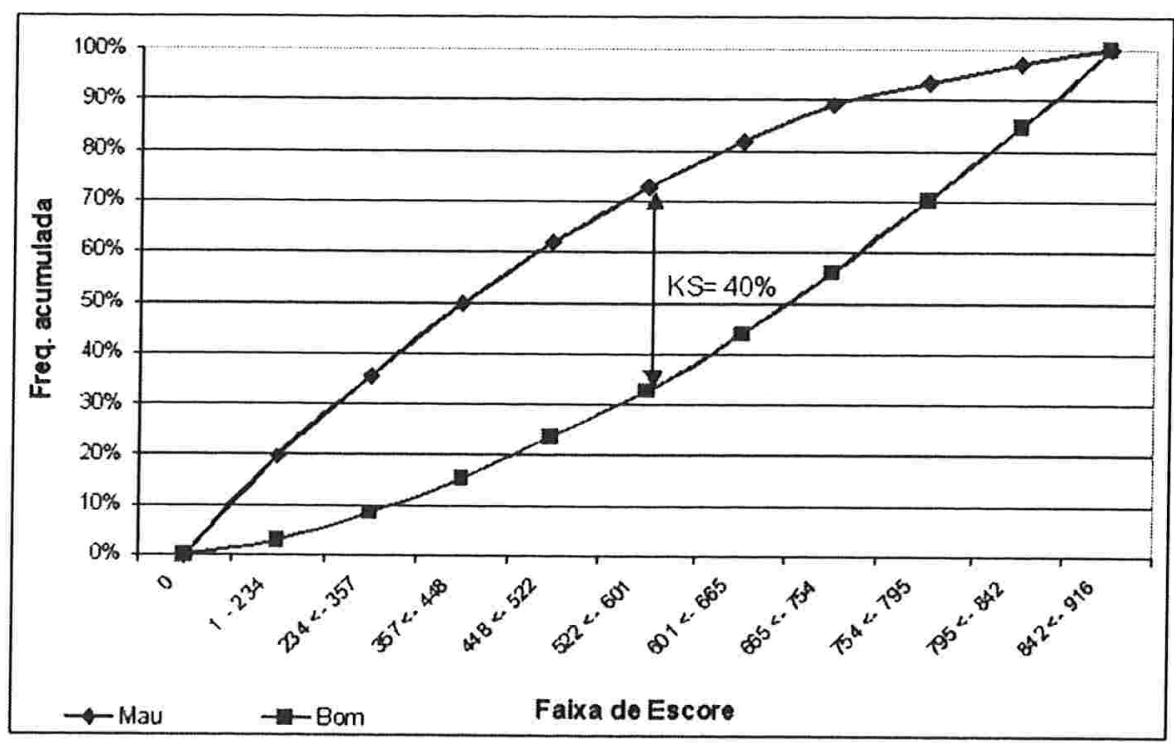

Usualmente, adotam-se no mercado de crédito, faixas de referência para a classificação onde o $K S$ calculado é enquadrado para indicar a qualidade dos modelos ajustados [Oliveira \& Andrade, 2002].

\section{2 Área Entre as Curvas de Distribuição Acumu- lada dos Escores}

A maneira que a estatística de Kolmogorov-Smirnov é utilizada no mercado de crédito para avaliar o desempenho dos modelos tende a comparar somente o ponto máximo de distância entre as duas funções de distribuição acumulada empíricas.

Assim, pensou-se em avaliar inteiramente as duas funções tomando como medida de avaliação de desempenho de modelos de Credit Score, a área entre as curvas de distribuição acumulada que definem a medida do $K S$. 
Considerando as funções de distribuição acumulada empíricas para clientes bons e maus, $F_{B}(\cdot)$ e $F_{M}(\cdot)$, definidas anteriormente em (4.1) e (4.2), respectivamente.

As áreas sob as curvas definadas por (4.1) e (4.2) foram estimadas por aproximação através da soma das áreas de retângulos. A base de cada retângulo foi formada pela diferença entre dois escores consecutivos e a altura pela função de distribuição acumulada empírica dos clientes bons até cada escore, analogamente foi tomada a altura para os clientes maus.

Assim, os estimadores da área sob cada uma das curvas de distribuição acumulada empírica dos escores podem ser descritos como:

$$
\begin{aligned}
& \widehat{A}(M)=\sum_{i=1}^{1000}\left(s_{i}-s_{i-1}\right) \times F_{M}\left(s_{i}\right), \\
& \widehat{A}(B)=\sum_{i=1}^{1000}\left(s_{i}-s_{i-1}\right) \times F_{B}\left(s_{i}\right) .
\end{aligned}
$$

De (4.5) e (4.6), segue que a estimativa da área entre as curvas pode ser calculada por:

$$
\widehat{A E C}=|\widehat{A}(M)-\widehat{A}(B)|
$$

A Figura 4.2 ilustra essa área. Nesta figura temos as duas curvas da distribuição acumulada empírica dos clientes inadimplentes e adimplentes por escore e a área escura representa a diferença entre as áreas estimadas sob cada uma das curvas utilizadas para o cálculo do $K S$.

Analogamente ao KS quanto maior a área, melhor seria a discriminação entre os bons e maus clientes. A macro em SAS utilizada para o cálculo desta medida está no Apêndice D.

\subsection{Curva de Lorentz e Coeficiente de Gini}

A curva de Lorentz, mais conhecida como curva ROC (Receiver Operating Characteristic) surgiu durante a Segunda Guerra mundial com o uso de radares para detecção de sinais. O nome ROC sugere sua origem em estimar a classificação errada em transmissões e recebimento de mensagens [Thomas et al, 2002]. 
Figura 4.2: Gráfico da área entre as curvas.

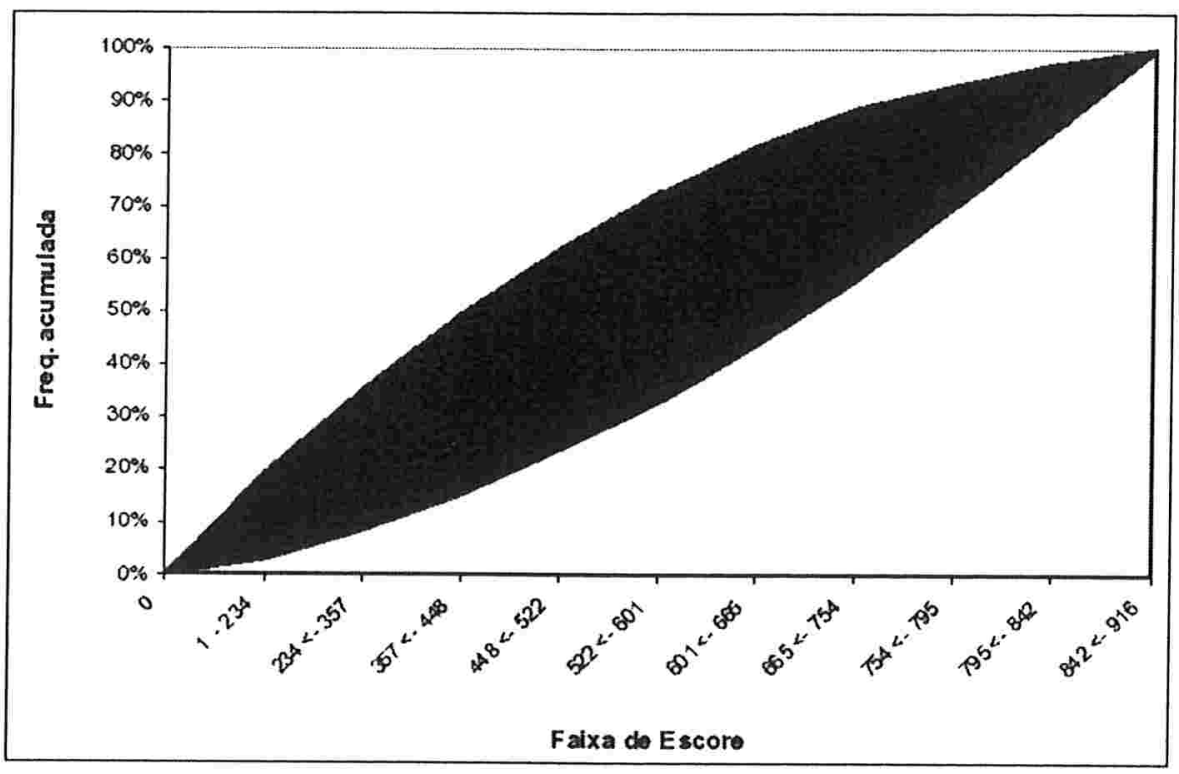

Posteriormente, foi largamente utilizada em epidemiologia e atualmente tem sido aplicada na área de crédito. A curva descreve como a classificação de bons e maus clientes varia de acordo com cada ponto de corte.

Para calcular a curva são necessárias duas medidas: a Sensitividade (Se) que é a proporção de clientes maus que foram classificados como maus e a Especificidade $(E s)$ que é a proporção de cliente bons que foram classificados como bons.

Supondo um ponto de corte no escore $s$, todo cliente com escore maior ou igual a $s$ é classificado como bom pagador. Assim, para cada escore é possível obter uma matriz $2 \times 2 \mathrm{com}$ a quantidade de clientes classificada em cada estado $(B / M)$ observado. Esta tabela $2 \times 2$ conhecida como matriz de confusão [Johnson \& Wichern, 1998], possibilita o cálculo da Especificidade e Sensitividade.

Na Tabela 4.1:

$m_{M}$ é o número de clientes classificados como maus corretamente;

$m_{m}$ é o número de clientes classificados como maus indevidamente;

$b_{B}$ é o número de clientes classificados como bons corretamente;

$b_{b}$ é o número de clientes classificados como bons indevidamente;

$n_{B}$ é o número de cliente bons na amostra; 
Tabela 4.1: Exemplo de matriz de confusão

\begin{tabular}{lccc} 
& \multicolumn{2}{c}{ Observado } & \\
\cline { 2 - 3 } Previsto & Maus & Bons & Total \\
\hline Abaixo do ponto de corte $(S):$ Maus & $m_{M}$ & $m_{m}$ & $m$ \\
Maior ou Igual ponto de corte $(S):$ Bons & $b_{b}$ & $b_{B}$ & $b$ \\
\hline Total & $n_{M}$ & $n_{B}$ & $n$
\end{tabular}

$n_{M}$ é o número de clientes maus na amostra;

$m$ é o número de clientes abaixo do ponto de corte e classificados como maus;

$b$ é o número de clientes maior ou igual ao ponto de corte e classificados como bons;

$n$ é o número total de clientes da amostra;

Obtém-se a sensitividade por:

$$
S e=m_{M} / n_{M}
$$

e a especificidade por:

$$
E s=b_{B} / n_{B}
$$

variando-se o ponto de corte para todo escore $s$, obtém-se as medidas para traçar a curva, sendo que no eixo $X$ considera-se $(1-E s)$ e no eixo $Y$ a $S e$.

Quanto mais distante a curva ROC estiver da reta $x=y$, melhor a discriminação do modelo. Esta curva representa o percentual de classificação correta em cada ponto do escore. Com isso, quanto mais distante da diagonal, maior o número de empresas corretamente classificadas.

A medida que expressa essa discriminação é conhecida como a área sob a curva ROC. Esta medida varia entre 0,5 e 1 , sendo que quanto maior o valor, melhor a discriminação do modelo. A área sob a curva ROC possui uma importante propriedade estatística que a equivale ao teste de postos de Wilcoxon [Fawcett, 2004], [Hanley \& McNeil, 1982].

O coeficiente de Gini é calculado a partir da curva ROC ou Lorentz [Hand \& Till, 2001], sendo duas vezes a área entre a reta $x=y$ e a curva ROC. A Figura 4.3 mostra um exemplo da curva ROC onde é possível visualizar a área sob a curva e a distância entre a curva e sua diagonal, utilizada para 
o cálculo do coeficiente de Gini. Como essa medida é função da curva ROC, segue o mesmo critério: quanto maior o seu valor, melhor a discriminação do modelo.

A macro em SAS utilizada para estimar a área sob a curva ROC e o coeficiente de Gini encontram-se no Apêndice D.

Figura 4.3: Exemplo de curva ROC.

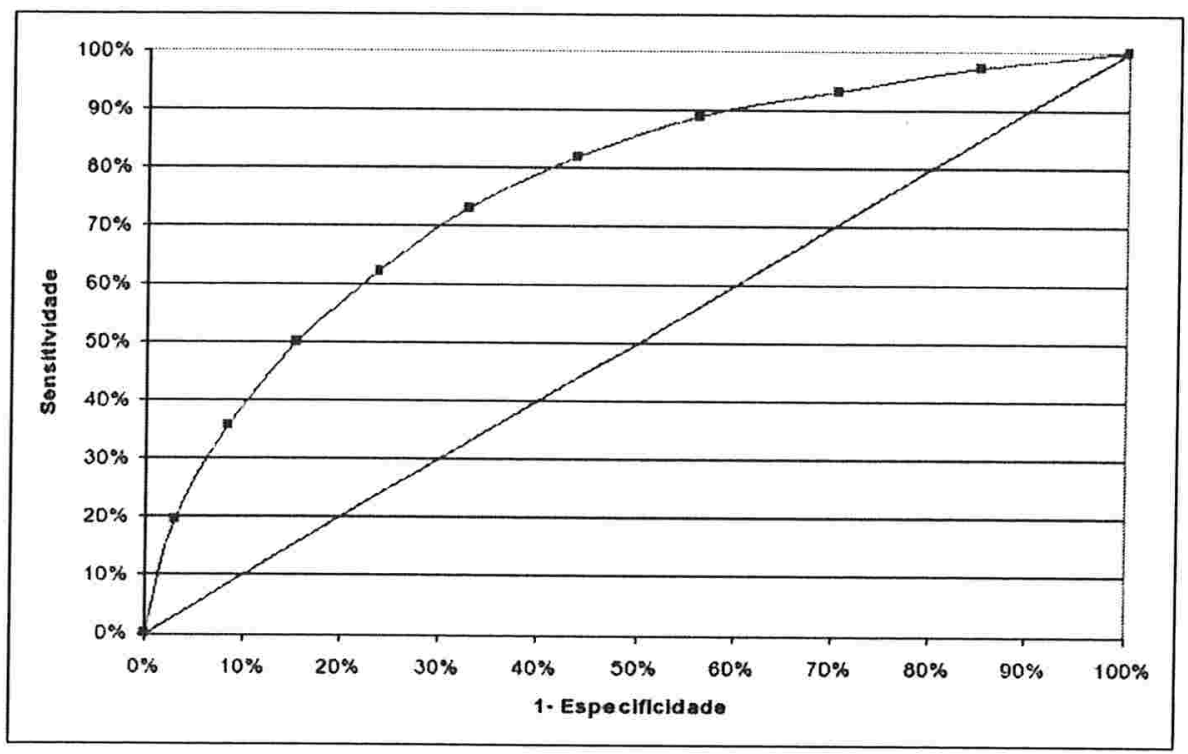

\subsection{Distância de Mahalanobis}

A distância de Mahalanobis é uma medida muito simples de se calcular e pode ser utilizada para a avaliação de qualidade dos modelos. Ela mede a distância entre a média amostral dos escores dos clientes bons e maus. Assim como o $K S$, esta medida não depende de um ponto de corte.

Seja $s_{B_{i}}$ o escore atribuído ao $i$-ésimo cliente bom pagador e $s_{M_{i}}$ o escore atribuído ao $i$-ésimo cliente mau pagador. Para o cálculo desta medida, segue que:

$$
\bar{x}_{B}=\frac{1}{n_{B}} \sum_{i=1}^{n_{B}} s_{B_{i}}
$$


e

$$
\bar{x}_{M}=\frac{1}{n_{M}} \sum_{i=1}^{n_{M}} s_{M_{i}}
$$

sendo $\bar{x}_{B}$ e $\bar{x}_{M}$ as médias, em que $n_{B}$ e $n_{M}$ são, respectivamente, o número de clientes adimplentes(bons) e inadimplentes(maus).

Seja $\hat{\sigma}$ o desvio padrão ponderado das duas amostras:

$$
\hat{\sigma}=\left(\frac{n_{B} \hat{\sigma}_{B}^{2}+n_{M} \hat{\sigma}_{M}^{2}}{n}\right)^{\frac{1}{2}}
$$

sendo que $\hat{\sigma}_{B}^{2}$ e $\hat{\sigma}_{M}^{2}$ são, respectivamente, as variâncias para cada grupo de clientes bons e maus e $n$ o total de clientes.

Então a estatística da distância de Mahalanobis $M A H$ é dada pela diferença entre as médias, dividida pela desvio padrão ponderado.

$$
M A H=\left(\frac{\bar{X}_{B}-\bar{X}_{M}}{\hat{\sigma}}\right) .
$$

Para a distância de Mahalanobis, tem-se que quanto maior a medida, melhor a discriminação do modelo.

\subsection{Diferença Entre as Taxas de Inadimplência}

Uma característica importante em um modelo de Credit Score é a capacidade de ordenação da taxa de inadimplência que o modelo proporciona com a variação do escore. Ou seja, quanto maior o escore, menor deve ser a proporção de observações classificadas como maus e vice-versa, o que indica que, quanto maior o escore menor é a chance do cliente se tornar inadimplente. Com isso, pode-se criar indicadores baseados nesta capacidade de ordenação de um modelo.

Tomando a taxa de inadimplência em cada intervalo definido pelos decis do escore, a diferença entre essa taxa no intervalo do primeiro decil em relação ao do último decil, fornece uma dimensão da separação entre bons e maus proporcionada pelo modelo.

Para calcular a diferença entre as taxas de inadimplência, primeiro temse que encontrar os decis do escore, depois construir os intervalos, calcular a freqüência total de observações e também calcular a frequiência de clientes 
classificados como bons e maus para cada intervalo. A taxa de inadimplência em cada intervalo é dada pelo total de clientes classificados como maus dividido pelo total de clientes em cada faixa do escore, conforme dado na Tabela 4.2.

Tabela 4.2: Cálculo da taxa de inadimplência em cada intervalo

\begin{tabular}{lcccl} 
Decis & Total & Maus & Bons & Taxa Maus \\
\hline $1^{\circ}$ intervalo & $t_{1}$ & $m_{1}$ & $b_{1}$ & $t m_{1}=m_{1} / t_{1}{ }^{*} 100$ \\
$2^{\circ}$ intervalo & $t_{2}$ & $m_{2}$ & $b_{2}$ & $t m_{2}=m_{2} / t_{2} * 100$ \\
$3^{\circ}$ intervalo & $t_{3}$ & $m_{3}$ & $b_{3}$ & $t m_{3}=m_{3} / t_{3}{ }^{*} 100$ \\
$4^{\circ}$ intervalo & $t_{4}$ & $m_{4}$ & $b_{4}$ & $t m_{4}=m_{4} / t_{4} * 100$ \\
$5^{\circ}$ intervalo & $t_{5}$ & $m_{5}$ & $b_{5}$ & $t m_{5}=m_{5} / t_{5} * 100$ \\
$6^{\circ}$ intervalo & $t_{6}$ & $m_{6}$ & $b_{6}$ & $t m_{6}=m_{6} / t_{6}{ }^{*} 100$ \\
$7^{\circ}$ intervalo & $t_{7}$ & $m_{7}$ & $b_{7}$ & $t m_{7}=m_{7} / t_{7}{ }^{*} 100$ \\
$8^{\circ}$ intervalo & $t_{8}$ & $m_{8}$ & $b_{8}$ & $t m_{8}=m_{8} / t_{8}{ }^{*} 100$ \\
$9^{\circ}$ intervalo & $t_{9}$ & $m_{9}$ & $b_{9}$ & $t m_{9}=m_{9} / t_{9} * 100$ \\
$10^{\circ}$ intervalo & $t_{10}$ & $m_{10}$ & $b_{10}$ & $t m_{10}=m_{10} / t_{10} * 100$ \\
\hline
\end{tabular}

Em que:

$t_{k}$ é o total de casos no $k$-ésimo intervalo;

$m_{k}$ é o total de maus no $k$-ésimo intervalo;

$b_{k}$ é o total de bons no $k$-ésimo intervalo;

$t m_{k}$ é a taxa de maus em relação ao total para o $k$-ésimo intervalo; $\operatorname{com} k=1, \ldots, 10$.

A diferença entre as taxas de inadimplência nos intervalos extremos é dada por

$$
\operatorname{DTI}(1 ; 10)=t m_{1}-t m_{10}
$$

Essa medida expressa em quantos pontos percentuais o escore consegue reduzir a inadimplência; quanto maior o valor, melhor a separação proporcionada pelo modelo. Essa diferença pode ser avaliada em todos os intervalos, mas para este trabalho foram escolhidos somente os intervalos extremos. Numa outra abordagem, poderia ser considerada a diferença entre as taxas de inadimplência dos intervalos extremos, dividida pela taxa de inadimplência do primeiro intervalo. 
A Figura 4.5 apresenta um exemplo com a taxa de inadimplência em cada intervalo do escore:

Figura 4.4: Taxa de inadimplentes por intervalo do escore.

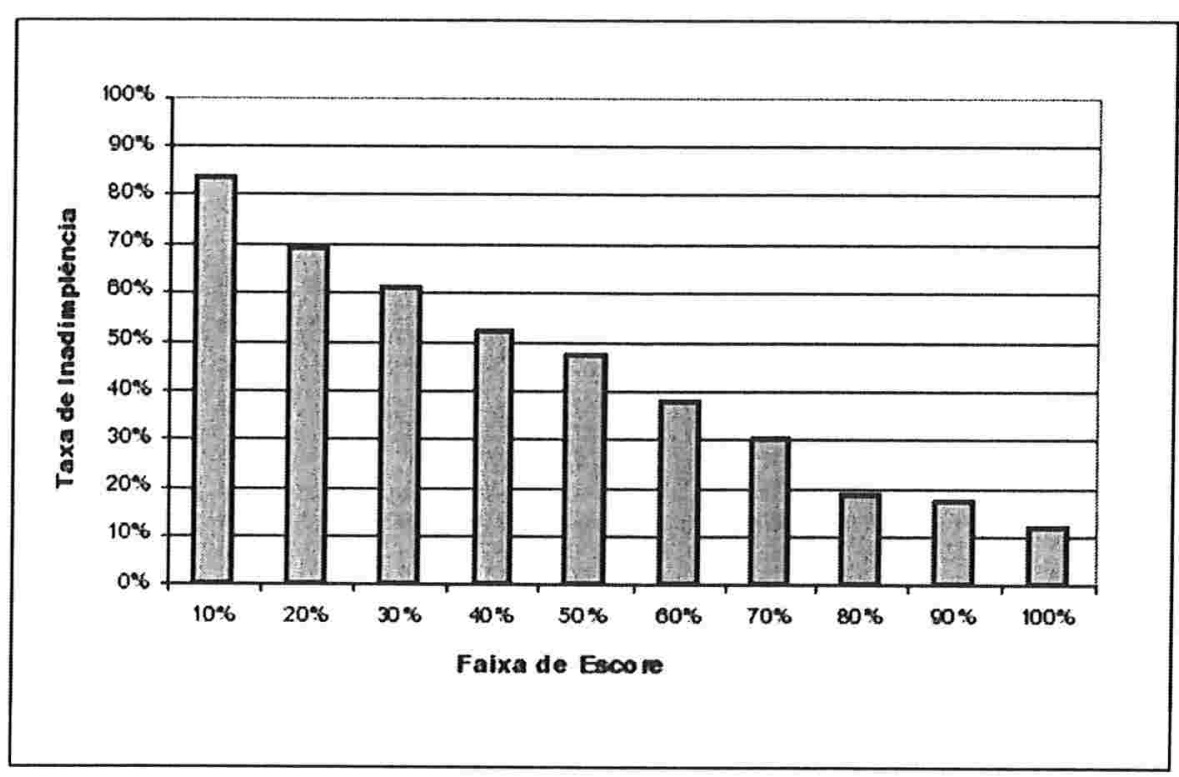

A medida para este exemplo foi:

$$
\operatorname{DTI}(1 ; 10)=84 \%-11 \%=73 \%,
$$

ou seja, no primeiro intervalo o modelo conseguiu classificar $84 \%$ dos clientes mau pagadores, enquanto que no último intervalo o percentual de clientes maus pagadores está em torno de $11 \%$, resultando uma diferença igual a $73 \%$. Essa distância fornece uma idéia da efetividade do modelo.

Na prática, o ponto de corte escolhido para um modelo combina a informação da taxa de inadimplência para cada faixa de escore e a proporção mínima de clientes que poderão ser aprovados para que o negócio seja rentável. 


\section{Capítulo 5}

\section{Modelos Ajustados e Resultados}

Neste capítulo serão descritos os métodos utilizados para a seleção das covariáveis nos ajustes de cada um dos modelos anteriormente descritos e como foi feito o processo de reamostragem utilizado para estimação das médias e desvios-padrão das medidas de avalição de desempenho, bem como os resultados obtidos nesta pesquisa.

\subsection{Seleção das Variáveis e Ajuste dos Modelos}

Inicialmente, para os ajustes dos modelos tomou-se apenas a amostra original para a qual foram incluídas todas as covariáveis diponíveis para o desenvolvimento dos modelos de Credit Score.

O método conhecido como stepwise [Neter et al, 1996], foi utilizado para a seleção das variáveis nos ajustes dos modelos de Regressão Logística e Cox, usando a opção disponível nos respectivos pacotes para ajuste de cada modelo no programa estatístico SAS.

Para o ajuste dos modelos Exponencial e Weibull, o método backward [Neter et al, 1996] foi aplicado manualmente. Em ambos os métodos, considerou-se como limite $10 \%$ de significância para entrada ou saída das covariáveis do modelo.

O procedimento seguido nesta pesquisa foi o mesmo para todos os modelos ajustados. Primeiro tomou-se a amostra original com todas as covariáveis, ajustou-se um modelo inicial utilizando a respectiva metodologia de seleção de covariáveis disponível para o ajuste de cada modelo. 
As Tabelas 5.1 a 5.4 mostram o ajuste inicial e as covariáveis selecionadas. A função de sobrevivência basal para o modelo de Cox ajustado encontra-se na Tabela 5.5 .

A Tabela 5.1 mostra o ajuste inicial do modelo Logístico considerando a amostra de desenvolvimento original.

Nas Tabelas 5.2 e 5.3 estão os coeficientes estimados para o modelo Exponencial e Weibull, respectivamente, considerando a amostra original de desenvolvimento. A inversão do sinal dos coeficientes estimados em relação aos estimados pelo modelo logístico, dá-se por causa da parametrização adotada pelo SAS.

A Tabela 5.4 contém os coeficientes estimados na amostra original de desenvolvimento para o modelo de riscos proporcionais de Cox. A função de sobrevivência basal $\left(S_{0}\right)$ para o modelo de Cox estimada por Produto-Limite está na Tabela 5.5.

A interpretação dos coeficientes em cada um dos modelos ajustados depende da parametrização adotada no pacote estatístico. Esta diferença provoca inclusive inversões de sinais para uma mesma covariável. Por exemplo a covariável idade1 representa a categoria onde as empresas possuem de 0 a 2 anos de idade, considerando a data desde sua fundação até a da consulta. A categoria de referência ou basal é a faixa de idade igual a 3 anos. No modelo Logístico (Tabela 5.1) pode-se interpretar que um empresa na faixa de idade 0 a 2 anos apresenta $2,64(\exp (1,2923)=3,64)$ mais chance de se tornar inadimplente nos próximos 18 meses em relação às empresas que estão na faixa de 3 anos de idade. Nos modelos Weibull (Tabela 5.3) e Exponencial (Tabela 5.2), a interpretação é a seguinte: uma empresa que está na faixa de 0 a 2 anos de idade tem, respectivamente, cerca de $40 \%(\exp (-0,5080)=0,60)$ e $49 \%(\exp (-0,6755)=0,51)$ de chance de não apresentar inadimplência nos próximos 18 meses. Finalmente, para o modelo de Cox (Tabela 5.4) tem-se que o risco de uma empresa nesta faixa apresentar inadimplência nos próximos 18 meses é $1,1(\exp (0,7422)=2,10)$ vezes maior que as empresas que se encontram na categoria basal. A lista das covariáveis utilizadas nos ajustes destes modelos estão no Capítulo 2. 
Tabela 5.1: Ajuste do Modelo Logístico.

\begin{tabular}{lccc} 
Covariável & Coeficiente & Erro Padrão & P-Valor \\
\hline \hline Intercepto & -1.1634 & 0.0573 & $<.0001$ \\
idade1 & 1.2923 & 0.0779 & $<.0001$ \\
idade3 & -0.3440 & 0.0612 & $<.0001$ \\
idade4 & -0.7162 & 0.0614 & $<.0001$ \\
setor2 & 0.1862 & 0.0726 & 0.0103 \\
setor4 & -0.5140 & 0.0531 & $<.0001$ \\
cheque1 & 1.5312 & 0.2395 & $<.0001$ \\
protesto1 & 0.4385 & 0.1614 & 0.0066 \\
protesto2 & 0.8496 & 0.1619 & $<.0001$ \\
soma_restr1 & 0.5664 & 0.1439 & $<.0001$ \\
regiao2 & 0.4761 & 0.1121 & $<.0001$ \\
num_func1 & 0.8934 & 0.0719 & $<.0001$ \\
num_func2 & 1.0512 & 0.0760 & $<.0001$ \\
num_func3 & 1.2128 & 0.0841 & $<.0001$ \\
num_func4 & 1.3619 & 0.0801 & $<.0001$ \\
participacao1 & 0.3827 & 0.0608 & $<.0001$ \\
participacao2 & 0.5454 & 0.0561 & $<.0001$ \\
cap_social4 & 0.3201 & 0.0590 & $<.0001$ \\
cap_social5 & 0.2157 & 0.0682 & 0.0016 \\
\hline
\end{tabular}

Tabela 5.2: Ajuste do Modelo Exponencial.

\begin{tabular}{lccc} 
Covariável & Coeficiente & Erro Padrão & P-Valor \\
\hline \hline Intercepto & 3.3654 & 0.0436 & $<.0001$ \\
idade1 & -0.6755 & 0.0438 & $<.0001$ \\
idade3 & 0.1709 & 0.0431 & $<.0001$ \\
idade4 & 0.3756 & 0.0435 & $<.0001$ \\
setor4 & 0.3172 & 0.0358 & $<.0001$ \\
cheque1 & -0.7704 & 0.1089 & $<.0001$ \\
protesto1 & -0.2384 & 0.097 & 0.014 \\
protesto2 & -0.6159 & 0.0958 & $<.0001$ \\
soma_restr1 & -0.3734 & 0.0897 & $<.0001$ \\
num_func1 & -0.3581 & 0.0483 & $<.0001$ \\
num_func2 & -0.4475 & 0.0486 & $<.0001$ \\
num_func3 & -0.4944 & 0.0519 & $<.0001$ \\
num_func4 & -0.5589 & 0.0461 & $<.0001$ \\
participacao1 & -0.2078 & 0.0415 & $<.0001$ \\
participacao2 & -0.3156 & 0.038 & $<.0001$ \\
cap_social1 & 0.2106 & 0.0507 & $<.0001$ \\
cap_social2 & 0.1536 & 0.0414 & 0.0002 \\
\hline
\end{tabular}


Tabela 5.3: Ajuste do Modelo Weibull.

\begin{tabular}{lccc} 
Covariável & Coeficiente & Erro Padrão & P-Valor \\
\hline \hline Intercepto & 3.0889 & 0.0474 & $<.0001$ \\
idade1 & -0.5080 & 0.0307 & $<.0001$ \\
idade3 & 0.1163 & 0.0299 & $<.0001$ \\
idade4 & 0.2621 & 0.0302 & $<.0001$ \\
setor4 & 0.2227 & 0.0250 & $<.0001$ \\
cheque1 & -0.5934 & 0.0760 & $<.0001$ \\
protesto1 & -0.1866 & 0.0675 & 0.0057 \\
protesto2 & -0.4939 & 0.0667 & $<.0001$ \\
soma_restr1 & -0.2656 & 0.0625 & $<.0001$ \\
regiao1 & 0.0835 & 0.0289 & 0.0039 \\
num_soc1 & -0.0918 & 0.0401 & 0.0220 \\
num_func1 & -0.2121 & 0.0338 & $<.0001$ \\
num_func2 & -0.2870 & 0.0343 & $<.0001$ \\
num_func3 & -0.3140 & 0.0366 & $<.0001$ \\
num_func4 & -0.3655 & 0.0329 & $<.0001$ \\
participacao1 & -0.2011 & 0.0415 & $<.0001$ \\
participacao2 & -0.2824 & 0.0393 & $<.0001$ \\
cap_social1 & 0.1613 & 0.0352 & $<.0001$ \\
cap_social2 & 0.1121 & 0.0288 & $<.0001$ \\
escala & 0.6901 & 0.0090 & \\
forma & 1.4491 & 0.0189 & \\
\hline
\end{tabular}

Tabela 5.4: Ajuste do Modelo de Cox.

\begin{tabular}{lccc} 
Covariável & Coeficiente & Erro Padrão & P-Valor \\
\hline \hline idade1 & 0.7422 & 0.0440 & $<.0001$ \\
idade3 & -0.1745 & 0.0432 & $<.0001$ \\
idade4 & -0.3877 & 0.0435 & $<.0001$ \\
setor2 & 0.0954 & 0.0456 & 0.0363 \\
setor4 & -0.3078 & 0.0373 & $<.0001$ \\
cheque1 & 0.8585 & 0.1095 & $<.0001$ \\
protesto1 & 0.2596 & 0.0974 & 0.0077 \\
protesto2 & 0.7429 & 0.0963 & $<.0001$ \\
soma_restr1 & 0.3846 & 0.0901 & $<.0001$ \\
regiao1 & -0.1303 & 0.0423 & 0.0021 \\
num_soc1 & 0.1620 & 0.0580 & 0.0052 \\
num_func1 & 0.3144 & 0.0487 & $<.0001$ \\
num_func2 & 0.4245 & 0.0492 & $<.0001$ \\
num_func3 & 0.4658 & 0.0525 & $<.0001$ \\
num_func4 & 0.5360 & 0.0480 & $<.0001$ \\
participacao1 & 0.3255 & 0.0601 & $<.0001$ \\
participacao2 & 0.4260 & 0.0567 & $<.0001$ \\
cap_social1 & -0.2440 & 0.0510 & $<.0001$ \\
cap_social2 & -0.1583 & 0.0417 & 0.0001 \\
\hline & & &
\end{tabular}


Tabela 5.5: Função de sobrevivência basal para o Modelo de Cox.

\begin{tabular}{cc} 
Tempo & $S_{0}$ \\
\hline \hline 0 & 1.0000 \\
1 & 0.9618 \\
2 & 0.9245 \\
3 & 0.8892 \\
4 & 0.8549 \\
5 & 0.8237 \\
6 & 0.7932 \\
7 & 0.7619 \\
8 & 0.7310 \\
9 & 0.6987 \\
10 & 0.6663 \\
11 & 0.6320 \\
12 & 0.5957 \\
13 & 0.5525 \\
14 & 0.5018 \\
15 & 0.4429 \\
16 & 0.3693 \\
17 & 0.2274 \\
\hline
\end{tabular}

\subsection{Reamostragem por Bootstrap}

O método de reamostragem por Bootstrap foi utilizado para estimar a média e o desvio-padrão de cada medida de avalição de desempenho utilizada nesta pesquisa, possibilitando a comparação dos modelos de Credit Score ajustados.

Foi escolhida a metodologia Bootstrap pois ela é indicada para situações em que deseja-se avaliar a acurácia dos coeficientes dos modelos ajustados e as medidas de avaliação, bem como o erro-padrão associado a cada estimativa [Efron \& Tibshirani, 1993].

Foram construídos três diferentes cenários para as amostras de desenvolvimento e validação, variando-se a quantidade de casos censurados.

A primeira comparação foi baseada na reamostragem da base original de desenvolvimento com as 10.000 empresas de pequeno porte, onde haviam 5.714 empresas classificadas como adimplentes (boas) e 4.286 classificadas como inadimplentes (más) conforme Tabela 2.1 no Capítulo 2. Utilizando a metodologia de Bootstrap, foram realizadas 300 novas subamostras com repetição da amostra de desenvolvimento mantendo o mesmo tamanho da amostra original e as mesmas proporções. Para cada repetição da amostra foram estimados os parâmetros de todos os modelos testados e calculadas todas as medidas 
de avaliação de desempenho. Para avaliar se os coeficientes estimados eram consistentes e também se os indicadores de desempenho apresentavam estabilidade, repetiu-se todo processo para a amostra de validação.

Figura 5.1: Esquema da reamostragem por Bootstrap.
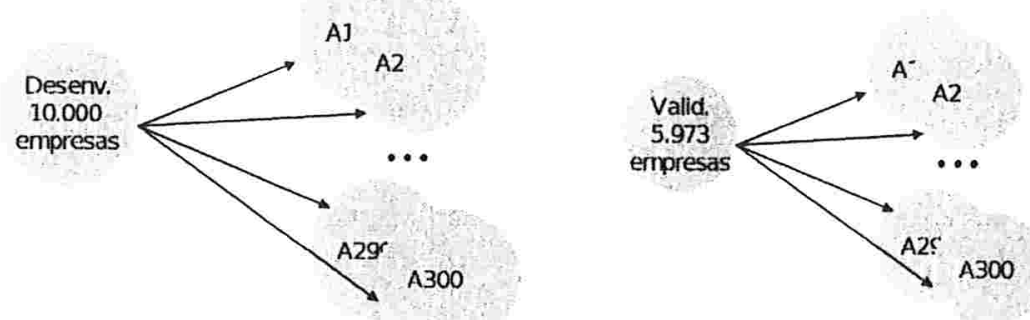

Definindo-se as medidas de avaliação de desempenho : $K S_{i}, A E C_{i}, R O C_{i}$, $G I N I_{i}, M A H_{i}$ e $D T I_{i}$, que foram calculadas para cada modelo de Credit Score ajustado respectivamente por Regressão Logística (L), Cox (C), Weibull (W) e Exponencial (E), em cada amostra $i$ gerada por Bootstrap, sendo que $i=1, \ldots, 300$.

Para simplificar a notação, adotou-se $\boldsymbol{\theta}_{i}$ genérico para indicar a medida de avaliação de desempenho, pois todas as estimativas da média e desviopadrão foram calculadas da mesma maneira para todas as medidas de interesse tratadas neste trabalho.

Por exemplo: seja a média amostral para a medida de avaliação de desempenho $(K S)$ do ajuste por Regressão Logistica $(L)$ dada por:

$$
\hat{\theta}_{(K S)}^{L}=\sum_{i=1}^{B} \frac{\theta_{\left(K S_{i}\right)}^{L}}{B}
$$

E o desvio-padrão amostral dado por:

$$
\hat{s}_{(K S)}^{L}=\left[\sum_{i=1}^{B} \frac{\left[\theta_{\left(K S_{i}\right)}^{L}-\hat{\theta}_{(K S)}^{L}\right]^{2}}{B-1}\right]^{\frac{1}{2}} .
$$

Com $i=1, \ldots, B$ e $B$ o número de reamostragens realizadas.

De maneira genérica pode-se definir como a média amostral para cada medida de avaliação de desempenho (.) e cada tipo de modelo ajustado *, dada por: 


$$
\hat{\theta}_{(\cdot)}^{*}=\sum_{i=1}^{B} \frac{\theta_{(\cdot i)}^{*}}{B}
$$

E o desvio-padrão amostral dado por:

$$
\hat{s}_{(\cdot)}^{*}=\left[\sum_{i=1}^{B} \frac{\left[\theta_{(\cdot)}^{*}-\hat{\theta}_{(\cdot)}^{*}\right]^{2}}{B-1}\right]^{\frac{1}{2}} .
$$

Com a intenção de verificar se as medidas de avalição de desempenho de modelos sofriam influência do número de casos censurados na amostra, adotouse duas abordagens aumentando e e diminuindo o número de censuras nas amostras, da seguinte maneira:

$\mathrm{Na}$ abordagem onde aumentou-se a proporção de falhas, foram excluídos aleatoriamente 1.000 dos casos de adimplência (censura) da amostra de desenvolvimento e acrescentando-se a mesma quantidade de casos de falhas retirados da amostra de validação, desta forma foi possível manter o tamanho da amostra de desenvolvimento e evitar algum possível efeito decorrente da variação do tamanho da amostra. Depois de feita a substituição realizou-se novamente 300 reamostragens, estimando-se os parâmetros de cada modelo, bem como todas as medidas de interesse em cada iteração.

O processo foi repetido para a amostra de validação, onde para manter a mesma proporção de inadimplentes/adimplentes (falhas/censuras) utilizadas na abordagem anterior para a amostra de desenvolvimento, foram selecionados aleatoriamente 610 casos de empresas adimplentes da amostra de desenvolvimento e substituídas pelas mesma quantidade de empresas inadimplentes selecionadas aleatoriamente da amostra de validação. Observe a distribuição na Tabela 5.6.

Tabela 5.6: Distribuição dos adimplentes e inadimplentes nas amostras com menos casos censurados

\begin{tabular}{lrrrr} 
Indicador & \multicolumn{2}{c}{ Desenvolvimento } & \multicolumn{2}{c}{ Validação } \\
\hline Empresas & $\mathrm{N}$ & $\%$ & $\mathrm{~N}$ & $\%$ \\
\hline \hline Inadimplentes (Maus) & 5.286 & $53 \%$ & 3.157 & $53 \%$ \\
Adimplentes (Bons) & 4.714 & $47 \%$ & 2.816 & $47 \%$ \\
Total & 10.000 & $100 \%$ & 5.973 & $100 \%$ \\
\hline
\end{tabular}


$\mathrm{Na}$ terceira abordagem aumentou-se a proporção de censura, excluíndo-se aleatoriamente 1.000 dos casos de inadimplência da amostra de desenvolvimento e acrescentando-se a mesma quantidade de adimplentes retirados da amostra de validação. Depois de feita a substituição realizou novamente 300 reamostragens, repetindo o processo de estimação.

Observando o critério de manter a mesma proporção de falha/censura da amostra de desenvolvimento, foram selecionados aleatoriamente 584 casos de empresas inadimplentes da amostra de desenvolvimento e substituídas pelas mesma quantidade de empresas adimplentes da amostra de validação. A nova distribuição desta amostra está na Tabela 5.7.

Tabela 5.7: Distribuição dos adimplentes e inadimplentes nas amostras com mais casos censurados

\begin{tabular}{lrrrr} 
Indicador & \multicolumn{2}{c}{ Desenvolvimento } & \multicolumn{2}{c}{ Validação } \\
\hline Empresas & $\mathrm{N}$ & $\%$ & $\mathrm{~N}$ & $\%$ \\
\hline \hline Inadimplentes (Maus) & 3.286 & $33 \%$ & 1.963 & $33 \%$ \\
Adimplentes (Bons) & 6.714 & $67 \%$ & 4.010 & $67 \%$ \\
Total & 10.000 & $100 \%$ & 5.973 & $100 \%$ \\
\hline
\end{tabular}

Através da metodologia Bootstrap foi possível calcular a média e o desviopadrão de todas as medidas de avaliação de desempenho de modelos de Credit Score calculadas para cada tipo de técnica apresentada, bem como os coeficientes estimados para todos os modelos ajustados.

\subsection{Resultados}

A utilização da Análise de Sobrevivência no desenvolvimento de modelos de Credit Score produziu resultados semelhantes aos modelos estimados por de Regressão Logística, segundo as medidas de avaliação de desempenho de modelos de Credit Score que foram testadas e sugeridas neste trabalho.

\subsubsection{Coeficientes Estimados}

As Tabelas 5.8 a 5.11 apresentam os coeficientes médios estimados e respectivos desvios-padrão para a amostra de desenvolvimento após o processo de 
reamostragem, mostrando ainda as abordagens variando-se o número de casos censurados.

Os coeficientes estimados após a reamostagem para as amostras de validação estão dispostos no Apêndice C.

A Tabela 5.8 mostra a consistência dos coeficientes estimados pelo ajuste do modelo Logístico para os três tipos de amostras. Observa-se que, com exceção do intercepto, os demais coeficientes apresentaram pouca diferença nos valores estimados e não houve alteração nos sinais. O intercepto sofre influência da proporção de casos inadimplentes e adimplentes da amostra em questão.

Tabela 5.8: Coeficientes estimados pela Regressão Logística - amostra de desenvolvimento.

\begin{tabular}{lcccccc} 
& \multicolumn{2}{c}{ Amostra Original } & \multicolumn{2}{c}{ Mais censura } & \multicolumn{2}{c}{ Menos Censura } \\
\cline { 2 - 7 } Covariável & Média & desvio-padrão & Média & desvio-padrão & Média & desvio-padrão \\
\hline \hline intercepto & $-1,1626$ & 0,0555 & $-1,5612$ & 0,0559 & $-0,7761$ & 0,0525 \\
idade1 & 1,2897 & 0,0785 & 1,2997 & 0,0770 & 1,2721 & 0,0729 \\
idade3 & $-0,3474$ & 0,0570 & $-0,3943$ & 0,0640 & $-0,3245$ & 0,0580 \\
idade4 & $-0,7208$ & 0,0604 & $-0,7508$ & 0,0635 & $-0,7099$ & 0,0554 \\
setor2 & 0,1895 & 0,0683 & 0,2108 & 0,0702 & 0,1654 & 0,0724 \\
setor4 & $-0,5206$ & 0,0549 & $-0,4798$ & 0,0522 & $-0,4806$ & 0,0543 \\
cheque1 & 1,5335 & 0,2543 & 1,6321 & 0,2798 & 1,6949 & 0,2735 \\
protesto1 & 0,4479 & 0,1705 & 0,4491 & 0,1653 & 0,4880 & 0,1794 \\
protesto2 & 0,8550 & 0,1736 & 0,9122 & 0,1676 & 0,8961 & 0,1672 \\
somarestr1 & 0,5689 & 0,1532 & 0,5352 & 0,1485 & 0,5236 & 0,1525 \\
regiao2 & 0,4796 & 0,1122 & 0,4781 & 0,1162 & 0,5187 & 0,1167 \\
num_func1 & 0,8898 & 0,0704 & 0,9207 & 0,0757 & 0,8879 & 0,0699 \\
num_func2 & 1,0444 & 0,0714 & 1,0849 & 0,0815 & 1,0601 & 0,0676 \\
num_func3 & 1,2091 & 0,0837 & 1,2498 & 0,0983 & 1,2047 & 0,0950 \\
num_func4 & 1,3601 & 0,0791 & 1,3730 & 0,0921 & 1,3327 & 0,0849 \\
participacao1 & 0,3821 & 0,0605 & 0,3183 & 0,0668 & 0,3834 & 0,0628 \\
participacao2 & 0,5501 & 0,0569 & 0,5252 & 0,0597 & 0,5348 & 0,0554 \\
cap_social4 & 0,3229 & 0,0547 & 0,2765 & 0,0634 & 0,3216 & 0,0600 \\
cap_social5 & 0,2196 & 0,0686 & 0,1972 & 0,0744 & 0,2379 & 0,0694 \\
\hline
\end{tabular}

As Tabelas 5.9 e 5.10 apresentam as estimativas da média e desvio-padrão para os coeficientes estimados pelo ajuste dos modelos Weibull e Exponencial, respectivamente. Nota-se uma maior variação no valor médio do intercepto. Não houve alteração nos sinais dos coeficientes. 
Tabela 5.9: Coeficientes estimados pelo Modelo Weibull - amostra de desenvolvimento.

\begin{tabular}{lcccccc} 
& \multicolumn{2}{c}{ Amostra Original } & \multicolumn{2}{c}{ Mais censura } & \multicolumn{2}{c}{ Menos Censura } \\
\cline { 2 - 7 } Covariável & Média & desvio-padrão & Média & desvio-padrão & Média & desvio-padrão \\
\hline \hline Intercepto & 3,0857 & 0,0458 & 3,3132 & 0,0556 & 2,9099 & 0,0424 \\
idade1 & $-0,5062$ & 0,0303 & $-0,5726$ & 0,0348 & $-0,4499$ & 0,0256 \\
idade3 & 0,1175 & 0,0273 & 0,1751 & 0,0347 & 0,0842 & 0,0256 \\
idade4 & 0,2630 & 0,0289 & 0,3204 & 0,0356 & 0,2286 & 0,0241 \\
setor4 & 0,2255 & 0,0246 & 0,2439 & 0,0281 & 0,1690 & 0,0234 \\
cheque1 & $-0,5902$ & 0,0930 & $-0,6841$ & 0,1140 & $-0,5758$ & 0,0886 \\
protesto1 & $-0,1895$ & 0,0760 & $-0,2145$ & 0,0824 & $-0,1873$ & 0,0703 \\
protesto2 & $-0,4946$ & 0,0750 & $-0,5486$ & 0,0835 & $-0,4706$ & 0,0666 \\
soma_restr1 & $-0,2670$ & 0,0675 & $-0,2588$ & 0,0754 & $-0,2348$ & 0,0630 \\
regiao1 & 0,0834 & 0,0293 & 0,0619 & 0,0292 & 0,0985 & 0,0253 \\
num_socio1 & $-0,0907$ & 0,0420 & $-0,0670$ & 0,0476 & $-0,1234$ & 0,0369 \\
num_func1 & $-0,2089$ & 0,0315 & $-0,2842$ & 0,0379 & $-0,1503$ & 0,0305 \\
num_func2 & $-0,2833$ & 0,0322 & $-0,3680$ & 0,0391 & $-0,2330$ & 0,0273 \\
num_func3 & $-0,3085$ & 0,0348 & $-0,4150$ & 0,0424 & $-0,2410$ & 0,0348 \\
num_func4 & $-0,3641$ & 0,0305 & $-0,4691$ & 0,0384 & $-0,2747$ & 0,0305 \\
participacao1 & $-0,1995$ & 0,0417 & $-0,1878$ & 0,0509 & $-0,1931$ & 0,0369 \\
participacao2 & $-0,2841$ & 0,0426 & $-0,2942$ & 0,0467 & $-0,2576$ & 0,0361 \\
cap_social1 & 0,1597 & 0,0337 & 0,1443 & 0,0428 & 0,1521 & 0,0305 \\
cap_social2 & 0,1130 & 0,0255 & 0,1115 & 0,0300 & 0,1035 & 0,0247 \\
escala & 0,6889 & 0,0083 & 0,6977 & 0,0098 & 0,6898 & 0,0067 \\
forma & 1,4488 & 0,0190 & 1,4329 & 0,0217 & 1,4462 & 0,0169 \\
\hline
\end{tabular}


Tabela 5.10: Coeficientes estimados pelo Modelo Exponencial - amostra de desenvolvimento.

\begin{tabular}{lcccccc} 
& \multicolumn{2}{c}{ Amostra Original } & \multicolumn{2}{c}{ Mais censura } & \multicolumn{2}{c}{ Menos Censura } \\
\cline { 2 - 7 } Covariável & Média & desvio-padrāo & Média & desvio-padrão & Média & desvio-padrão \\
\hline \hline Intercepto & 3,3636 & 0,0386 & 3,6947 & 0,0435 & 3,0788 & 0,0347 \\
idade1 & $-0,6734$ & 0,0379 & $-0,7696$ & 0,0439 & $-0,5857$ & 0,0312 \\
idade3 & 0,1727 & 0,0366 & 0,2447 & 0,0465 & 0,1284 & 0,0329 \\
idade4 & 0,3773 & 0,0388 & 0,4529 & 0,0477 & 0,3274 & 0,0312 \\
setor4 & 0,3213 & 0,0330 & 0,3410 & 0,0368 & 0,2469 & 0,0302 \\
cheque1 & $-0,7647$ & 0,1139 & $-0,8886$ & 0,1464 & $-0,7424$ & 0,1038 \\
protesto1 & $-0,2427$ & 0,0969 & $-0,2742$ & 0,1066 & $-0,2464$ & 0,0865 \\
protesto2 & $-0,6179$ & 0,0955 & $-0,6898$ & 0,1078 & $-0,5962$ & 0,0816 \\
soma_restr1 & $-0,3746$ & 0,0873 & $-0,3766$ & 0,0980 & $-0,3132$ & 0,0778 \\
num_func1 & $-0,3546$ & 0,0412 & $-0,4532$ & 0,0505 & $-0,2736$ & 0,0384 \\
num_func2 & $-0,4427$ & 0,0405 & $-0,5554$ & 0,0521 & $-0,3686$ & 0,0334 \\
num_func3 & $-0,4882$ & 0,0446 & $-0,6274$ & 0,0560 & $-0,3867$ & 0,0439 \\
num_func4 & $-0,5577$ & 0,0391 & $-0,6984$ & 0,0498 & $-0,4263$ & 0,0377 \\
participacao1 & $-0,2070$ & 0,0362 & $-0,2070$ & 0,0453 & $-0,1661$ & 0,0319 \\
participacao2 & $-0,3191$ & 0,0359 & $-0,3524$ & 0,0407 & $-0,2549$ & 0,0304 \\
cap_social1 & 0,2085 & 0,0452 & 0,1911 & 0,0576 & 0,1922 & 0,0406 \\
cap_social2 & 0,1550 & 0,0334 & 0,1589 & 0,0402 & 0,1371 & 0,0320 \\
\hline
\end{tabular}

$\mathrm{Na}$ Tabela 5.11 estão as estimativas da média e desvio-padrão para os coeficientes estimados pelo modelo de Riscos Proporcionais de Cox. Diferentemente dos modelos anteriores, este modelo não apresenta intercepto. Os coeficientes estimados apresentaram consistência. 
Tabela 5.11: Coeficientes estimados pelo Modelo de Cox - amostra de desenvolvimento.

\begin{tabular}{lcccccc} 
& \multicolumn{2}{c}{ Amostra Original } & \multicolumn{2}{c}{ Mais censura } & \multicolumn{2}{c}{ Menos Censura } \\
\cline { 2 - 6 } Covariável & Média & desvio-padrão & Média & desvio-padrão & Média & desvio-padrão \\
\hline \hline idade1 & 0,7414 & 0,0445 & 0,8289 & 0,0507 & 0,6580 & 0,0385 \\
idade3 & $-0,1759$ & 0,0408 & $-0,2552$ & 0,0509 & $-0,1282$ & 0,0386 \\
idade4 & $-0,3899$ & 0,0429 & $-0,4654$ & 0,0524 & $-0,3444$ & 0,0359 \\
setor2 & 0,1002 & 0,0432 & 0,1175 & 0,0473 & 0,0565 & 0,0390 \\
setor4 & $-0,3105$ & 0,0382 & $-0,3340$ & 0,0430 & $-0,2332$ & 0,0365 \\
cheque1 & 0,8540 & 0,1337 & 0,9924 & 0,1612 & 0,8366 & 0,1267 \\
protesto1 & 0,2629 & 0,1158 & 0,3026 & 0,1236 & 0,2612 & 0,1061 \\
protesto2 & 0,7439 & 0,1140 & 0,8244 & 0,1241 & 0,7042 & 0,1002 \\
soma_restr1 & 0,3890 & 0,1030 & 0,3587 & 0,1140 & 0,3378 & 0,0962 \\
regiao1 & $-0,1299$ & 0,0436 & $-0,0967$ & 0,0436 & $-0,1517$ & 0,0378 \\
num_socio1 & 0,1605 & 0,0621 & 0,1268 & 0,0688 & 0,2071 & 0,0547 \\
num_func1 & 0,3108 & 0,0479 & 0,4135 & 0,0552 & 0,2273 & 0,0463 \\
num_func2 & 0,4200 & 0,0466 & 0,5360 & 0,0569 & 0,3466 & 0,0416 \\
num_func3 & 0,4578 & 0,0515 & 0,5996 & 0,0623 & 0,3618 & 0,0521 \\
num_func4 & 0,5340 & 0,0440 & 0,6713 & 0,0575 & 0,4138 & 0,0447 \\
participacao1 & 0,3234 & 0,0625 & 0,3060 & 0,0734 & 0,3138 & 0,0556 \\
participacao2 & 0,4292 & 0,0631 & 0,4404 & 0,0671 & 0,3907 & 0,0539 \\
cap_social1 & $-0,2428$ & 0,0504 & $-0,2154$ & 0,0629 & $-0,2308$ & 0,0454 \\
cap_social2 & $-0,1604$ & 0,0385 & $-0,1545$ & 0,0440 & $-0,1485$ & 0,0379 \\
\hline
\end{tabular}

Na Tabela 5.12 estão as estimativas da média e desvio-padrão para a função de sobrevivência basal estimada por Produto-Limite. Observa-se que, quanto menor a proporção de censuras, mais acentuada é a probabilidade de sobrevivência, conforme Figura 5.2 . 
Tabela 5.12: Estimativas da função de sobrevivência basal $\left(S_{0}\right)$ - amostra de desenvolvimento.

\begin{tabular}{lcccccc} 
& \multicolumn{2}{c}{ Amostra Original } & \multicolumn{2}{c}{ Mais censura } & \multicolumn{2}{c}{ Menos Censura } \\
\cline { 2 - 7 } Instante de tempódia & desvio-padrāo & Média & desvio-padrão & Média & desvio-padrāo \\
\hline \hline 0 & 1,0000 & 0,0000 & 1,0000 & 0,0000 & 1,0000 & 0,0000 \\
1 & 0,9620 & 0,0018 & 0,9721 & 0,0014 & 0,9495 & 0,0019 \\
2 & 0,9249 & 0,0026 & 0,9447 & 0,0021 & 0,9012 & 0,0027 \\
3 & 0,8896 & 0,0032 & 0,9198 & 0,0026 & 0,8541 & 0,0035 \\
4 & 0,8554 & 0,0036 & 0,8944 & 0,0031 & 0,8099 & 0,0041 \\
5 & 0,8241 & 0,0039 & 0,8715 & 0,0034 & 0,7708 & 0,0044 \\
6 & 0,7935 & 0,0043 & 0,8505 & 0,0037 & 0,7300 & 0,0049 \\
7 & 0,7622 & 0,0046 & 0,8275 & 0,0039 & 0,6922 & 0,0049 \\
8 & 0,7314 & 0,0051 & 0,8049 & 0,0043 & 0,6542 & 0,0052 \\
9 & 0,6989 & 0,0056 & 0,7791 & 0,0047 & 0,6155 & 0,0053 \\
10 & 0,6663 & 0,0059 & 0,7538 & 0,0053 & 0,5759 & 0,0058 \\
11 & 0,6318 & 0,0064 & 0,7265 & 0,0057 & 0,5361 & 0,0061 \\
12 & 0,5954 & 0,0066 & 0,6991 & 0,0064 & 0,4943 & 0,0063 \\
13 & 0,5522 & 0,0073 & 0,6629 & 0,0070 & 0,4474 & 0,0071 \\
14 & 0,5011 & 0,0078 & 0,6188 & 0,0079 & 0,3956 & 0,0075 \\
15 & 0,4425 & 0,0091 & 0,5672 & 0,0088 & 0,3341 & 0,0078 \\
16 & 0,3696 & 0,0098 & 0,5014 & 0,0100 & 0,2635 & 0,0084 \\
17 & 0,2270 & 0,0127 & 0,3654 & 0,0144 & 0,1312 & 0,0075 \\
\hline
\end{tabular}

Figura 5.2: Curvas de sobrevivência basal.

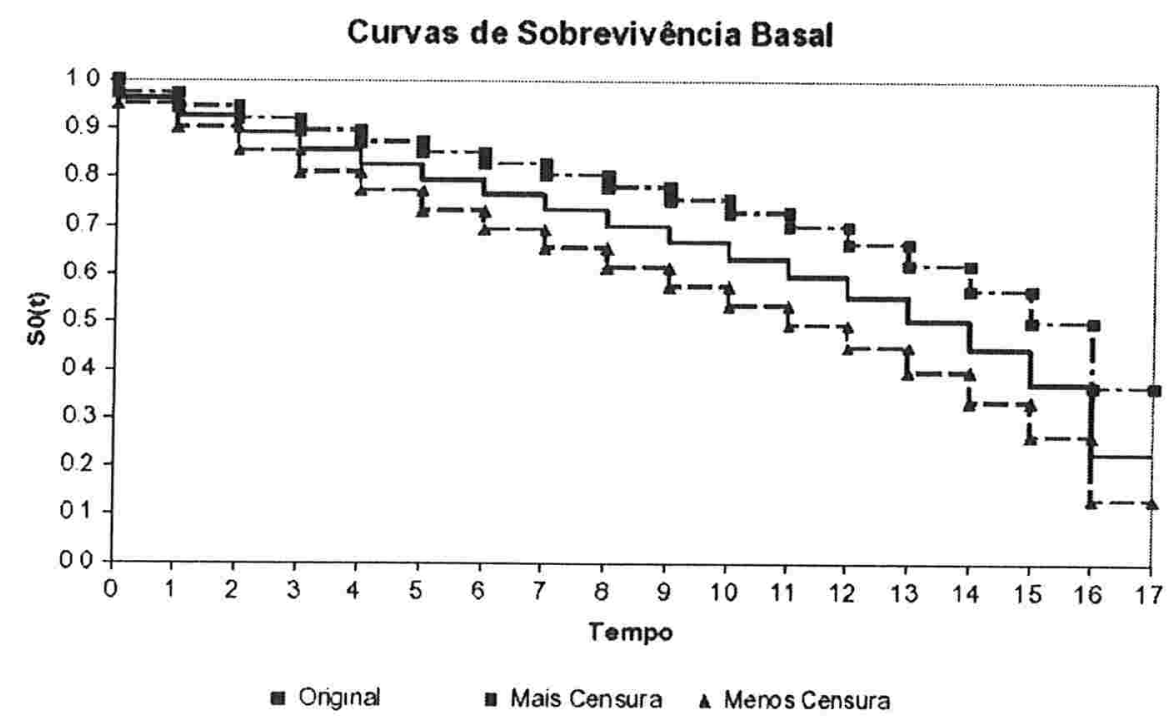




\subsubsection{Resultados das Medidas de Avaliação de Desempenho}

Os modelos ajustados por Análise de Sobreviência e Regressão Logística apresentaram semelhantes desempenhos quanto a discriminação de empresas inadimplentes e adimplentes.

O KS médio apresentou valores próximos para todos os modelos como mostra a Tabela 5.13. As amostras com mais casos de censura obtiveram os maiores desvios-padrão das estimativas das medidas de avaliação para todos tipos de modelos ajustados.

Observando-se a Figura 5.3 não é possível determinar qual o melhor modelo, pois todos os modelos ajustados proporcionaram curvas semelhantes, o que era esperado, dada a proximidade das estimativas observadas na Tabela 5.13

Tabela 5.13: Média e desvio-padrão para medida KS - amostra desenvolvimento.

\begin{tabular}{lcccccc} 
KS & \multicolumn{2}{c}{ Amostra Original } & \multicolumn{2}{c}{ Mais Censura } & \multicolumn{2}{c}{ Menos Censura } \\
\hline Modelo & média & desv. pad. & média & desv. pad. & média & desv. pad. \\
\hline \hline Logística & 0,4071 & 0,0087 & 0,4141 & 0,0095 & 0,4031 & 0,0086 \\
Cox & 0,3940 & 0,0089 & 0,4025 & 0,0098 & 0,3860 & 0,0090 \\
Weibull & 0,3924 & 0,0090 & 0,4010 & 0,0099 & 0,3854 & 0,0092 \\
Exponencial & 0,3968 & 0,0091 & 0,4049 & 0,0097 & 0,3901 & 0,0089 \\
\hline
\end{tabular}


Figura 5.3: Gráficos da medida: KS - amostra de desenvolvimento
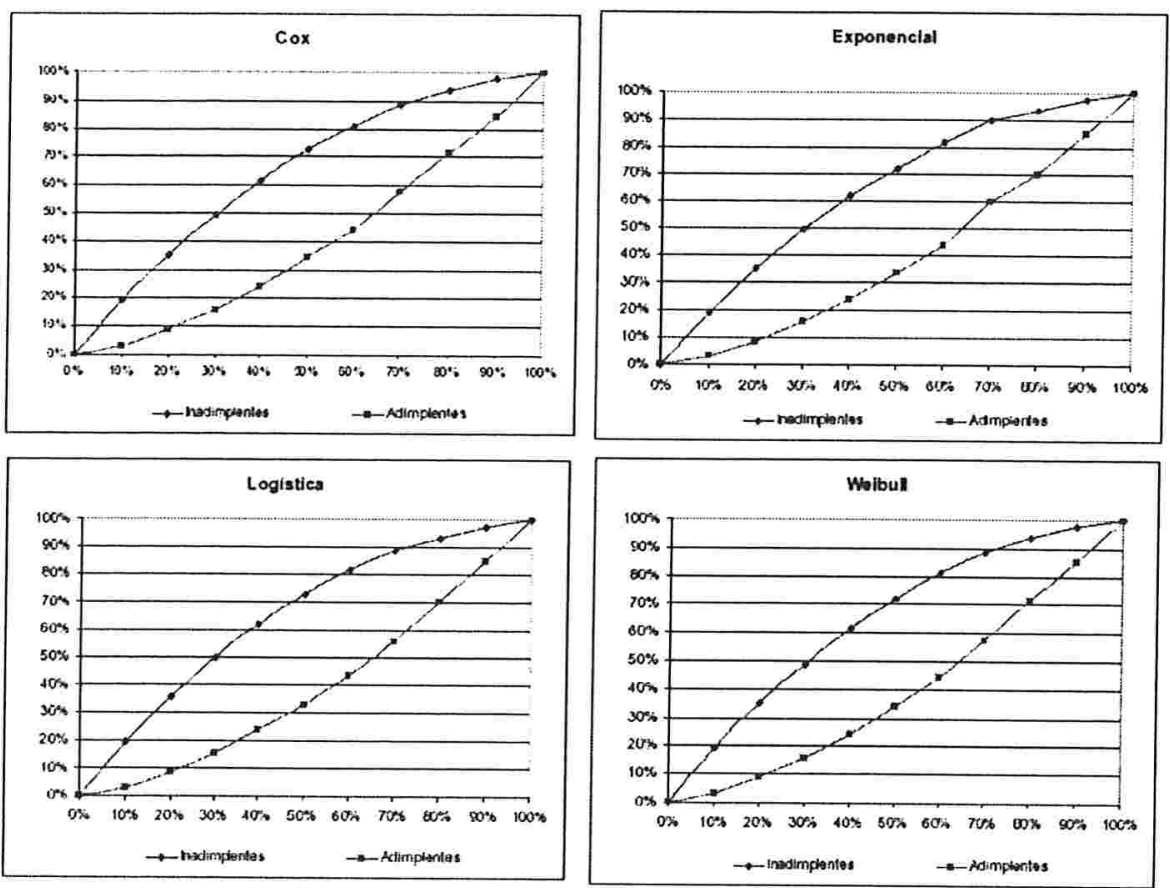

Nas amostras de validação, o KS continuou com valores próximos. A estimativas tanto para desenvolvimento e quanto para validação, sugerem consistência das medidas e dos modelos ajustados.

Para todos os modelos, as estimativas dos desvios-padrão foram maiores nas amostras de validação que na amostra de desenvolvimento, conforme observa-se na Tabela 5.14 .

Os valores de KS observados, tanto para amostra de desenvolvimento (Tabela 5.13) como para de validação (Tabela 5.14), apresentaram bom desempenho segundo as práticas de mercado. 
Tabela 5.14: Média e desvio-padrão para medida: KS - amostra de validação.

\begin{tabular}{lcccccc} 
KS & \multicolumn{2}{c}{ Amostra Original } & \multicolumn{2}{c}{ Mais Censura } & \multicolumn{2}{c}{ Menos Censura } \\
\hline Modelo & média & desv. pad. & média & desv. pad. & média & desv. pad. \\
\hline \hline Logística & 0,4116 & 0,0127 & 0,4091 & 0,0116 & 0,4080 & 0,0122 \\
Cox & 0,4010 & 0,0128 & 0,4072 & 0,0124 & 0,3893 & 0,0128 \\
Weibull & 0,4012 & 0,0129 & 0,4078 & 0,0124 & 0,3893 & 0,0128 \\
Exponencial & 0,4034 & 0,0128 & 0,4084 & 0,0119 & 0,3965 & 0,0122 \\
\hline
\end{tabular}

A Tabela 5.15 mostra a medida proposta da área entre as curvas da distribuição acumulada (AEC) também apresentou valores muito próximos para todos os modelos ajustados. Essa medida sugere maior estabilidade para todos os tipos de técnicas e amostras, pois apresentou menores desvios-padrão que os estimados para o cálculo do KS. Para todos os modelos ajustados a amostra com mais casos censurados apresentaram os maiores valores médios.

Tabela 5.15: Média e desvio-padrão para a medida: área entre as curvas amostra de desenvolvimento.

\begin{tabular}{lcccccc} 
AEC & \multicolumn{2}{c}{ Amostra Original } & \multicolumn{2}{c}{ Mais Censura } & \multicolumn{2}{c}{ Menos Censura } \\
\hline Modelo & média & desv. pad. & média & desv. pad. & média & desv. pad. \\
\hline \hline Logística & 0,2676 & 0,0045 & 0,2693 & 0,0050 & 0,2645 & 0,0044 \\
Cox & 0,2598 & 0,0047 & 0,2645 & 0,0051 & 0,2527 & 0,0047 \\
Weibull & 0,2595 & 0,0047 & 0,2644 & 0,0050 & 0,2525 & 0,0046 \\
Exponencial & 0,2631 & 0,0046 & 0,2663 & 0,0050 & 0,2579 & 0,0044 \\
\hline
\end{tabular}

A Tabela 5.16 mostra que na validação, as reamostragens com mais casos de censura obtiveram os maiores valores para as medidas em relação a amostra original e a amostra com menos casos censurados. 
Tabela 5.16: Média e desvio-padrão para a medida: área entre as curvas amostra de validação.

\begin{tabular}{lcccccc} 
AEC & \multicolumn{2}{c}{ Amostra Original } & \multicolumn{2}{c}{ Mais Censura } & \multicolumn{2}{c}{ Menos Censura } \\
\hline Modelo & média & desv. pad. & média & desv. pad. & média & desv. pad. \\
\hline \hline Logística & 0,2737 & 0,0063 & 0,2739 & 0,0060 & 0,2715 & 0,0060 \\
Cox & 0,2628 & 0,0066 & 0,2685 & 0,0064 & 0,2536 & 0,0066 \\
Weibull & 0,2630 & 0,0066 & 0,2686 & 0,0063 & 0,2538 & 0,0066 \\
Exponencial & 0,2677 & 0,0065 & 0,2710 & 0,0061 & 0,2627 & 0,0063 \\
\hline
\end{tabular}

A medida área sob a curva ROC também apresentou valores muito próximos para todos os modelos ajustados, tanto para desenvolvimento (Tabela 5.17) quanto para validação (Tabela 5.18) e para as três abordagens de amostras.

Nestas mesmas tabelas, quando comparou-se as medidas entre todas as amostras, observou-se que o ajuste pelo modelo de riscos proporcionais de Cox, apresentou os maiores desvios-padrão tanto no desenvolvimento (Tabela 5.17) quanto na validação (Tabela 5.18).

A Figura 5.4 mostra a curva ROC para os quatro modelos ajustados. Também é possível observar a distância entre a curva ROC e a diagonal, utilizada para o cálculo da medida coeficiente de Gini.

Tabela 5.17: Média e desvio-padrão para a medida: área sob a curva ROC amostra de desenvolvimento.

\begin{tabular}{lcccccc} 
ROC & \multicolumn{2}{c}{ Amostra Original } & \multicolumn{2}{c}{ Mais Censura } & \multicolumn{2}{c}{ Menos Censura } \\
\hline Modelo & média & desv. pad. & média & desv. pad. & média & desv. pad. \\
\hline \hline Logística & 0,7321 & 0,0045 & 0,7304 & 0,0050 & 0,7352 & 0,0044 \\
Cox & 0,7268 & 0,0060 & 0,7289 & 0,0058 & 0,7221 & 0,0071 \\
Weibull & 0,7399 & 0,0048 & 0,7353 & 0,0050 & 0,7468 & 0,0047 \\
Exponencial & 0,7367 & 0,0046 & 0,7335 & 0,0050 & 0,7420 & 0,0044 \\
\hline
\end{tabular}


Figura 5.4: Gráficos da área sob a curva ROC - amostra de desenvolvimento original.
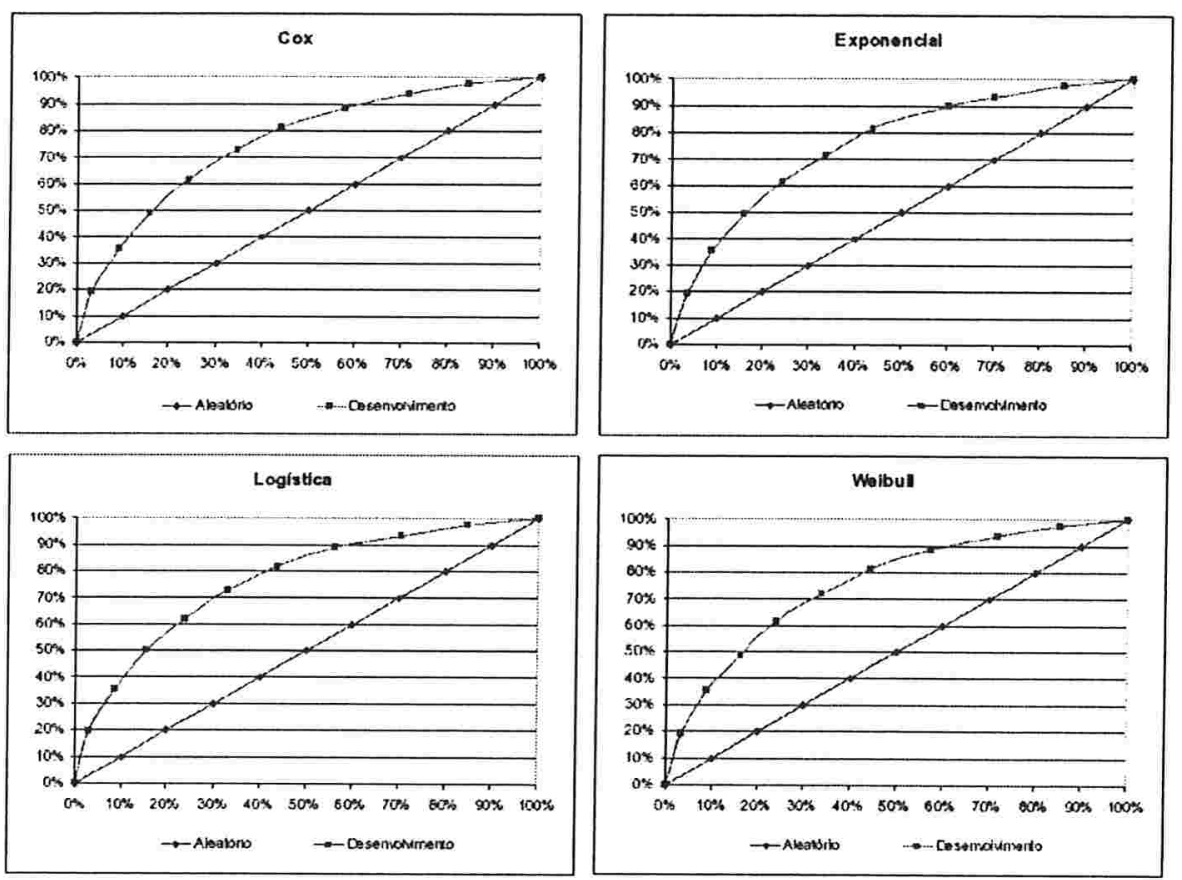

Tabela 5.18: Média e desvio-padrão para a medida: área sob a curva ROC amostra de validação.

\begin{tabular}{lcccccc} 
ROC & \multicolumn{2}{c}{ Amostra Original } & \multicolumn{2}{c}{ Mais Censura } & \multicolumn{2}{c}{ Menos Censura } \\
\hline Modelo & média & desv. pad. & média & desv. pad. & média & desv. pad. \\
\hline \hline Logística & $\mathbf{0 , 7 2 6 1}$ & $\mathbf{0 , 0 0 6 3}$ & $\mathbf{0 , 7 2 5 8}$ & $\mathbf{0 , 0 0 6 0}$ & 0,7283 & 0,0060 \\
Cox & 0,7289 & 0,0080 & 0,7256 & 0,0074 & 0,7279 & 0,0106 \\
Weibull & 0,7365 & 0,0067 & 0,7310 & 0,0064 & 0,7453 & 0,0066 \\
Exponencial & 0,7322 & 0,0065 & 0,7288 & 0,0062 & 0,7372 & 0,0063 \\
\hline
\end{tabular}

Como o coeficiente de Gini é calculado a partir da área sob a curva ROC (ver Figura 5.4), estes dois indicadores são muito correlacionados. Os coeficientes de Gini calculados apresentaram valores muito próximos para os diferentes tipos de modelos ajustados, conforme Tabelas 5.19 e 5.20. O modelo de Cox continuou apresentando o maior desvio-padrão. 
Tabela 5.19: Média e desvio-padrão para a medida: coeficiente de GINI amostra de desenvolvimento.

\begin{tabular}{lcccccc} 
GINI & \multicolumn{2}{c}{ Amostra Original } & \multicolumn{2}{c}{ Mais Censura } & \multicolumn{2}{c}{ Menos Censura } \\
\hline Modelo & média & desv. pad. & média & desv. pad. & média & desv. pad. \\
\hline \hline Logística & 0,4641 & 0,0089 & 0,4608 & 0,0100 & 0,4705 & 0,0087 \\
Cox & 0,4536 & 0,0120 & 0,4578 & 0,0116 & 0,4441 & 0,0142 \\
Wcibull & 0,4797 & 0,0095 & 0,4706 & 0,0101 & 0,4935 & 0,0094 \\
Exponencial & 0,4734 & 0,0091 & 0,4669 & 0,0099 & 0,4841 & 0,0089 \\
\hline
\end{tabular}

Tabela 5.20: Média e desvio-padrão para a medida: coeficiente de GINI amostra de validação.

\begin{tabular}{lcccccc} 
GINI & \multicolumn{2}{c}{ Amostra Original } & \multicolumn{2}{c}{ Mais Censura } & \multicolumn{2}{c}{ Menos Censura } \\
\hline Modelo & média & desv. pad. & média & desv. pad. & média & desv. pad. \\
\hline \hline Logística & 0,4522 & $\mathbf{0 , 0 1 2 6}$ & $\mathbf{0 , 4 5 1 6}$ & 0,0121 & 0,4566 & 0,0120 \\
Cox & 0,4578 & 0,0160 & 0,4512 & 0,0148 & 0,4558 & 0,0211 \\
Weibull & 0,4730 & 0,0133 & 0,4620 & 0,0128 & 0,4906 & 0,0132 \\
Exponencial & 0,4643 & 0,0131 & 0,4575 & 0,0123 & 0,4743 & 0,0126 \\
\hline
\end{tabular}

A distância de Mahalanobis também apresentou valores próximos para todos os modelos. Os maiores valores estimados do indicador foram gerados pela amostra com mais casos de censura, conforme Tabela 5.21. O mesmo ocorreu na amostra de validação, conforme Tabela 5.22.

Tabela 5.21: Média e desvio-padrão para a medida: distância de Mahalanobis amostra de desenvolvimento.

\begin{tabular}{lcccccc} 
MAH & \multicolumn{2}{c}{ Amostra Original } & \multicolumn{2}{c}{ Mais Censura } & \multicolumn{2}{c}{ Menos Censura } \\
\hline Modelo & média & desv. pad. & média & desv. pad. & média & desv. pad. \\
\hline \hline Logística & 1,0513 & 0,0223 & 1,0781 & 0,0261 & 1,0329 & 0,0212 \\
Cox & 0,9580 & 0,0237 & 1,0017 & 0,0234 & 0,9164 & 0,0241 \\
Weibull & 1,0071 & 0,0225 & 1,0462 & 0,0249 & 0,9688 & 0,0217 \\
Exponencial & 1,0204 & 0,0221 & 1,0548 & 0,0252 & 0,9874 & 0,0209 \\
\hline
\end{tabular}


Tabela 5.22: Média e desvio-padrão para a medida: distância de Mahalanobis amostra de validação.

\begin{tabular}{lcccccc} 
MAH & \multicolumn{2}{c}{ Amostra Original } & \multicolumn{2}{c}{ Mais Censura } & \multicolumn{2}{c}{ Monos Censura } \\
\hline Modelo & média & desv. pad. & média & desv. pad. & média & desv. pad. \\
\hline \hline Logística & 1,4168 & 0,0417 & 1,4426 & 0,0408 & 1,3809 & 0,0384 \\
Cox & 1,2479 & 0,0429 & 1,3071 & 0,0406 & 1,1701 & 0,0440 \\
Weibull & 1,3429 & 0,0419 & 1,3982 & 0,0412 & 1,2657 & 0,0392 \\
Exponencial & 1,3748 & 0,0415 & 1,4185 & 0,0406 & 1,3146 & 0,0381 \\
\hline
\end{tabular}

A Tabela 5.23 mostra a medida diferença entre as taxas de inadimplência nos intervalos extremos definidos pelos decis (DTI) na amostra de desenvolvimento. Para a amostra original, a diferença entre a taxa de inadimplência foi de $72 \%$ entre os intervalos extremos. No caso da amostra com mais censuras, a diferença foi de $68 \%$ e na amostra com menos censura, foi de $71 \%$. Nesta abordagem considerou-se a diferença entre as taxas de inadimplência dos intervalos extremos, provocando menor sensibilidade no indicador quando aumentou-se a proporção de empresas adimplentes nas amostras.

Tabela 5.23: Média e desvio-padrão para a medida: diferença entre as taxas de inadimplência - amostra de desenvolvimento.

\begin{tabular}{lcccccc} 
DTI & \multicolumn{2}{c}{ Amostra Original } & \multicolumn{2}{c}{ Mais Censura } & \multicolumn{2}{c}{ Menos Censura } \\
\hline Modelo & média & desv. pad. & média & desv. pad. & média & desv. pad. \\
\hline \hline Logística & 71,53 & 1,69 & 67,97 & 2,01 & 71,21 & 1,73 \\
Cox & 70,25 & 1,86 & 66,20 & 1,73 & 67,37 & 1,91 \\
Weibull & 70,76 & 1,86 & 66,34 & 1,74 & 68,27 & 1,97 \\
Exponencial & 71,17 & 1,73 & 66,51 & 1,83 & 70,20 & 1,82 \\
\hline
\end{tabular}

A Tabela 5.24 mostra que a amostra de validação apresentou indicadores com valores superiores aos da amostra de desenvolvimento, como ocorreu com a maioria dos indicadores aqui estudados.

A Figura 5.5 mostra que a taxa de inadimplência apresenta boa ordenação para todos os modelos ajustados, sendo que para os intervalos dos escores mais baixos apresentou a maior taxa de inadimplência e essa taxa foi decrescente a medida que aumentava o escore, demostrando uma boa discriminação 
Tabela 5.24: Média e desvio-padrão para a medida: diferença entre as taxas de inadimplência - amostra de validação.

\begin{tabular}{lcccccc} 
DTI & \multicolumn{2}{c}{ Amostra Original } & \multicolumn{2}{c}{ Mais Censura } & \multicolumn{2}{c}{ Menos Censura } \\
\hline Modelo & média & desv. pad. & média & desv. pad. & média & desv. pad. \\
\hline \hline Logística & 76,72 & 2,13 & 72,00 & 2,17 & 75,16 & 2,02 \\
Cox & 73,53 & 2,24 & 71,23 & 2,29 & 69,33 & 2,43 \\
Wcibull & 73,50 & 2,27 & 71,30 & 2,27 & 69,63 & 2,46 \\
Exponencial & 75,92 & 2,00 & 71,72 & 2,26 & 74,07 & 2,19 \\
\hline
\end{tabular}

entre adimplentes e inadimplentes. Somente o ajuste do modelo Exponencial apresentou uma pequena estabilidade na taxa de inadimplência entre as faixas determinadas pelos percentis 50 e $60 \%$, mas sem grande implicação na qualidade do modelo ajustado.

Figura 5.5: Gráficos da taxa de inadimplência nos intervalos definidos pelos decis - amostra de desenvolvimento original
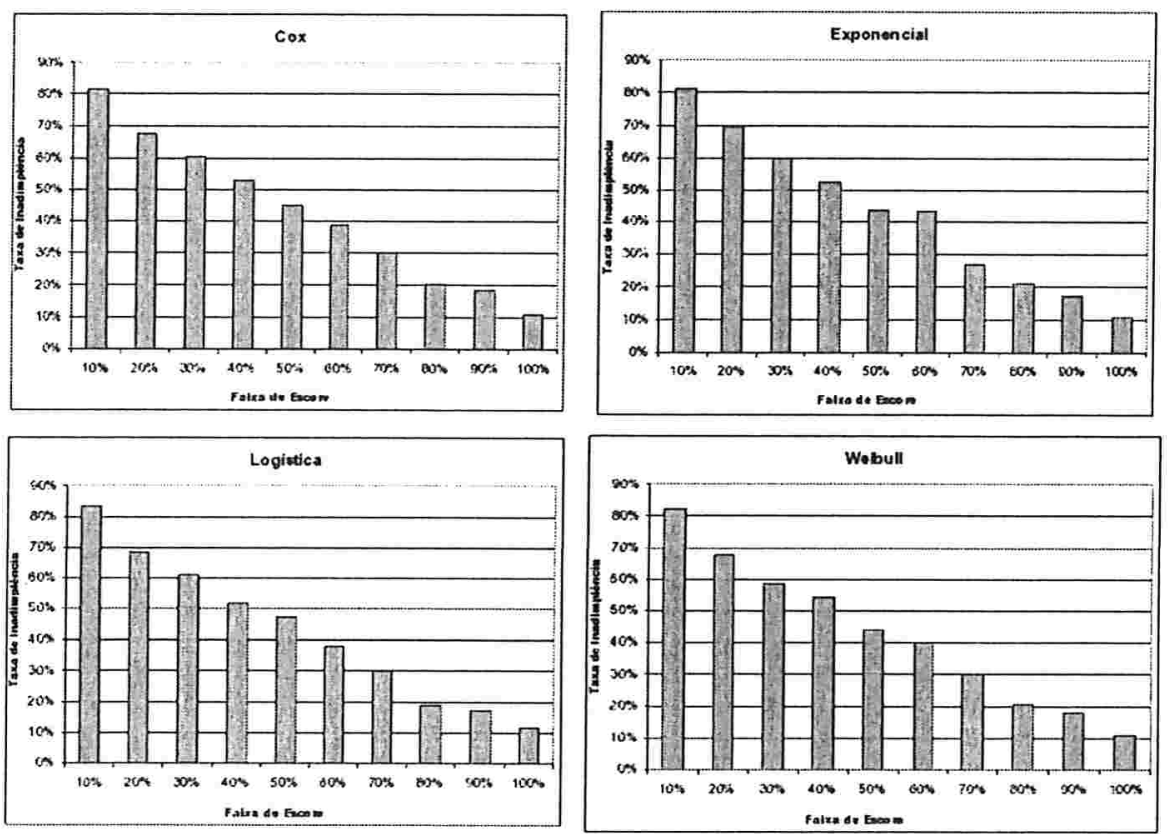


\section{Capítulo 6}

\section{Considerações Finais}

Considerando as medidas de avaliação de desempenho discutidas nesta pesquisa, tanto a Regressão Logística quanto a Análise de Sobrevivência apresentaram semelhantes resultados com relação ao desempenho esperado dos modelos. Os modelos ajustados por Análise de Sobrevivência consideraram as mesmas condições do modelo Logístico em termos de categorização das covariáveis e período de acompanhamento.

As medidas KS, área entre as curvas (AEC), distância de Mahalanobis, diferença entre as taxas de inadimplência (DTI), área sob a curva ROC e coeficiente de Gini apresentaram desempenho muito semelhante para todos os modelos ajustados pelas diferentes metodologias, considerando o ponto de vista do mercadológico. Isto indica que o ajuste por modelos de sobrevivência apresenta desempenho semelhante aos modelos tradicionalmente utilizados. Levando-se em conta que os modelos de sobrevivência apresentam informações relacionadas ao instante de ocorrência do evento, podemos considerar vantajoso seu estudo para utilização em Credit Score.

As medidas de avaliação de desempenho de modelos apresentaram poucas alterações quando as proporções de casos censurados variaram nas amostras de desenvolvimento e validação, demonstrando com isso que não sofrem muita influência da censura. As medidas $R O C, G I N I$ e $A E C$, calculadas a partir de áreas, apresentaram menores desvios-padrão, sugerindo maior estabilidade. Uma próxima abordagem da medida $A E C$ seria determinar as bandas de classificação do nível de discriminação dos modelos, analogamente aos usuais considerados para o KS. O indicador baseado na diferença entre as taxas de inadimplência nos intervalos extremos apresentou maior variabilidade.

Não é recomendável basear a escolha do melhor modelo observando so- 
mente uma medida de avaliação de desempenho, o ideal é considerar um conjunto delas. Atualmente, a medida $K S$ é a mais popular no mercado de crédito, sendo por isso a mais discutida e requisitada quando se anuncia um novo modelo de Credit Score.

Para escolha do ponto de corte em uma aplicação usual do Credit Score, são observadas a combinação de critérios como o maior $K S$ no intervalo que apresenta uma taxa de inadimplência aceitável e ainda o percentual de inadimplentes classificados corretamente em relação ao total de clientes que serão rejeitados por apresentar pontuação abaixo do ponto de corte escolhido.

Como os modelos ajustados por Análise de Sobrevivência apresentaram bom desempenho em relação a discriminação entre as empresas classificadas como adimplentes e inadimplentes, uma aplicação destes modelos traria uma vantagem competitiva à intituição que considerasse o instante $t$, onde foi calculado a probabilidade de sobrevivência, como importante informação para negociar o prazo de pagamento do crédito. Com essa informação adicional seria possível definir novas políticas de crédito associadas a diferentes prazos de pagamento, podendo oferecer planos diferenciados a partir do perfil do solicitante.

Outra vantagem do modelo ajustado por Análise de Sobrevivência é que não há necessidade de fixar o período de acompanhamento, resultando em apenas um modelo com o qual se obtém a probabilidade de uma empresa superar $6,12,18$ ou $t$ meses sem apresentar inadimplência (sendo $t$ o período máximo considerado para definir a censura), enquanto que em um ajuste por Regressão Logística seriam necessários tantos modelos, quantos diferentes períodos de acompanhamento desejados.

Atualmente algumas instituições credoras utilizam a ferramenta Credit Score somente para uma decisão binária de aprovação ou rejeição de um cliente. Esta decisão é baseada na pontuação associada à probabilidade de inadimplência. Com a aplicação de um modelo de sobrevivência aumentariam as possibilidades de utilização do Credit Score, pois os produtos poderiam contemplar diversas opções de prazos e preços adequados ao perfil de cada cliente, proporcionando uma rentabilidade dos produtos, a partir de uma melhor seleção de clientes. 


\section{Apêndice A}

\section{Tabelas Descritivas}

Tabela A.1: Quantidade de dívidas com empresa no momento da consulta.

\begin{tabular}{lrrrr} 
Covariável & Bons (\%) & Maus (\%) & Total & Razão M/B \\
\hline \hline 0 & $5560(57,27)$ & $4148(42,73)$ & 9708 & 0,99 \\
1 ou + & $154(52,74)$ & $138(47,26)$ & 292 & 1,19 \\
\hline Total & $5714(57,14)$ & $4286(42,86)$ & 10000 &
\end{tabular}

Tabela A.2: Quantidade cheques devolvidos no momento da consulta.

\begin{tabular}{lrrrr} 
Covariável & Bons (\%) & Maus (\%) & Total & Razão M/B \\
\hline \hline 0 & $5682(57,74)$ & $4158(42,26)$ & 9840 & 0,98 \\
1 ou + & $32(20,00)$ & $128(80,00)$ & 160 & 5,33 \\
\hline Total & $5714(57,14)$ & $4286(42,86)$ & 10000 &
\end{tabular}

Tabela A.3: Quantidade de ações judiciais ou executivas de busca e apreensão no momento da consulta.

\begin{tabular}{lrrrr} 
Covariável & Bons (\%) & Maus (\%) & Total & Razão M/B \\
\hline \hline 0 & $5701(57,15)$ & $4274(42,85)$ & 9975 & 1,00 \\
1 ou + & $13(52,00)$ & $12(48,00)$ & 25 & 1,23 \\
\hline Total & $5714(57,14)$ & $4286(42,86)$ & 10000 &
\end{tabular}


Tabela A.4: Quantidade de protestos no momento da consulta.

\begin{tabular}{lrrrr} 
Covariável & Bons (\%) & Maus (\%) & Total & Razão M/B \\
\hline \hline 0 & $5147(61,04)$ & $3285(38,96)$ & 8432 & 0,85 \\
1 & $294(39,52)$ & $450(60,48)$ & 744 & 2,04 \\
$2+$ & $273(33,13)$ & $551(66,87)$ & 824 & 2,69 \\
\hline Total & $5714(57,14)$ & $4286(42,86)$ & 10000 &
\end{tabular}

Tabela A.5: Soma das quantidades de restrições no momento da consulta.

\begin{tabular}{lrrrr} 
Covariável & Bons (\%) & Maus (\%) & Total & Razão M/B \\
\hline \hline 0 & $7998(61,93)$ & $4916(38,07)$ & 12914 & 0,82 \\
1 ou + & $1142(37,33)$ & $1917(62,67)$ & 3059 & 2,25 \\
\hline Total & $5714(57,14)$ & $4286(42,86)$ & 10000 &
\end{tabular}

Tabela A.6: Setor de atividade da empresa.

\begin{tabular}{lrrrr} 
Covariável & Bons (\%) & Maus (\%) & Total & Razão M/B \\
\hline \hline Comércio & $3137(55,25)$ & $2541(44,75)$ & 5678 & 1,08 \\
Indústria & $563(46,22)$ & $655(53,78)$ & 1218 & 1,55 \\
Primário & $40(57,97)$ & $29(42,03)$ & 69 & 0,97 \\
Serviço & $1974(65,04)$ & $1061(34,96)$ & 3035 & 0,72 \\
\hline Total & $5714(57,14)$ & $4286(42,86)$ & 10000 &
\end{tabular}

Tabela A.7: Quantidade de sócios pessoa-física da empresa.

\begin{tabular}{lrrrr} 
Covariável & Bons (\%) & Maus (\%) & Total & Razão M/B \\
\hline \hline 0 & $106(49,07)$ & $110(50,93)$ & 216 & 1,38 \\
1 & $2917(67,49)$ & $1405(32,51)$ & 4322 & 0,64 \\
2 & $2241(48,24)$ & $2405(51,76)$ & 4646 & 1,43 \\
3 ou + & $450(55,15)$ & $366(44,85)$ & 816 & 1,08 \\
\hline Total & $5714(57,14)$ & $4286(42,86)$ & 10000 &
\end{tabular}


Tabela A.8: Região ou estado da sede da empresa

\begin{tabular}{lrrrr} 
Covariável & Bons (\%) & Maus (\%) & Total & Razão M/B \\
\hline \hline CO & $428(56,17)$ & $334(43,83)$ & 762 & 1,04 \\
NE & $1239(62,32)$ & $749(37,68)$ & 1988 & 0,81 \\
NO & $204(47,11)$ & $229(52,89)$ & 433 & 1,50 \\
SE & $756(54,00)$ & $644(46,00)$ & 1400 & 1,14 \\
SP & $1641(55,38)$ & $1322(44,62)$ & 2963 & 1,07 \\
SU & $1446(58,92)$ & $1008(41,08)$ & 2454 & 0,93 \\
\hline Total & $5714(57,14)$ & $4286(42,86)$ & 10000 &
\end{tabular}

Tabela A.9: Número de funcionários da empresa.

\begin{tabular}{lrrrr} 
Covariável & Bons (\%) & Maus (\%) & Total & Razão M/B \\
\hline \hline 0 & $3784(68,29)$ & $1757(31,71)$ & 5541 & 0,62 \\
1 a 2 & $598(50,04)$ & $597(49,96)$ & 1195 & 1,33 \\
3 a 5 & $476(44,11)$ & $603(55,89)$ & 1079 & 1,69 \\
6 a 10 & $365(41,20)$ & $521(58,80)$ & 886 & 1,90 \\
11 ou + & 491 & 808 & 1299 & 2,19 \\
\hline Total & $5714(57,14)$ & $4286(42,86)$ & 10000 &
\end{tabular}

Tabela A.10: Percentual de participação do sócio majoritário da empresa.

\begin{tabular}{lrrrr} 
Covariável & Bons (\%) & Maus (\%) & Total & Razão M/B \\
\hline \hline$<50 \%$ & $348(59,28)$ & $239(40,72)$ & 587 & 0,92 \\
$50 \%$ & $1121(50,59)$ & $1095(49,41)$ & 2216 & 1,30 \\
$50 \% \mid-100 \%$ & $1432(46,42)$ & $1653(53,58)$ & 3085 & 1,54 \\
$100 \%$ & $2813(68,41)$ & $1299(31,59)$ & 4112 & 0,62 \\
\hline Total & $5714(57,14)$ & $4286(42,86)$ & 10000 &
\end{tabular}


Tabela A.11: Capital social da empresa.

\begin{tabular}{lrrrr} 
Covariável & Bons (\%) & Maus (\%) & Total & Razão M/B \\
\hline \hline$<3000$ & $1142(69,34)$ & $505(30,66)$ & 1647 & 0,59 \\
$3000 \mid-8000$ & $1605(66,05)$ & $825(33,95)$ & 2430 & 0,69 \\
$8000 \mid-15000$ & $1192(56,49)$ & $918(43,51)$ & 2110 & 1,03 \\
$15000 \mid-50000$ & $967(46,76)$ & $1101(53,24)$ & 2068 & 1,52 \\
50000 ou + & $808(46,30)$ & $937(53,70)$ & 1745 & 1,55 \\
\hline Total & $5714(57,14)$ & $4286(42,86)$ & 10000 &
\end{tabular}

Tabela A.12: Tipo de controle acionário.

\begin{tabular}{lrrrr} 
Covariável & Bons (\%) & Maus (\%) & Total & Razão M/B \\
\hline \hline Outros & $74(52,48)$ & $67(47,52)$ & 141 & 1,21 \\
Nacional Privado & $5640(57,21)$ & $4219(42,79)$ & 9859 & 1,00 \\
\hline Total & $5714(57,14)$ & $4286(42,86)$ & 10000 &
\end{tabular}




\section{Apêndice B}

\section{Gráficos}

Figura B.1: Quantidade de dívidas com empresa no momento da consulta.

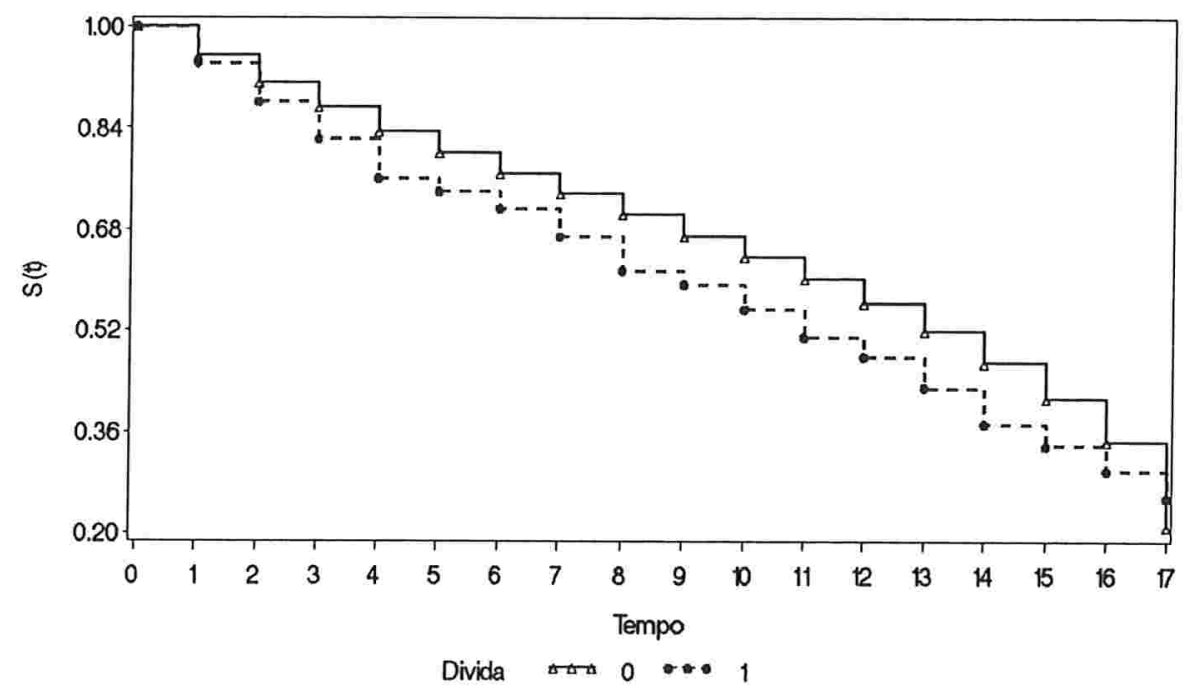


Figura B.2: Quantidade cheques devolvidos no momento da consulta.

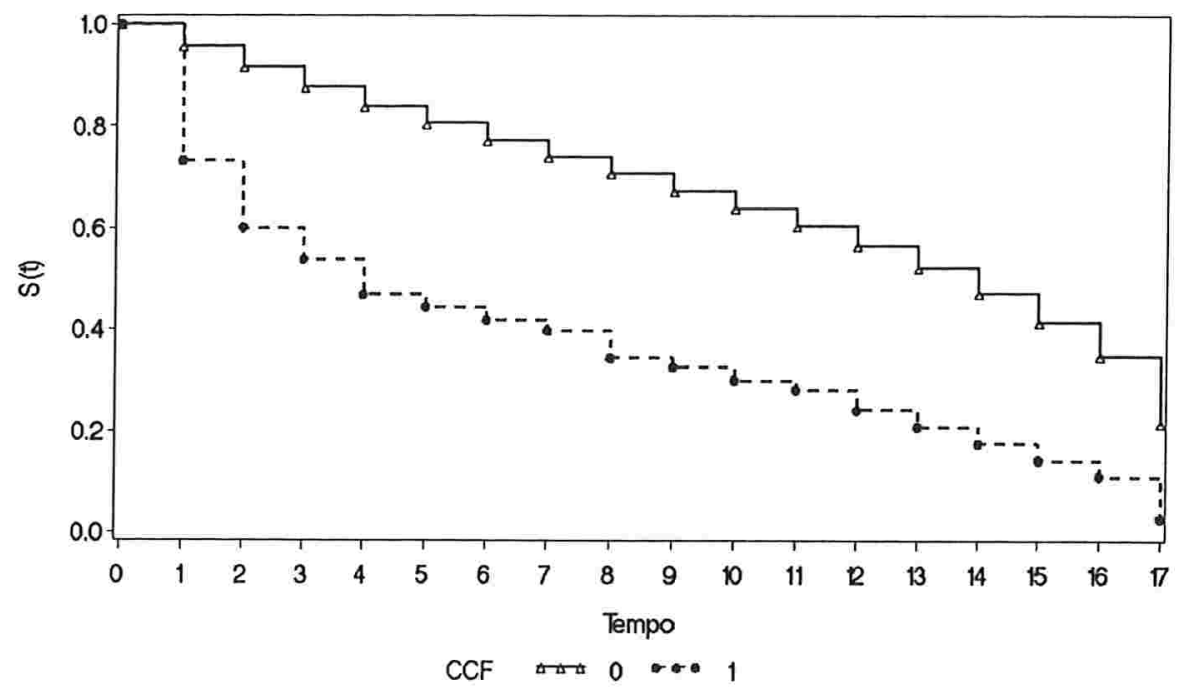

Figura B.3: Quantidade de ações judiciais ou executivas de busca e apreenção no momento da consulta.

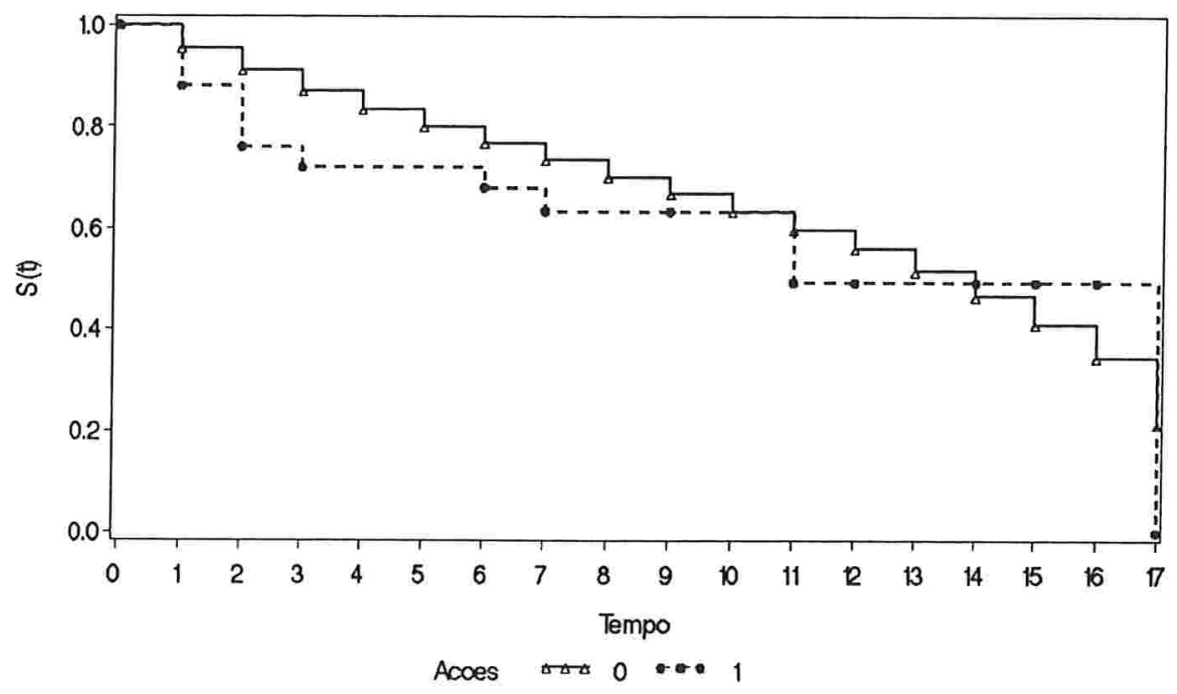


Figura B.4: Quantidade de protestos no momento da consulta.

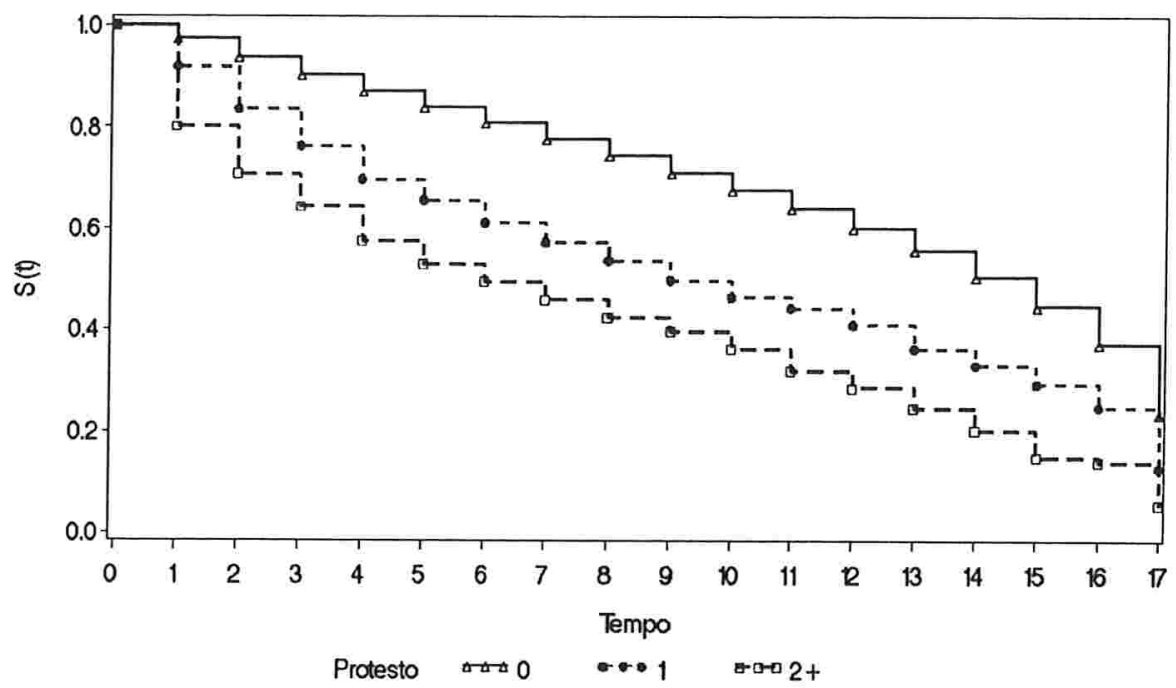

Figura B.5: Soma das quantidades de restrições no momento da consulta.

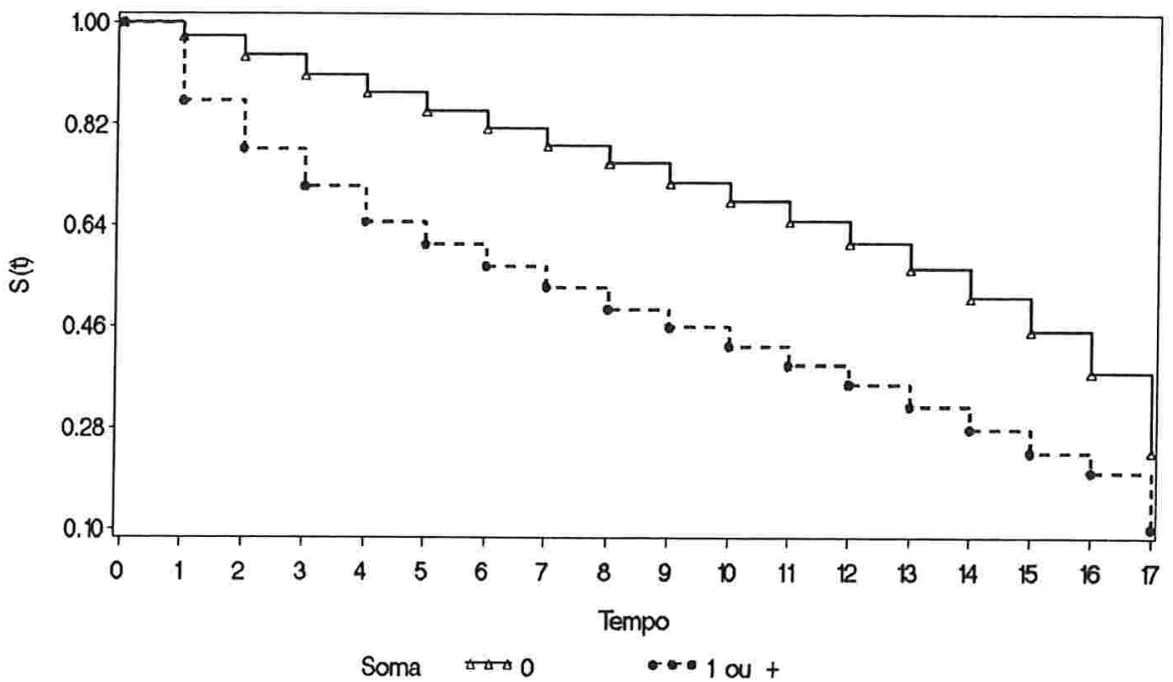


Figura B.6: Setor de atividade da empresa.

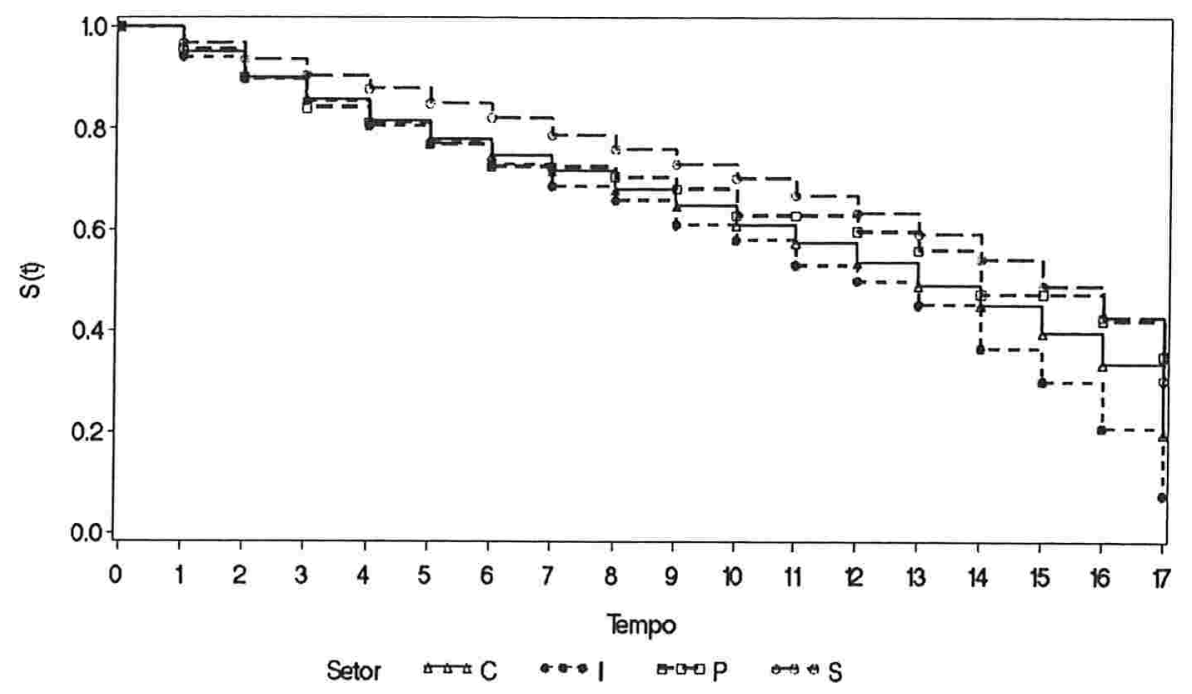

Figura B.7: Quantidade de sócios pessoa-física na empresa.

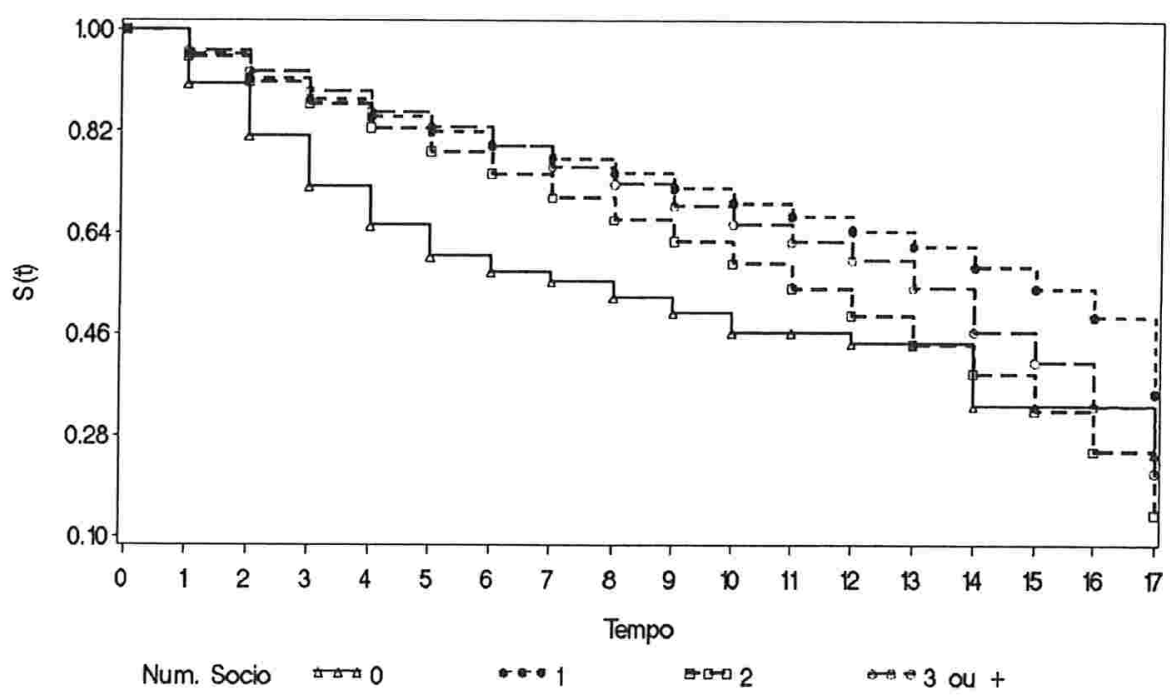


Figura B.8: Região ou estado de sede da empresa.

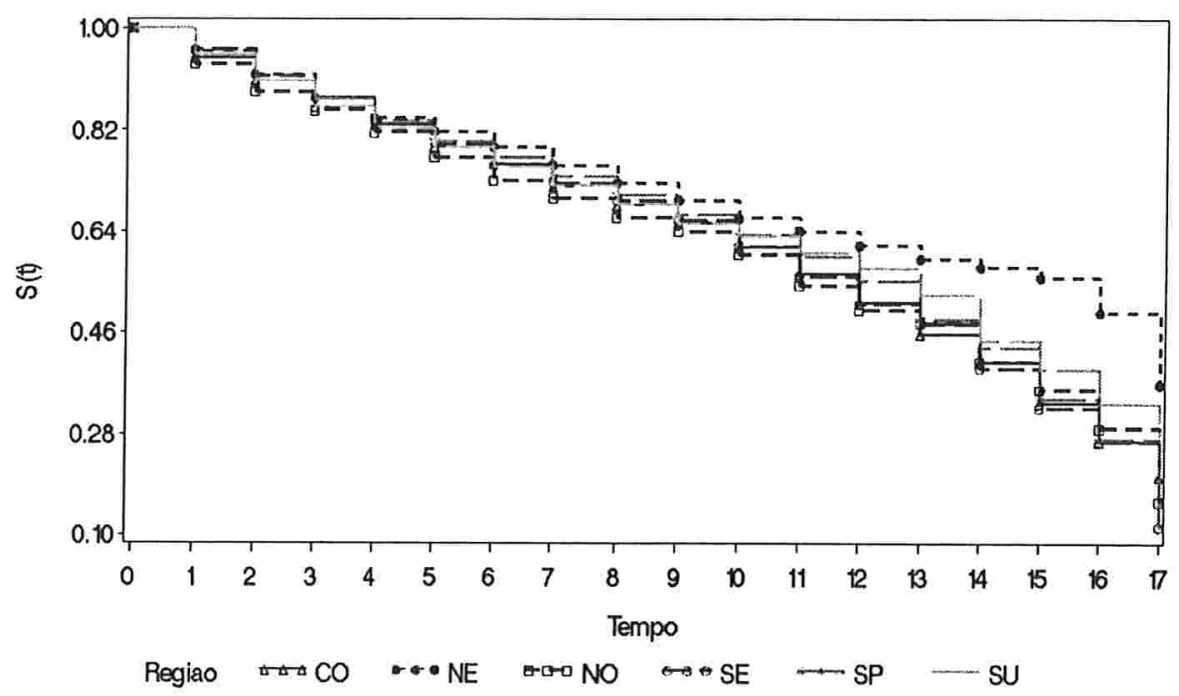

Figura B.9: Número de funcionários da empresa.

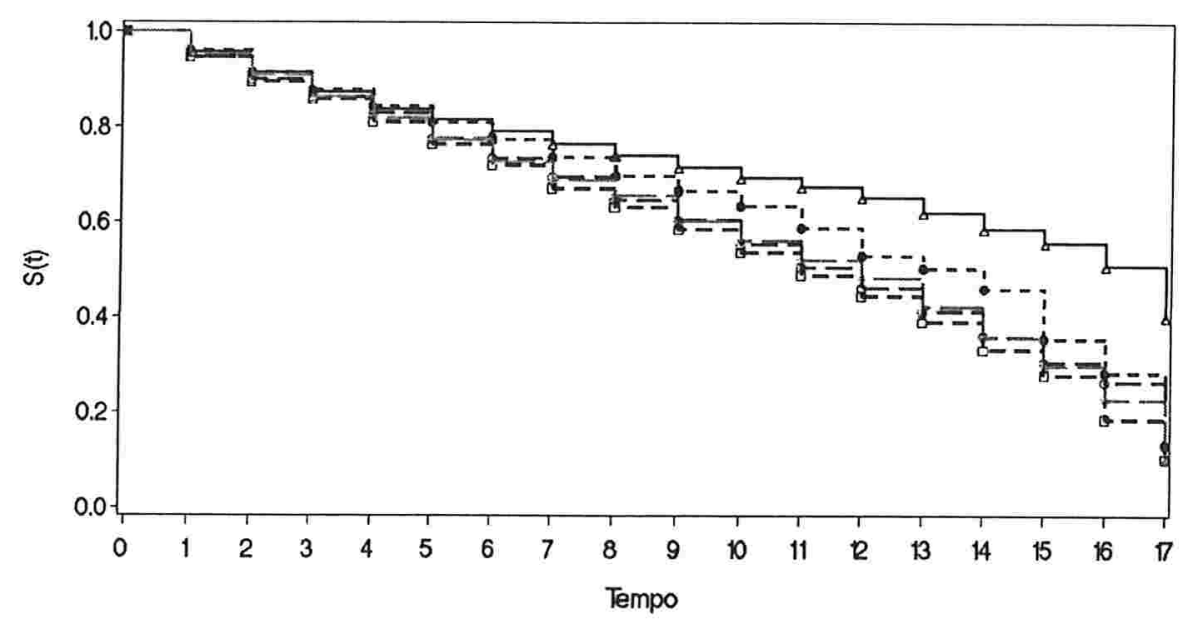

Num. Empreg. 0

$\rightarrow 3$ a 5 empregados 
Figura B.10: Percentual de participação do sócio majoritário da empresa.

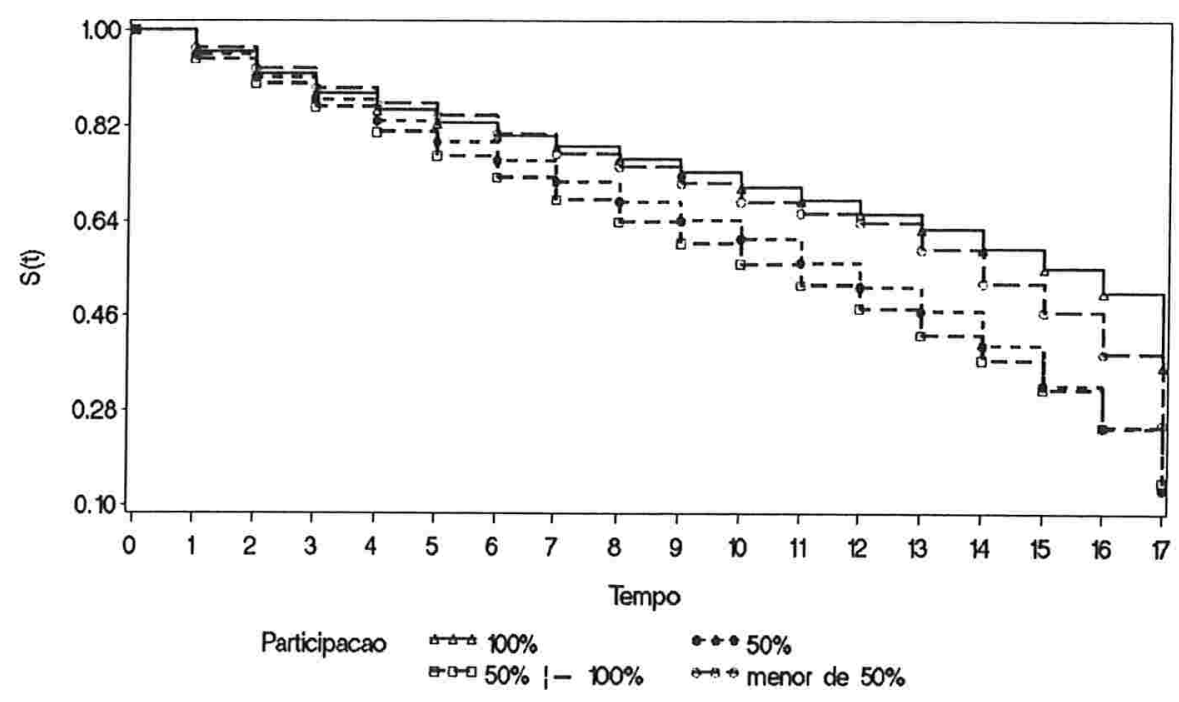

Figura B.11: Capital social da empresa.

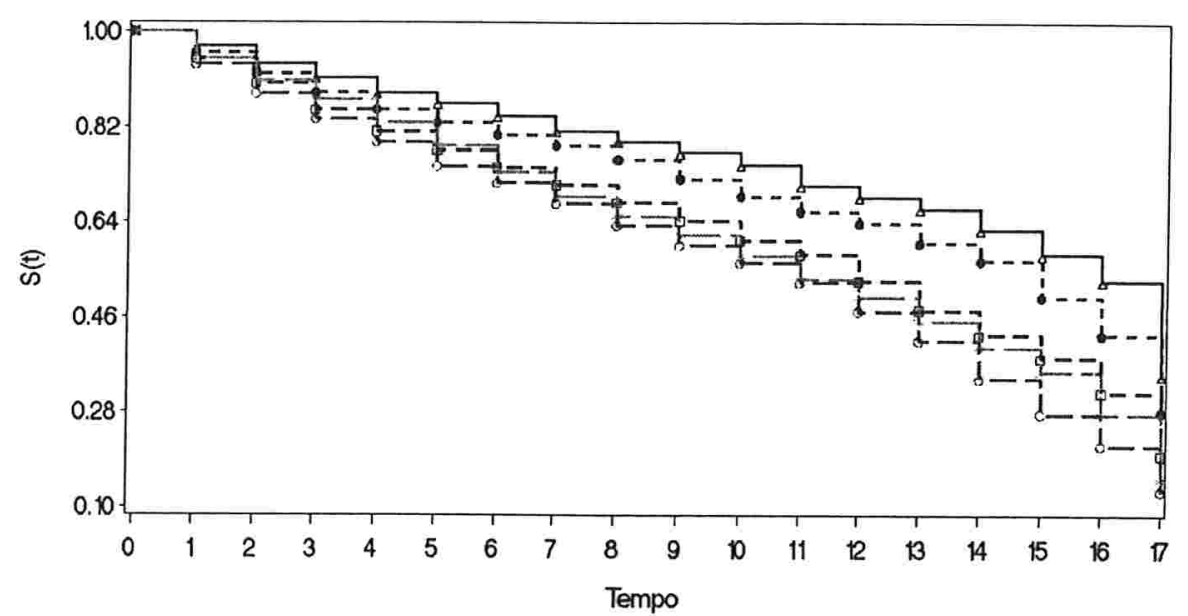

Cap. Social $\leftrightarrow$ menor que $3000 \quad 5000 \quad 50000000<5000$ 
Figura B.12: Tipo de controle acionário.

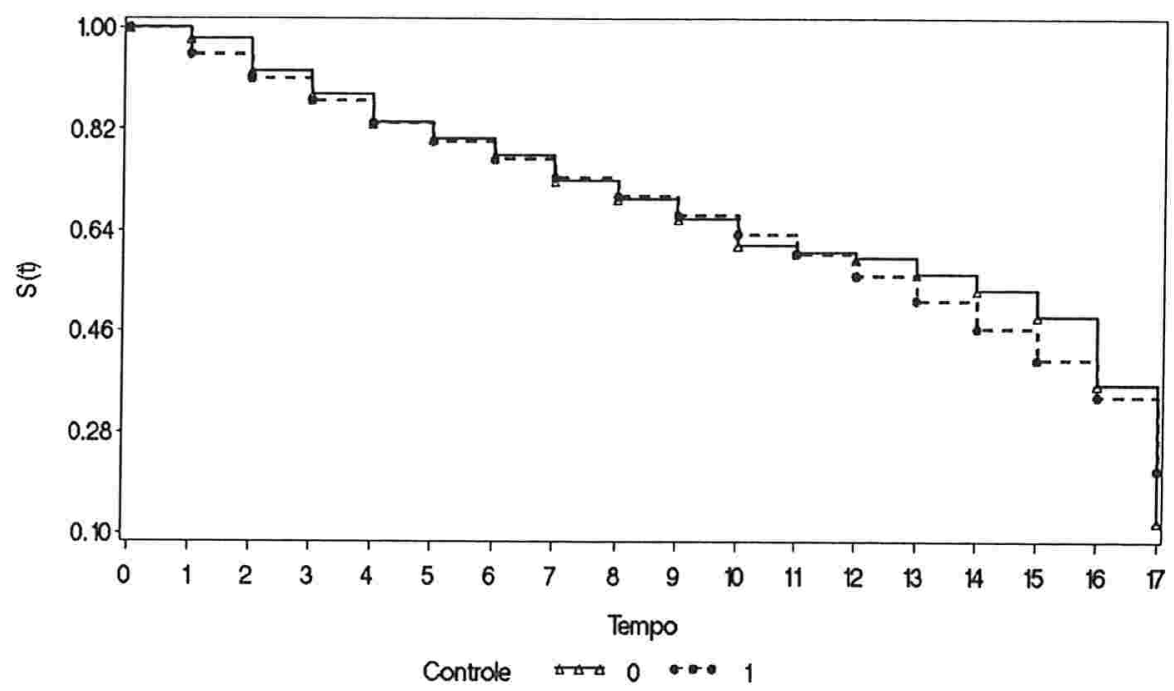




\section{Apêndice C}

\section{Coeficientes estimados para amostra de validação após a reamostragem}

Tabela C.1: Coeficientes estimados pela Regressão Logística - amostra de validação.

\begin{tabular}{lcccccc} 
& \multicolumn{2}{c}{ Amostra Original } & \multicolumn{2}{c}{ Mais censura } & \multicolumn{2}{c}{ Menos Censura } \\
\cline { 2 - 7 } Covariável & Média & Desvio Padrão & Média & Desvio Padrão & Média & Desvio Padrão \\
\hline \hline intercepto & $-1,1804$ & 0,0674 & $-1,6560$ & 0,0761 & $-0,7564$ & 0,0733 \\
idade1 & 1,4366 & 0,1046 & 1,4378 & 0,1026 & 1,4052 & 0,1007 \\
idade3 & $-0,3101$ & 0,0799 & $-0,2601$ & 0,0836 & $-0,2957$ & 0,0780 \\
idade4 & $-0,7626$ & 0,0805 & $-0,7184$ & 0,0822 & $-0,7532$ & 0,0804 \\
setor2 & 0,1764 & 0,0829 & 0,1906 & 0,0963 & 0,1340 & 0,0954 \\
setor4 & $-0,4390$ & 0,0697 & $-0,4245$ & 0,0678 & $-0,4552$ & 0,0696 \\
cheque1 & 2,0754 & 0,3488 & 1,9871 & 0,3660 & 2,3705 & 0,4178 \\
protesto1 & 0,3743 & 0,2199 & 0,3085 & 0,2282 & 0,3216 & 0,2241 \\
protesto2 & 1,3542 & 0,2187 & 1,2459 & 0,2194 & 1,2706 & 0,2251 \\
soma_restr1 & 0,3520 & 0,1869 & 0,4396 & 0,1960 & 0,4121 & 0,1899 \\
regiao2 & 0,8541 & 0,1577 & 0,7240 & 0,1677 & 0,7395 & 0,1633 \\
num_func1 & 1,0069 & 0,0984 & 1,0624 & 0,0969 & 0,9946 & 0,0859 \\
num_func2 & 1,2073 & 0,1060 & 1,2983 & 0,1053 & 1,2817 & 0,1038 \\
num_func3 & 1,2395 & 0,1136 & 1,2635 & 0,1187 & 1,2898 & 0,1107 \\
num_func4 & 1,4726 & 0,1118 & 1,4792 & 0,1089 & 1,4252 & 0,1059 \\
participacao1 & 0,3347 & 0,0734 & 0,3235 & 0,0815 & 0,2876 & 0,0832 \\
participacao2 & 0,4418 & 0,0706 & 0,4630 & 0,0809 & 0,4228 & 0,0774 \\
cap_social4 & 0,2029 & 0,0792 & 0,1999 & 0,0781 & 0,2107 & 0,0721 \\
cap_social5 & 0,1258 & 0,0913 & 0,1305 & 0,0931 & 0,1716 & 0,0916 \\
\hline
\end{tabular}


Tabela C.2: Coeficientes estimados pela Modelo de Cox - amostra de validação.

\begin{tabular}{lcccccc} 
& \multicolumn{2}{c}{ Amostra Original } & \multicolumn{2}{c}{ Mais censura } & \multicolumn{2}{c}{ Menos Censura } \\
\cline { 2 - 7 } Covariável & Média & Desvio Padrão & Média & Desvio Padrão & Média & Desvio Padrão \\
\hline \hline idade1 & 0,7534 & 0,0593 & 0,8668 & 0,0722 & 0,6436 & 0,0519 \\
idade3 & $-0,2271$ & 0,0612 & $-0,1993$ & 0,0668 & $-0,1858$ & 0,0526 \\
idade4 & $-0,4528$ & 0,0617 & $-0,4555$ & 0,0671 & $-0,3916$ & 0,0532 \\
setor2 & 0,0152 & 0,0596 & 0,0409 & 0,0695 & $-0,0236$ & 0,0555 \\
setor4 & $-0,2442$ & 0,0507 & $-0,2530$ & 0,0517 & $-0,2334$ & 0,0460 \\
cheque1 & 0,9027 & 0,1849 & 0,9799 & 0,2175 & 0,9510 & 0,1603 \\
protesto1 & 0,1249 & 0,1575 & 0,0328 & 0,1786 & 0,2317 & 0,1369 \\
protesto2 & 0,7098 & 0,1444 & 0,6647 & 0,1649 & 0,7743 & 0,1346 \\
soma_restr1 & 0,4231 & 0,1365 & 0,5354 & 0,1539 & 0,3135 & 0,1245 \\
regiao1 & $-0,2617$ & 0,0542 & $-0,2974$ & 0,0621 & $-0,2537$ & 0,0503 \\
num_socio1 & 0,2171 & 0,0828 & 0,2545 & 0,0973 & 0,2242 & 0,0840 \\
num_func1 & 0,4055 & 0,0605 & 0,5263 & 0,0714 & 0,2768 & 0,0528 \\
num_func2 & 0,4530 & 0,0689 & 0,6322 & 0,0711 & 0,3514 & 0,0589 \\
num_func3 & 0,5366 & 0,0713 & 0,6353 & 0,0817 & 0,4232 & 0,0612 \\
num_func4 & 0,5760 & 0,0654 & 0,7501 & 0,0729 & 0,4226 & 0,0571 \\
participacao1 & 0,2460 & 0,0827 & 0,2586 & 0,0964 & 0,2143 & 0,0857 \\
participacao2 & 0,3159 & 0,0808 & 0,3705 & 0,0939 & 0,3046 & 0,0840 \\
cap_social1 & $-0,2857$ & 0,0714 & $-0,3215$ & 0,0728 & $-0,2592$ & 0,0639 \\
cap_social2 & $-0,1569$ & 0,0534 & $-0,2328$ & 0,0635 & $-0,1336$ & 0,0455 \\
\hline
\end{tabular}

Tabela C.3: Estimativas da função basal $S_{0}$ - amostra de validação.

\begin{tabular}{lcccccc} 
& \multicolumn{2}{c}{ Amostra Original } & \multicolumn{2}{c}{ Mais censura } & \multicolumn{2}{c}{ Menos Censura } \\
\cline { 2 - 7 } Instante de tempódia & Média & Desvio Padrão & Média & Desvio Padrão & Média & Desvio Padrão \\
\hline \hline 0 & 1,0000 & 0,0000 & 1,0000 & 0,0000 & 1,0000 & 0,0000 \\
1 & 0,9573 & 0,0025 & 0,9691 & 0,0020 & 0,9456 & 0,0030 \\
2 & 0,9197 & 0,0033 & 0,9424 & 0,0029 & 0,8969 & 0,0042 \\
3 & 0,8804 & 0,0044 & 0,9132 & 0,0038 & 0,8472 & 0,0047 \\
4 & 0,8478 & 0,0051 & 0,8891 & 0,0043 & 0,8049 & 0,0052 \\
5 & 0,8160 & 0,0056 & 0,8675 & 0,0048 & 0,7653 & 0,0056 \\
6 & 0,7880 & 0,0060 & 0,8465 & 0,0050 & 0,7295 & 0,0059 \\
7 & 0,7592 & 0,0064 & 0,8250 & 0,0054 & 0,6921 & 0,0063 \\
8 & 0,7259 & 0,0069 & 0,8004 & 0,0059 & 0,6514 & 0,0066 \\
9 & 0,6954 & 0,0072 & 0,7764 & 0,0062 & 0,6129 & 0,0068 \\
10 & 0,6567 & 0,0078 & 0,7454 & 0,0067 & 0,5696 & 0,0073 \\
11 & 0,6243 & 0,0082 & 0,7229 & 0,0072 & 0,5309 & 0,0078 \\
12 & 0,5895 & 0,0090 & 0,6960 & 0,0076 & 0,4895 & 0,0080 \\
13 & 0,5533 & 0,0098 & 0,6678 & 0,0088 & 0,4445 & 0,0091 \\
14 & 0,5073 & 0,0103 & 0,6287 & 0,0098 & 0,3942 & 0,0095 \\
15 & 0,4607 & 0,0110 & 0,5863 & 0,0107 & 0,3432 & 0,0096 \\
16 & 0,3919 & 0,0127 & 0,5246 & 0,0117 & 0,2687 & 0,0101 \\
17 & 0,2288 & 0,0161 & 0,3628 & 0,0187 & 0,1223 & 0,0107 \\
\hline
\end{tabular}


Tabela C.4: Coeficientes estimados pela Modelo Weibull - amostra de validação.

\begin{tabular}{lcccccc} 
& \multicolumn{2}{c}{ Amostra Original } & \multicolumn{2}{c}{ Mais censura } & \multicolumn{2}{c}{ Menos Censura } \\
\cline { 2 - 6 } Covariável & Média & Desvio Padrão & Média & Desvio Padrão & Média & Desvio Padrão \\
\hline \hline Intercepto & 3,0921 & 0,0666 & 3,3840 & 0,0819 & 2,8700 & 0,0649 \\
idade1 & $-0,5336$ & 0,0424 & $-0,6176$ & 0,0530 & $-0,4475$ & 0,0365 \\
idade3 & 0,1592 & 0,0420 & 0,1435 & 0,0464 & 0,1210 & 0,0358 \\
idade4 & 0,3180 & 0,0426 & 0,3283 & 0,0470 & 0,2661 & 0,0374 \\
setor4 & 0,1746 & 0,0339 & 0,1874 & 0,0361 & 0,1569 & 0,0302 \\
cheque1 & $-0,6637$ & 0,1263 & $-0,7208$ & 0,1507 & $-0,6611$ & 0,1151 \\
protesto1 & $-0,0932$ & 0,1070 & $-0,0197$ & 0,1222 & $-0,1569$ & 0,0937 \\
protesto2 & $-0,5153$ & 0,1004 & $-0,4790$ & 0,1159 & $-0,5403$ & 0,0945 \\
soma_restr1 & $-0,3051$ & 0,0940 & $-0,3902$ & 0,1066 & $-0,2326$ & 0,0840 \\
regiao1 & 0,1812 & 0,0383 & 0,2084 & 0,0438 & 0,1669 & 0,0346 \\
num_socio1 & $-0,1494$ & 0,0605 & $-0,1776$ & 0,0712 & $-0,1485$ & 0,0593 \\
num_func1 & $-0,2779$ & 0,0424 & $-0,3759$ & 0,0496 & $-0,1814$ & 0,0360 \\
num_func2 & $-0,3256$ & 0,0479 & $-0,4601$ & 0,0509 & $-0,2446$ & 0,0396 \\
num_func3 & $-0,3628$ & 0,0510 & $-0,4459$ & 0,0576 & $-0,2678$ & 0,0428 \\
num_func4 & $-0,4066$ & 0,0454 & $-0,5402$ & 0,0530 & $-0,2812$ & 0,0376 \\
participacao1 & $-0,1752$ & 0,0600 & $-0,1882$ & 0,0690 & $-0,1459$ & 0,0588 \\
participacao2 & $-0,2196$ & 0,0583 & $-0,2628$ & 0,0677 & $-0,2029$ & 0,0585 \\
cap_social1 & 0,2000 & 0,0501 & 0,2224 & 0,0519 & 0,1757 & 0,0436 \\
cap_social2 & 0,1141 & 0,0374 & 0,1701 & 0,0446 & 0,0968 & 0,0310 \\
escala & 0,7179 & 0,0109 & 0,7235 & 0,0137 & 0,7029 & 0,0103 \\
forma & 1,3889 & 0,0235 & 1,3797 & 0,0268 & 1,4179 & 0,0215 \\
\hline
\end{tabular}


Tabela C.5: Coeficientes estimados pela Modelo Exponencial - amostra de validação.

\begin{tabular}{lcccccc} 
& \multicolumn{2}{c}{ Amostra Original } & \multicolumn{2}{c}{ Mais censura } & \multicolumn{2}{c}{ Menos Censura } \\
\cline { 2 - 7 } Covariável & Média & Desvio Padrão & Média & Desvio Padrão & Média & Desvio Padrão \\
\hline \hline Intercepto & 3,3135 & 0,0490 & 3,6806 & 0,0601 & 3,0224 & 0,0453 \\
idade1 & $-0,6908$ & 0,0512 & $-0,8070$ & 0,0644 & $-0,5802$ & 0,0440 \\
idade3 & 0,2119 & 0,0538 & 0,1978 & 0,0602 & 0,1594 & 0,0463 \\
idade4 & 0,4275 & 0,0538 & 0,4464 & 0,0607 & 0,3621 & 0,0474 \\
setor4 & 0,2479 & 0,0432 & 0,2695 & 0,0453 & 0,2259 & 0,0380 \\
cheque1 & $-0,8690$ & 0,1463 & $-0,9315$ & 0,1772 & $-0,8564$ & 0,1287 \\
protesto1 & $-0,1350$ & 0,1311 & $-0,0530$ & 0,1499 & $-0,1960$ & 0,1143 \\
protesto2 & $-0,6726$ & 0,1232 & $-0,6355$ & 0,1419 & $-0,6841$ & 0,1137 \\
soma_restr1 & $-0,3686$ & 0,1156 & $-0,4784$ & 0,1308 & $-0,2911$ & 0,1031 \\
num_func1 & $-0,4251$ & 0,0537 & $-0,5608$ & 0,0632 & $-0,3102$ & 0,0445 \\
num_func2 & $-0,4974$ & 0,0594 & $-0,6648$ & 0,0639 & $-0,4010$ & 0,0486 \\
num_func3 & $-0,5221$ & 0,0624 & $-0,6311$ & 0,0723 & $-0,4091$ & 0,0513 \\
num_func4 & $-0,5820$ & 0,0552 & $-0,7411$ & 0,0640 & $-0,4291$ & 0,0456 \\
participacao1 & $-0,1287$ & 0,0446 & $-0,1325$ & 0,0574 & $-0,0902$ & 0,0435 \\
participacao2 & $-0,1944$ & 0,0441 & $-0,2338$ & 0,0554 & $-0,1677$ & 0,0418 \\
cap_social1 & 0,2656 & 0,0651 & 0,2886 & 0,0680 & 0,2330 & 0,0558 \\
cap_social2 & 0,1429 & 0,0466 & 0,2100 & 0,0582 & 0,1202 & 0,0395 \\
\hline
\end{tabular}




\section{Apêndice D}

\section{Macros SAS para cálculo das medidas de desempenho.}

Para a construção das macros e programas para o cálculo das medidas de avaliação de desempenho utilizadas nesta pesquisa, foi utilizado o programa SAS versão 8.1 [Allison, 1995] e [Sas help].

\section{Macro ROC_GINI}

\%ACRO ROC_GINI(ARQENT, ARQSAI, NUM);

$/ *$

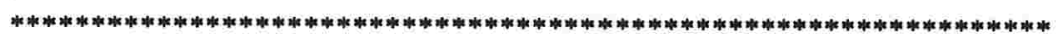
ESTA MACRO SERVE PARA CALCULAR AS MEDIDAS DE DESEMPENHO CONHECIDAS COMO AREA SOB A CURVA ROC E COEFICIENTE DE GINI.

ARQUENT: E O NOME DO ARQUIVO SAS QUE DEVE CONTER: OBS: IDENTIFICADOR DE CADA OBSERVACAO; RESP: VARIAVEL RESPOSTA, COM $0=$ BOM E $1=$ MAU; SCORE: SCORE FINAL ATRIBIDO A CADA OBSERVACAO, EM INTEIROS PARA UTILIZAR A MACRO SERA NECESSARIO RENOMEAR AS VARIAVEIS SCORE E RESPOSTA PARA OS NOMES ACIMA.

ARQSAI: E O NOME DO ARQUTVO SAS QUE DEVERA GRAVAR A SAIDA JA COM AS MEDIDAS CALCULADAS

NUM: E A VARIAVEL INDICADORA DE REAMOSTRAGEM. SE UTILIZAR APENAS UMA AMOSTRA COLOCAR SOMENTE O NUMERO 1, CASO FACA PARTE DE UMA REAMOSTRAGEM OOLOCAR O NUMERO DE REAMOSTRAGEM.

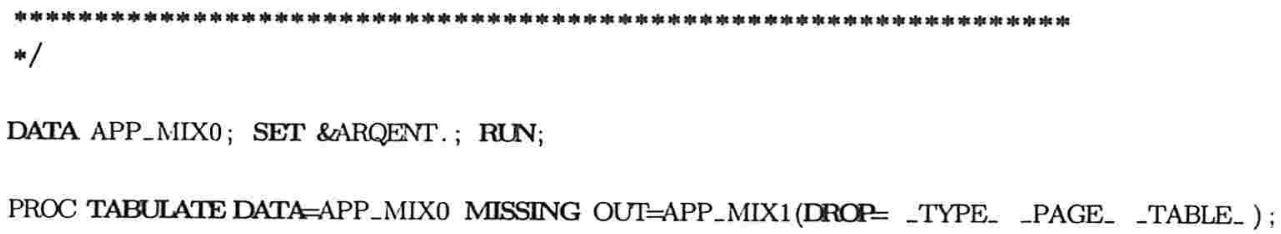


CLASS RESP SCORE;

TABLE SCORE, RESP *N ;

RUN ;

PROC SORT DATA=APP_MIX1; BY SCORE RESP; RUN;

PROC TRANSPOSE DATA=APP_MIX1 OUT=APP_MIX2 (DROP=NAME_) ; BY SCORE;

VAR N;

RUN;

ID RESP;

DATA APP_MIX2; SET APP_MIX2;

IF $-0=$. THEN $-0=0$;

RUN;

IF $-1=$. THEN $-1=0$;

PROC SORT DATA=APP_MIX2; BY DESCENDING SCORE; RUN;

DATA APP_MIX3; SET APP_MIX2 ;

RETAIN ACUM INV_ 0 ;

ACUM_INV_0 $=$ SUM(ACUMLINV_0,-0$)$;

RETAIN ACUM INV _ 1;

ACUMLINV_1 = SUM(AOUM INV_ $1,-1)$;

RUN;

PROC SQL;

CREATE TABLE MAXIMO AS

SELECT MAX(ACUMLINV_0) AS MAX 0,

MAX(AOUM_INV_1) AS MAX 1

FROM APP_MIX3;

QUIT;

PROC SQL;

CREATE TABLE APP_MIX4 AS SELECT *

FROM APP_MIX3, MAXIMO;

QUTT;

PROC SORT DATA=APP_MIX4; BY SOORE; RUN;

DATA APP_MIX4; SET APP_MIX4;

PCT_AC_0 = ACUMLINV_0/MAX_0;

RUN;

PCT_AC_ $1=$ ACUMLINV_ 1 MAX 1 ;

DATA APP_MIX4; SET APP_MIX4;

IF $-N_{-}$EQ 1 THEN ROCl= PCT_AC_ $0 *($ PCT_AC_ $1 / 2)$;

ELSE ROCl $=\left(\right.$ LAG1 $($ PCT_AC_0 $\left.)-P C T \_A C \_0\right) *(($ PCT_AC_1+LAG $($ PCT_AC_ 1 $)) / 2)$;

RUN;

PROC SQL;

CREATE TABLE \&ARQSAI. AS

SELECT "R\&NUM." AS ROD, SUM(ROC1) AS ROC,

$(\mathrm{SUM}(\mathrm{ROC1})-0.5) * 2$ AS GINI 
FROM APP_MIX4;

QUIT;

\%MND ROC_GINI;

\section{Macro MAHALANOBIS}

MAACRO MAHALANOBIS (ARQENT, ARQSAI, NUM);

/ ESTA MACRO SERVE PARA CALCULAR AS MEDIDAS DE DESEMPENHO CONHECIDAS COMO DISTANCIA DE MAHALANOBIS.

ARQUENT: E O NOME DO ARQUTVO SAS QUE DEVE CONTER: OBS: IDENTIFICADOR DE CADA OBSERVACAO; RESP: VARIAVEL RESPOSTA, COM $0=$ BOM E $1=$ MAU; SCORE: SCORE FINAL ATRIBIDO A CADA OBSERVACAO, EM INTEIROS PARA UTILIZAR A MACRO SERA NECESSARIO RENOMEAR AS VARIAVEIS SCORE E RESPOSTA PARA OS NOMES ACTMA.

ARQSAI: E O NOME DO ARQUIVO SAS QUE DEVERA GRAVAR A SAIDA JA COM AS MEDIDAS CALCULADAS

NUM: E A VARIAVEL INDICADORA DE REAMOSIRAGEM. SE UTILIZAR APENAS UMA AMOSTRA COLOCAR SOMENTE O NUMERO 1, CASO FACA PARTE DE UMA REAMOSTRAGEM COLOCAR O NUMERO DE REAMOSTRAGFM.

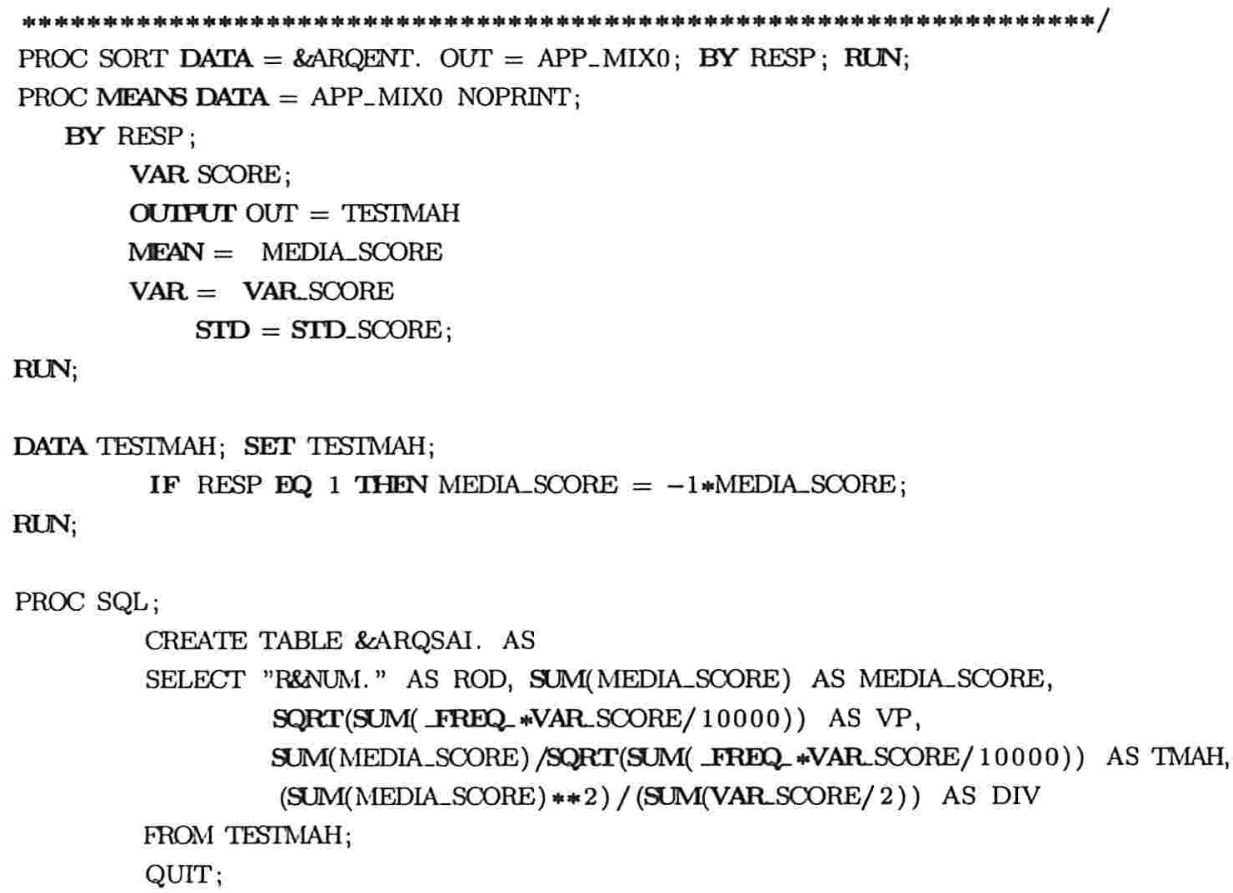

RUN;

DATA TESTMAH; SET TESTMAH;

IF RESP DQ 1 THEN MEDIA_SCORE $=-1$ \#MEDIA_SCORE;

RUN;

PROC SQL;

CREATE TABLE \&ARQSAI. AS

SELECT "RENUM." AS ROD, SUM(MEDIA_SCORE) AS MEDIA_SCORE, SQRT(SUM(_FREQ_*VAR_SCORE/ 10000)) AS VP, SUM(MEDIA_SCORE) /SQRT(SUM( FREQ_*VAR_SCORE/ 10000)) AS TMAH, (SUM(MEDIA_SCORE) $* * 2)$ / (SUM(VAR_SCORE/2)) AS DIV

FROM TESTMAH;

QUIT;

\%MEND MAHALANOBIS ;

\section{Macro AREA_EC}

\%ACRO AREA_EC (ARQENT, ARQSAI, NUM); 
/

ESTA MACRO SERVE PARA CALCULAR AS MEDIDAS DE DESEMPENHO SEGERIDA COMO AREA ENTRE AS CURVAS.

ARQUENT: E O NOME DO ARQUTVO SAS QUE DEVE CONTER: OBS: IDENTIFICADOR DE CADA OBSERVACAO; RESP: VARLAVEL RESPOSTA, COM $0=$ BOM E $1=$ MAU; SCORE: SOORE FINAL ATRIBIDO A CADA OBSERVACAO, EM INTEIROS PARA UTILIZAR A MACRO SERA NECESSARIO RENOMEAR AS VARIAVEIS SCORE E RESPOSTA PARA OS NOMES ACIMA.

ARQSAI: E O NOME DO ARQUIVO SAS QUE DEVERA GRAVAR A SAIDA JA COM AS MEDIDAS CALCULADAS

NUM: E A VARIAVEL INDICADORA DE REAMOGTRAGEM. SE UTILIZAR APENAS UMA AMOSTRA OOLOCAR SOMENIE O NUMERO 1, CASO FACA PARTE DE UMA REAMOSTRAGEM COLOCAR O NUMERO DE REAMOSTRAGEM.

DATA APP_MIX0; SET \&ARQENT.; RUN;

PROC TABULATE DATA=APP_MIX0 MISSING OUT=APP_MIX1(DROP_ _TYPE___PAGE_ _TABLE_ ); CLASS RESP SCORE; TABLE SCORE, RESP *N ;

RUN ;

PROC SORT DATA=APP_MIX1; BY SCORE RESP; RUN;

PROC TRANSPOSE DATA=APP_MIX1 OUT=APP_MIX2(DROP=_NAME ) ; BY SCORE;

VAR N; ID RESP;

RUN;

DATA APP_MIX2; SET APP_MIX2;

$$
\begin{aligned}
& \text { IF }-0=\text { THEN }-0=0 ; \\
& \text { IF }-1=\text { THEN }-1=0 ;
\end{aligned}
$$

RUN;

PROC SORT DATA=APP_MIX2; BY DESCENDING SOORE; RUN;

DATA APP_MIX2; SET APP_MIX2;

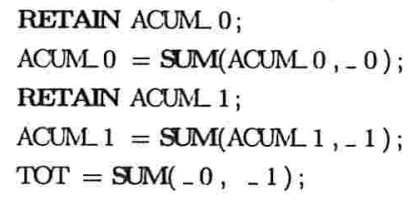

RUN;

DATA APP_MIX2; SET APP_MIX2;

RETAIN ACUMT;

ACUMLT $=$ SUM(ACUMLT, TOT);

$\mathrm{B}=\mathrm{LAG}(\mathrm{SCORE})$;

$\mathrm{T}=\mathrm{LAG}(\mathrm{ACUM} L \mathrm{~T}) ;$ 

IF _N_ EQ 1 THEN DO; B= SCORE ; $\mathrm{T}=\mathrm{AOUML} \mathrm{T}$;
END;

RUN;

DATA APP_MIX2; SET APP_MIX2; BASE_S = SOORE $-\mathrm{B}$; BASE_T $=$ ACUM $T-T$;

RUN;

PROC SQL;

CREATE TABLE MAXIMO AS

SELECT MAX(AOUM 0) AS MAX 0, $\operatorname{MAX}(A C U M$ 1) AS MAX 1, MAX(ACUMT) AS MAX T

QUIT;

FROM APP_MIX2;

PROC SQL;

CREATE TABLE APP_MIX3 AS SELECT * FROM APP_MIX2, MAXIMO;

QUIT;

DATA APP_MIX3; SET APP_MIX3;

PCT_AC_ $0=($ AOUM $0 / M A X ~ 0)$;

PCT_AC_ $1=($ ACUML 1/MAX 1);

PCT_AC_T $=$ (ACUMLTMAX T)

RUN;

PCT_T $=$ (BASE_T/MAX T);

DATA TEST1; SET APP_MIX3;

IF _N_ EQ 1 THEN AREAM $=$ PCT_T $*\left(P C T \_A C_{-} 1 / 2\right)$;

ELSE AREAM $=$ PCT_T $*\left(\left(P C T \_A C_{-} 1+L_{4} A G\left(P C T \_A C \_1\right)\right) / 2\right)$;

IF _N_ EQ 1 THEN AREAB $=$ PCT_T*(PCT_AC_0/2);

ELSE AREAB $=$ PCT_T* $\left(\left(P C T \_A C \_0+L A G\left(P C T \_A C \_0\right)\right) / 2\right)$;

RUN;

PROC SQL;

CREATE TABLE AREA AS

SELECT "R\&NUM." AS ROD, SUM(AREAM) AS AREAM, SUM(AREAB) AS AREAB

FROM TEST1;

QUTT;

DATA \&ARQSAI ; SET AREA;

$\mathrm{DIF}=\mathrm{ABS}(\mathrm{AREAM}-\mathrm{AREAB}) ;$

RUN;

\%END AREA_EC;

\section{Macro DTI}

\%AACRO DTI (ARQENT, ARQSAI, NUM); 
ESTA MACRO SERVE PARA CALCULAR AS MEDIDAS DE DESEMPENHO SEGERIDA COMO DIFERENCA ENTRE AS TAXAS DE INADIMPLENTES PARA OS DECIS EXTREMOS.

ARQUENT: E O NOME DO ARQUTVO SAS QUE DEVE CONIER:

OBS: IDENTIFICADOR DE CADA OBSERVACAO;

RESP: VARLAVEL RESPOSTA, COM $0=$ BOM E $1=$ MAU;

SCORE: SCORE FINAL ATRIBIDO A CADA OBSERVACAO, EM INTEIROS

PARA UTILIZAR A MACRO SERA NECESSARIO RENOMEAR AS VARIAVEIS

SCORE E RESPOSTA PARA OS NOMES ACIMA.

ARQSAI: E O NOME DO ARQUIVO SAS QUE DEVERA GRAVAR A SAIDA JA COM AS MEDIDAS CALCULADAS

NUM: E A VARIAVEL INDICADORA DE REAMOSTRAGFM. SE UTILIZAR APENAS UMA AMOSTRA COLOCAR SOMENTE O NUMERO 1, CASO FACA PARTE DE UMA REAMOSTRAGEM COLOCAR O NUMERO DE REAMOSTRAGEM.

PROC UNIVARIATE DATA $=$ \&ARQENT ;

VAR SCORE;

OUIPUT OUT $=$ SAIDA PCTLPTS $=10$ TO 100 BY 10 PCTLPRE $=$ POP $_{-}$; PROC TRANSPOSE DATA $=$ SAIDA OUTEDATA; PROC PRINT;

RUN;

DATA APP_MIX0; SET \&ARQENT.; RUN;

PROC TABULATE DATA=APP_MIX0 MISSING OUT=APP_MIX1 (DROP_ _TYPE_ _PAGE_ _TABLE_); CLASS RESP SCORE;

TABLE SCORE, RESP *N ;

RUN ;

PROC SORT DATA=APP_MIX1; BY SCORE RESP; RUN;

PROC TRANSPOSE DATA=APP_MIX1 OUT=APP_MIX2 (DROP=_NAME_); BY SCORE;

VAR N;

RUN;

ID RESP;

DATA APP_MIX2; SET APP_MIX2;

$$
\begin{aligned}
& \text { IF }-0=\text { THEN }-0=0 ; \\
& \text { IF }-1=\text {. THEN }-1=0 ;
\end{aligned}
$$

RUN;

PROC SQL;

CREATE TABLE APP_MIX3 AS SELECT A.*, B.COL1 FROM APP_MIX2 A, DATA B; QUTT;

DATA APP_MIX3; SET APP_MIX3;

IF SCORE GT COL1 THEN DERETE;

RUN; 
PROC SORT DATA=APP_MLX3; BY COL1 ; RUN;

PROC MEANS DATA = APP_MIX3 NOPRINT;

BY COL1 :

VAR - $0-1$

OUIPUT OUT $=$ APP_MIX 4

SUM $=$ SUM 0 SUM 1 ;

RUN;

DATA APP_MIX4; SET APP_MIX4;

DEC_1 = SUM 1 - LAG(SUML 1$)$;

DEC_0 = SUM 0 - LAG(SUM 0);

IF _N_ EQ 1 THEN DO; DEC_0 = SUM 0 ;

DEC_1 = SUM 1 ;

END;

RUN;

BAD_RATE $=\left(\right.$ DEC_ $1 /\left(\right.$ SUM $\left(\right.$ DEC_$_{-} 1$, DEC_ 0$\left.\left.)\right)\right) * 100$;

PROC TRANSPOSE DATA=APP_MIX4 OUT=APP_MIX5(DROP=_NAME ) ; VAR BAD_RATE;

RUN;

DATA \&ARQSAI. ; SET APP_MIX5;

ROD = "RENUM."

RUN;

DIF_DEC $=$ COL1 - COL10;

\%MEND DTI; 


\section{Referências Bibliográficas}

[Agresti, 1990] Agresti, A. (1990). Categorical data analisys. New York: Wiley.

[Allison, 1995] Allison, P. D. (1995). Survival Analysis Using the SAS System: A Practical Guide. Cary, NC: SAS Institute Inc.

[Altman, 1968] Altman, E. I. (1968). Financial Ratios, Discriminant Analysis and the Prediction of Corporate Bankruptcy, The Journal of Finance Vol. 23, No. 4 (Sep., 1968), pp. 589-609.

[Andersen et al, 1993] Andersen, P. K., Borgan, O., Gill, R. D. \& Keiding, N. (1993). Statistical models based on counting processes. New York: SpringerVerlag.

[Conover, 1999] Conover, W. J. (1999). Practical nonparametric statistics, 3 Ed. New York: John Wiley and Sons.

[Cox, 1972] Cox, D. R. (1972). Regession models and life-tables, Journal of the Royal Statistical Society, Ser. B39, 1-38.

[Cox, 1975] Cox, D. R. (1975). Partial likelihood, Biometrika 62, 269-276.

[Cox \& Oakes, 1984] Cox, D. R. \& Oakes, D. (1984). Analysis of survival data, 1st Ed. New York: Chapman and Hall Ltd.

[Durand, 1941] Durand, D., (1941). Risk Elements in Consumer Installment Financing, Studies in Consumer Installment Financing, National Bureau of Economic Research, Study 8. New York.

[Efron, 1977] Efron, B (1977). The efficiency of Cox'x likelihood function for cencored dada. J. Amer. Stat. Assoc.. 72 555-565.

[Efron \& Tibshirani, 1993] Efron, B \& Tibshirani, R. J. (1993). An introduction to the Bootstrap. Chapman \& Hall/CRC. 
[Fawcett, 2004] Fawcett, T. (2004). ROC graphs: notes and practical considerations for researchers. HP Laboratories. Palo Alto.

[Fisher, 1936] Fisher, R.A. (1936). The use of multiple measurements in taxonomic problems, Annals of Eugenics, 7, 179-188.

[Hand \& Till, 2001] Hand, D. J. \& Till, R. J. (2001). A simple generalization of the area under the ROC curve to multiple class classification problems, Machine Learning, 45(2) 171-186

[Hanley \& McNeil, 1982] Hanley, J. A. \& McNeil, B. J. (1982). The meaning and use of the area under a receiver operating characteistic (ROC) curve, Radiology, 143 29-36

[Hosmer \& Lemeshow, 1989] Hosmer, D. W. \& Lemeshow, S. (1989). Applied logistic regression. New York: John Wiley \& Sons, Inc.

[Hosmer \& Lemeshow, 1999] Hosmer, D. W. \& Lemeshow, S. (1999). Applied survival analysis: regression modeling of time to event data. New York: John Wiley \& Sons, Inc.

[Johnson \& Wichern, 1998] Johnson, R. A. \& Wichern, D. W. (1998). Applied multivariate staistical analysis. 4 ed., New York: PrenticeHall.

[Kaplan \& Meier, 1958] Kaplan, E. L. \& Meier, P. (1958). Nonparametric estimation fro incomplete observations. J. Amer. Stat. Assoc.,26, 227-237.

[Klein \& Moeschberger, 1997] Klein, J. P. \& Moeschberger, M. L. (1997). Survival analysis: techniques for censored and truncated data. New York: Springer.

[Lawless, 2003] Lawless, J. F. (2003). Statistical models and methods for lifetime data. 2 ed., Hoboken: John Wiley \& Sons, Inc.

[Neter et al, 1996] Neter, J., Wasserman, W., Kutner, M. H. \& Nachtsheim, C. J. (1996). Applied Linear Statistical Models. 4a ed., New York: McGrawHill.

[Oliveira \& Andrade, 2002] Oliveira, J. G. C. \& Andrade, F. W. M. (2002). Comparação de medidas de performance de modelos de credit scoring Tecnologia de Crédito, 33, 1 - 11.

[Pereira, 2004] Pereira, G. H. A. (2004). Modelos de Risco de Crédito de Clientes: Uma aplicação a Dados Reais. Dissertação de Mestrado. Instituto de Matemática e Estatítistica, Universidade de São Paulo. 
[Sas help] Sas Online Doc, V8: http://v8doc.sas.com/sashtml/

[Sen \& Singer, 1993] Sen, P. K. \& Singer, J. M. (1993). Large Sample Methods in Statistics: an introduction with applications. New York: Chapman \& Hall.

[Siegel, 1956] Siegel, S. (1956). Nonparametric Statistics for the Behavioral Sciences. New York: McGraw-Hill.

[Sicsu, 1998] Sicsu, A. L. (1998). Desenvolvimento de um Sistema de Credit Scoring Parte I, Tecnologia de Crédito. 4, p. 63-76

[Sicsu, 1998] Sicsu, A. L. (1998). Desenvolvimento de um Sistema de Credit Scoring Parte II, Tecnologia de Crédito. 5, p. 57-68

[Thomas et al, 2002] Thomas, L. C., Edelman, D.B. \& Crook, J. N. (2002). Credit Scoring and Its Applications. Philadelphia: Siam. 